\title{
ZUR GEOGRAPHIE DES SUHRENTALES
}

\author{
Paul Widmer
}

\section{Einleitung}

Die Täler des schweizerischen Mittellandes verlaufen alle, als Folge der allgemeinen Nordwest-Abdachung, ungefähr in der Richtung von Südosten nach Nordwesten. Das Suhrental kann als typischer Vertreter der Mittellandtäler aufgefaßt werden, denn es zieht sich über die ganze Breite der schweizerischen Hochebene hin, also vom Rand der Voralpen bis an den Jura (Abb. 1). Auch begrenzt beidseitig ein markanter Hügelzug seine Flanken, wie das bei den meisten Tälern der Fall ist. Das Untersuchungsgebiet präsentiert sich somit als eine relativ abgeschlossene Talschaft; nur im Norden (Aaretal) und bei Sursee (Wiggertal) weist es eine natürliche Verbindung mit der Umwelt auf. Die Umgrenzung bietet daher keine besonderen Schwierigkeiten. Als Grundlage dient das Einzugsgebiet des Hauptflusses, der Suhre, mit seinen Nebenflüssen. So erhalten wir ein sowohl nach physikalisch- als auch, wie noch zu zeigen sein wird, kulturgeographischen Gesichtspunkten relativ einheitliches Gebiet. Um jedoch die statistischen Angaben verwerten zu können, müssen die politischen Grenzen berücksichtigt werden. Glücklicherweise weichen diese aber nur selten geringfügig von denjenigen des Einzugsgebietes ab.

Politische Gliederung des Suhrentales. Die insgesamt 34 Gemeinden verteilen sich wie folgt auf die einzelnen Kantone und Bezirke:

Kanton Aargau

Bezirk Aarau: Suhr, Unterentfelden, Oberentfelden, Muhen, Hirschthal.

Bezirk Kulm: Holziken, Schöftland, Schloßrued, Schmiedrued.

Bezirk Zofingen: Kölliken, Safenwil, Staffelbach, Kirchleerau, Moosleerau, Attelwil, Reitnau, Uerkheim, Bottenwil, Wiliberg.

Kanton Luzern

Bezirk Sursee: Kulmerau, Winikon, Triengen, Wilihof, Schlierbach, Büron, Knutwil, Geuensee, Sursee, Schenkon, Oberkirch, Eich, Nottwil, Sempach, Neuenkirch.

Ein Vergleich mit dem Kanton Zug vermittelt sowohl nach Areal als auch in Bezug auf Einwohner ein anschauliches Bild über die Größe des Untersuchungsgebietes $(12,22)^{*}$.

$\begin{array}{lll} & \text { Suhrental } & \text { Kanton Zug } \\ \text { Fläche } & 232,8 \mathrm{~km}^{2} & 240 \mathrm{~km}^{2} \\ \text { Einwohner im Jahre 1950 } & 43129 & 42239\end{array}$

\section{Problemstellung}

Hauptgründe für die Wahl des Gebietes waren einerseits die Tatsache, daß es bisher noch nicht geographisch bearbeitet wurde und anderseits, daß der Verfasser in ihm aufgewachsen ist, es ihm also persönlich besonders vertraut ist. Das Ziel der Untersuchung besteht darin, einen Einblick in die Zusammenhänge der Landschaftselemente, hauptsächlich von Natur und Kultur (Siedlung, Wirtschaft, Verkehr usw.) zu bieten, unter besonderer Betonung ihrer bisherigen und zukünftigen Entwicklung. Es ist klar, daß die Lösung dieser Aufgabe nur durch eine Analyse der Landschaft möglich ist. Das Hauptgewicht der Arbeit liegt daher auf einer Darstellung der Veränderung der Landschaftselemente im Laufe der Zeit, wobei nicht eine gleichmäßige Behandlung

* Die eingeklammerten Zahlen verweisen auf das Quellenverzeichnis am Schluß der Arbeit. 


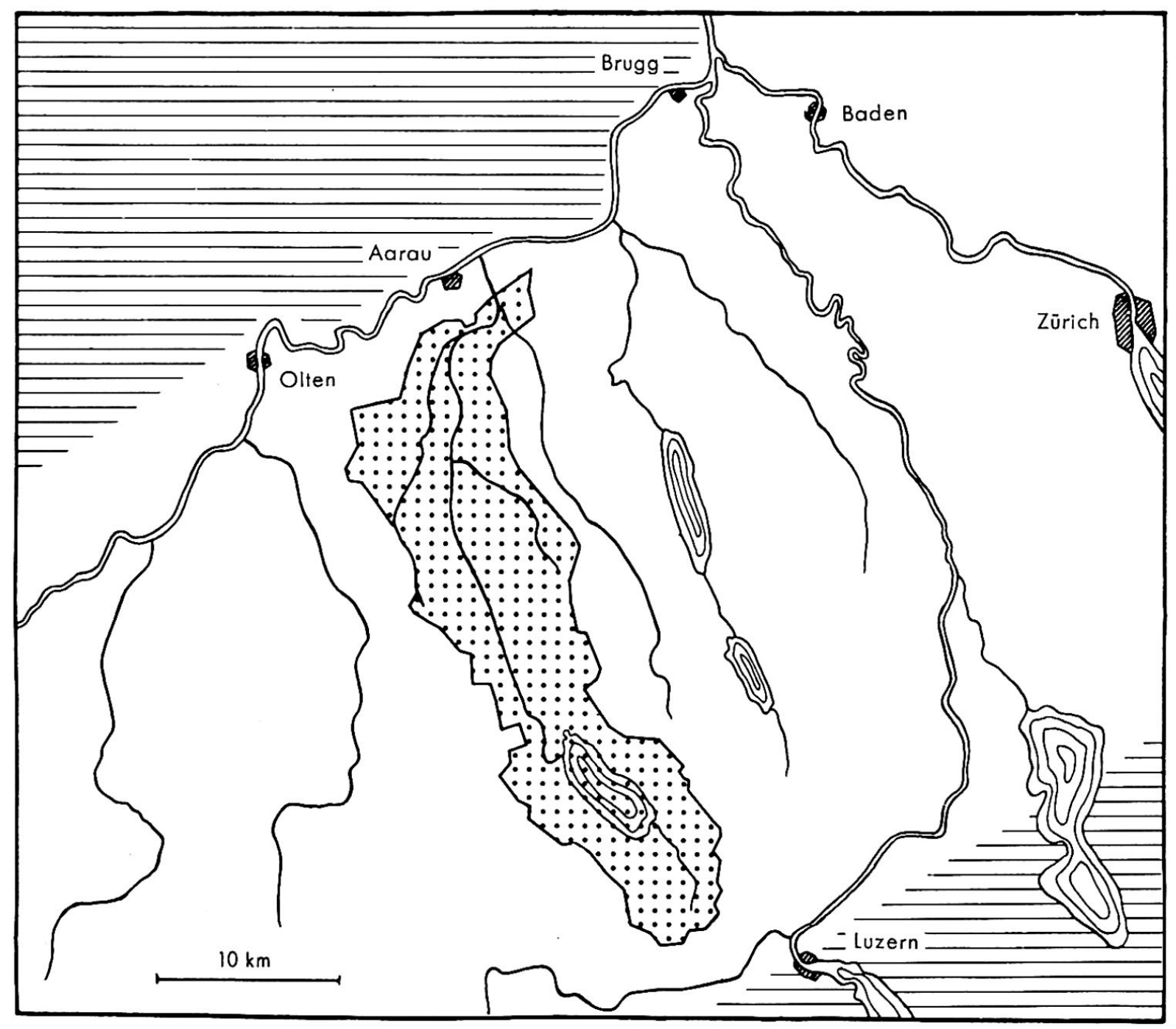

Abb. 1. Das Suhrental im Rahmen des schweizerischen Mittellandes. Schraffiert im Nordwesten der Jura und im Südosten die Voralpen.

beabsichtigt ist, sondern versucht wird, an typischen Beispielen einzelner Teillandschaften den Gesamtcharakter des Untersuchungsgebietes zu ergründen. Auf die Analyse folgt sodann der Versuch der Herausarbeitung der Hauptlandschaftstypen, die den $Z$ weck verfolgt, die geographische Ganzheit des Gebietes zum Ausdruck zu bringen. Den Abschluß bildet eine Skizzierung der Zukunftsentwicklung, die als Grundlage für regionalplanerische Überlegungen gedacht ist.

\section{Entwicklung zur Gegenwartslandschaft}

\subsection{DIE LANDSCHAFT ALS GANZES}

\subsection{NATURLANDSCHAFT}

\subsection{Geologische Verhältnisse}

Dem Ziel der Arbeit entsprechend sollen hier bloß die zum besseren Verständnis der Landschaft erforderlichen geologischen Grundlagen dargestellt werden (Abb.2). Dabei ist zu bemerken, daß die oft komplizierten Verhältnisse vor allem im luzernischen Abschnitt des Untersuchungsgebietes teilweise noch nicht genau abgeklärt sind $(6,7,8,9)$. 


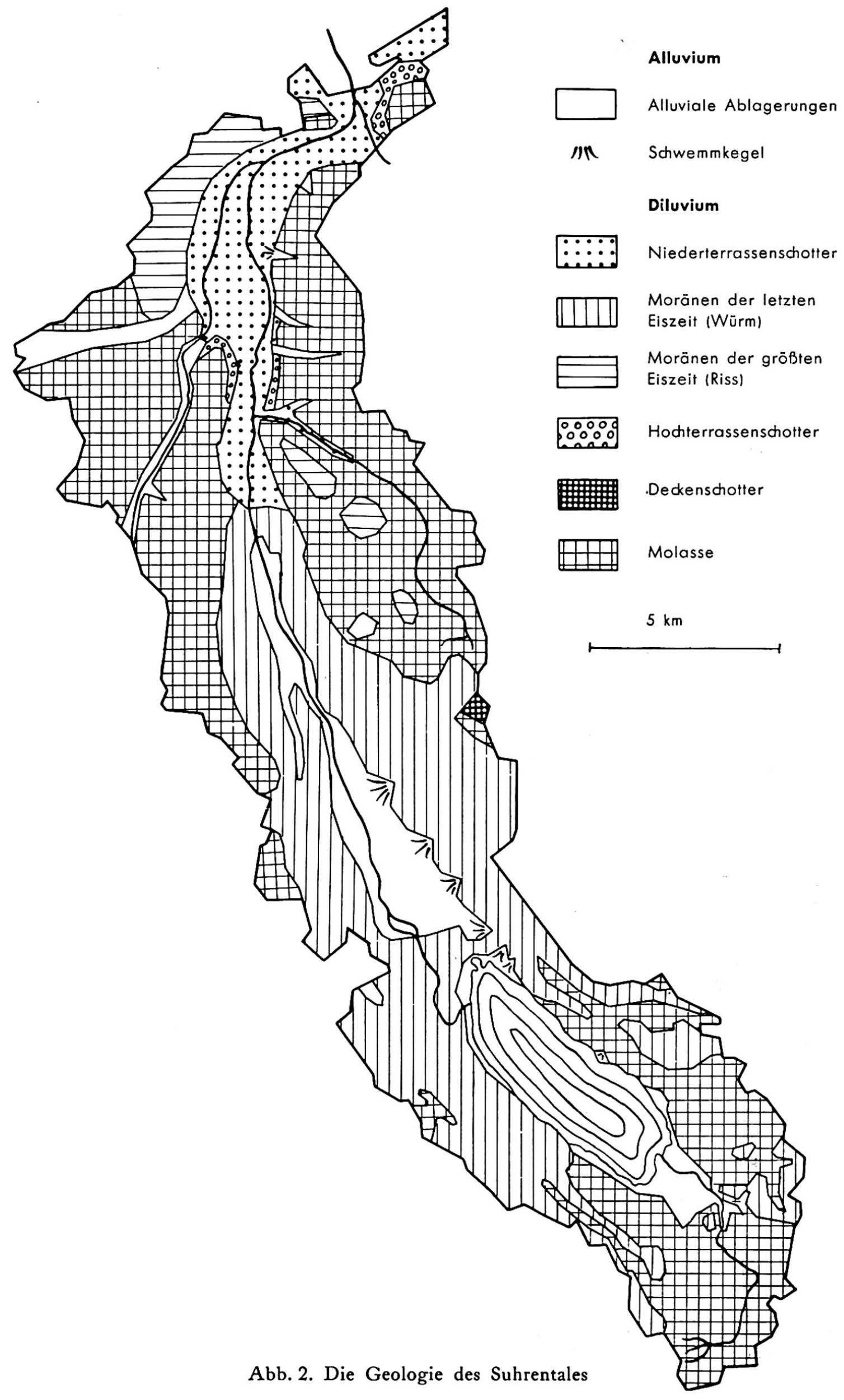


Als Region des schweizerischen Mittellandes gehört das Suhrental dem großen Molassetrog zwischen Jura und Alpen an (58). Somit finden sich als geologische Unterlage überall die Sedimente der Molasse, die zur Hauptsache aus Sandsteinen bestehen (31). Im Diluvium erhielt das Suhrental seine heutige Form; die letzten wichtigen, vor allem durch die Gletscher entstandenen Ablagerungen, datieren aus dieser Zeit. Da die Bildung von Decken-, Hochterrassen-, Niederterrassenschotter und Moränen für alle Täler des Mittellandes nach dem allgemein bekannten Schema vor sich ging, erübrigt sich eine genaue Darstellung der Verhältnisse im Suhrental. Immerhin verdienen die Moränenwälle der letzten Eiszeit (Würm), die im oberen Talabschnitt einen bedeutenden Einfluß auf die Landschaft ausüben, besondere Erwähnung. Die einzelnen Rückzugsstadien entsprechen den besser bekannten des Limmattales wie folgt (58) :

$\begin{array}{ll}\text { Suhrental } & \text { Limmattal } \\ \text { Endmoräne bei Staffelbach } & \text { Killwangerstadium } \\ \text { Endmoräne bei Triengen } & \text { Schlierenstadium } \\ \text { Endmoräne bei Sursee } & \text { Zürichstadium }\end{array}$

Da jedoch das Tal seit dem Gletscherrückgang keinen Anteil mehr an der Alpenentwässerung hat, die Suhre also nur eine relativ geringe Wassermenge aufnehmen muß, ist das vom Eis geprägte Relief viel besser erhalten geblieben als zum Beispiel im Limmat- oder Reußtal. Man darf daher im Suhrental den Prototyp eines glazial geformten Tales erblicken.

Der vollständige Talabschluß, den vor allem die Moräne bei Staffelbach darstellt, begünstigte zwar die alluvialen Ablagerungen auf dem Talboden, die aber nur eine geringe Mächtigkeit aufweisen. Bis zur Bildung des heutigen engen Durchflußweges der Suhre bei Staffelbach dürfte der Sempachersee wohl bis Staffelbach gereicht haben. Daraus resultierte die allgemeine Versumpfung der intramoränischen Talsohle.

Der Grund des Tales nördlich von Staffelbach hingegen besteht aus reinem Niederterrassenschotter, der ebenfalls während der Würmeiszeit abgelagert wurde.

\subsection{Relief}

Als wesentliche Faktoren für die Gestaltung der Oberfläche sind im Suhrental vor allem die Erosion und Akkumulation durch Wasser und Eis, die Härteunterschiede in der Molasse und die Art der Vegetationsdecke hervorzuheben. Als typisch glazial geformtes Tal beginnt seine Entstehungsgeschichte erst etwa mit dem Diluvium (vor ca. 1 Mio Jahren). Gletscher und Fluß bearbeiteten abwechslungsweise die einmal angedeutete kleine Rinne der «Ursuhre». Auf diese Weise entstand der breite, ebene Talboden, wie er sich heute präsentiert. Sein Gefälle ist selbst für schweizerische Verhältnisse gering; beträgt es doch $0,45 \%$, da der Höhenunterschied vom Sempachersee ( 504 m ü. M.) bis Suhr (398 m ü. M.) nur $106 \mathrm{~m}$ ausmacht. Die höchsten Erhebungen der beiden talparallelen Hügelzüge erreichen im aargauischen Teil im Mittel ungefähr $660 \mathrm{~m}$ ü. M., steigen aber im Kanton Luzern bis auf $860 \mathrm{~m}$ ü. M. an (Schiltwald). Diese Höhe dürfte annähernd der oberen Grenze der Molasse entsprechen, da hier die einzigen Überreste des älteren Deckenschotters anzutreffen sind. Der südliche Übergang ins Reußtal ist relativ flach ( $560 \mathrm{~m}$ ü. M.). Dies hängt wohl auch wieder mit den hydrographischen Zuständen im Diluvium zusammen, als die Reuß oder der Reußgletscher durch das Suhrental floß. Der heutige unnatürliche Lauf jener Wassermassen durch das Reußtal wurde durch das Rücksinken des nördlichen Alpenrandes hervorgerufen (58). Die letzte Vergletscherung der Würmeiszeit, die nur bis Staffelbach reichte, verursachte im oberen Suhrental nochmals bedeutende Veränderungen. Demzufolge erscheinen heute 2 verschiedene Relieftypen. 
Das intramoränische Relief. Die bereits erwähnten, markanten Endmoränen (diejenige von Staffelbach erhebt sich um $42 \mathrm{~m}$ über den Talboden) der letzten Vergletscherung unterbrechen die ebene Talsohle und unterteilen sie in einzelne Kammern (31). Die Endmoränen finden ihre Fortsetzung oft in gewaltigen Seitenmoränen, die sich an den Hügeln talaufwärts hinziehen. Es ist anzunehmen, daß diese ausgedehnten Schottermassen die durch frühere Schmelzwässer erodierten Seitentäler wieder auffüllten. Deshalb weisen die Hänge der Hügelzüge im oberen Talabschnitt ein derart «mildes» Relief auf (38).

Das extramoränische Relief. Im Gegensatz zum oberen Suhrental wird die Talsohle im Gebiet nördlich der Moräne von Staffelbach nicht durch Querwälle unterbrochen. Die Landschaft hat folglich einen viel offeneren Charakter. Dazu trägt allerdings noch die Verbreiterung des Talbodens von der Einmündung des Uerkentales an abwärts bei. Breite des Talbodens:

$\begin{array}{ll}\text { bei Büron } & 1,3 \mathrm{~km} \\ \text { bei Reitnau } & 1,3 \mathrm{~km} \\ \text { bei Schöftland } & 1,1 \mathrm{~km} \\ \text { bei Muhen } & 2,7 \mathrm{~km} \\ \text { bei Oberentfelden } & 2,5 \mathrm{~km}\end{array}$

Der relativ harte Knauersandstein des Gönhard, eines Hügelzuges zwischen Unterentfelden und Suhr, veranlaßte ein Abbiegen des Tales gegen Osten und folglich die Vereinigung mit dem Wynental, kurz vor der Einmündung in die West-Ost-Furche der Aare. Im Gegensatz zum intramoränischen Suhrental resultieren viel ausgeprägtere Seitentäler infolge Ausbleibens von glazialen Ablagerungen der Würmeiszeit und der längerwirkenden Erosion durch Wasser. Wie auch aus den Längsprofilen (Abb. 4) ersichtlich ist, hat sich hier die Form der Seitentäler mehr der Erosionsterminante genähert. Die Täler der Uerke und der Ruederchen haben sogar eine so breite Sohle, daß sie für ganze Ortschaften genügend Raum bieten. Die Landschaft ist hier also stärker gegliedert.

\subsection{Klima}

Da das Suhrental als Region des schweizerischen Mittellandes betrachtet werden kann, und somit die allgemein bekannten Klimaverhältnisse vorherrschen, soll hier bloß auf einige spezifische Merkmale hingewiesen werden.

Temperatur. Mangels 'Temperaturmeßstationen im Untersuchungsgebiet seien die Resultate von zwei Nachbarstationen behelfsmäßig aufgezeichnet.

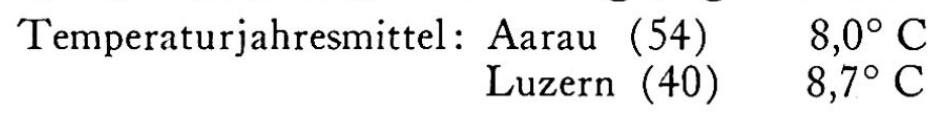

Für Luzern dürfte wohl der Vierwaldstättersee und der stärkere Föhneinfluß cine kleine Erhöhung des Jahresmittels verursachen. Folglich liegen für das Suhrental die Werte ungefähr bei $8,0^{\circ} \mathrm{C}$.

Winde. Naturgemäß sind die Westwinde vorherrschend und haben im ganzen Gebiet ungefähr den gleichen Einfluß. Der Bise kommt des östlichen Hügelzuges wegen keine große Bedeutung zu. Einzig im untersten Abschnitt, wo das Tal gegen Osten umbiegt, hat sie freien Zutritt und kann ungehindert über die Ebene hinwegstreichen. Bloß die Gemeinden Suhr, Unter-, Oberentfelden und Kölliken verzeichnen somit eine wahrnehmbare Beeinträchtigung des Lokalklimas. Der Föhn hingegen kann bei starkem Auftreten bis an den Fuß des Jura vordringen, da das Suhrental eine natürliche Fortsetzung der zentralschweizerischen Föhntäler darstellt. Im Frühling bringt dieser warme, trockene Wind oft eine intensive Schneeschmelze, was dem Tal zu nicht geringem Vorteil gereicht (Landwirtschaft, Verkehr). 
Niederschläge. Wie die nachfolgenden Resultate (25) der im Gebiet sich befindlichen Meßstationen zeigen, sind die Niederschläge in der ganzen Region ungefähr gleich groß.

Höhe m. ü. M. Durchschnittlicher Jahres-

$\begin{array}{llr} & & \text { niederschlag } \\ \text { Aarau } & 406 & 1061 \\ \text { Kölliken } & 431 & 1119 \\ \text { Triengen } & 523 & 1105 \\ \text { Sursee } & 502 & 1107 \\ \text { Zürich } & 493 & 1072\end{array}$

Der Vergleich mit Zürich bestätigt, daß ohne Bedenken auf die bekannten Verhältnisse des Mittellandes verwiesen werden kann.

\subsection{Hydrographie}

Die Hydrographie des Untersuchungsgebietes wird einerseits durch die Oberflächengewässer und anderseits durch den Grundwasserstrom bestimmt.

Oberflächengewässer. Die Begrenzung des Suhrentales ist absichtlich so gewählt worden, daß sie das Einzugsgebiet der Suhre umschließt; es ist daher hydrographisch eine geschlossene Einheit. Der Sempachersee übt auf den Wasserstand der Suhre einen ausgleichenden Einfluß aus, der aber durch die vielen $Z$ uflüsse bald wieder aufgehoben wird. Leider ist es unmöglich, dies mit Meßresultaten zu belegen, da an der Suhre Wassermeßstationen vorläufig noch fehlen. Wie aber der folgende Vergleich zeigt, ist das Einzugsgebiet des Sempachersees gegenüber demjenigen der übrigen Suhrezuflüsse (Gebiet nördlich Sursee) bedeutend kleiner.

$$
\text { Einzugsgebiet des Sempachersees (13): } \quad 74,2 \mathrm{~km}^{2}
$$

Einzugsgebiet der Suhre ohne Sempacherseegebiet: $173,0 \mathrm{~km}^{2}$

Diese Anhaltspunkte begründen das rasche Anschwellen der Suhre im unteren Suhrental bei Regenfällen.

Das Längsprofil der Suhre (Abb. 3) zeigt, wie ihr Gefälle von den Endmoränen stark beeinflußt wird. Einzig der unbedeutendste Moränenwall, derjenige von Triengen, macht sich im Profil nicht bemerkbar. Währenddem die Suhre südlich von Staffelbach gemächlich durch die Ebene fließt, kann sie nach dem letzten Moränendurchbruch oft zum reißenden Gewässer werden. Nach Suhr steigert sich das Gefälle nochmals beträchtlich, da auf kurzer Distanz der Niveauunterschied zwischen Suhr und dem Aaretal, ungefähr 35 m (Suhr: 400 m ü. M., Aare bei der Suhrenmündung: $365 \mathrm{~m}$ ü. M.), überwunden wird.

Die zahlreichen Zuflüsse der Suhre aus den Seitentälern haben ihren Ursprung fast ausnahmslos in einer oder mehreren Quellen, deren Bildung durch den Bau der

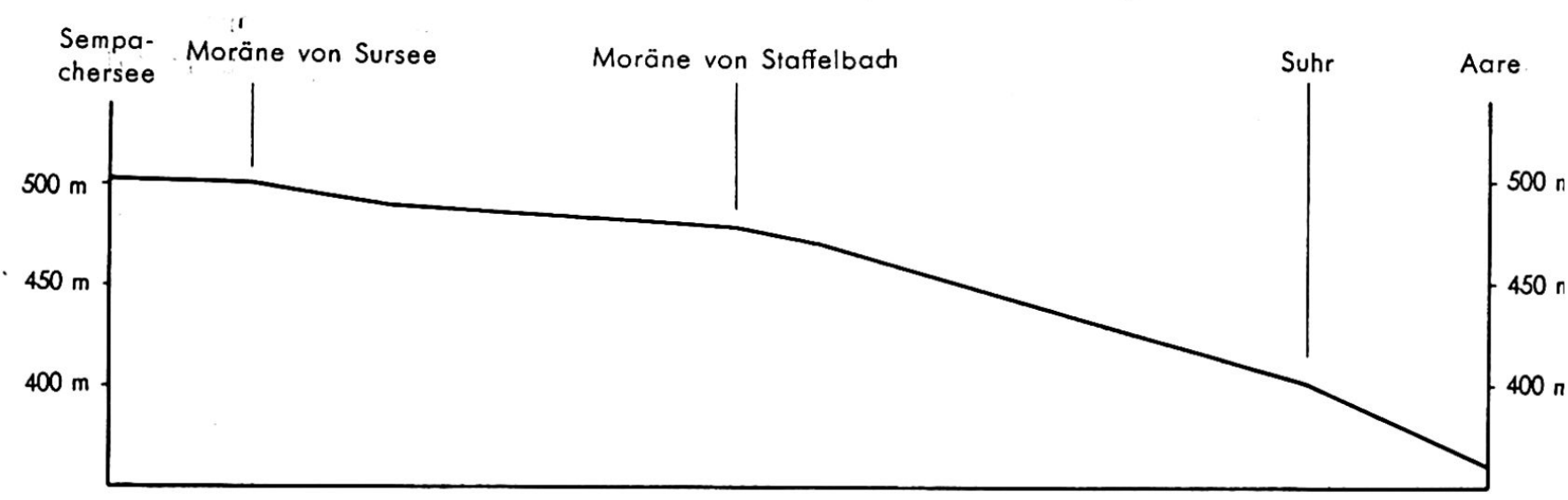

Abb. 3. Längsprofil der Suhre 


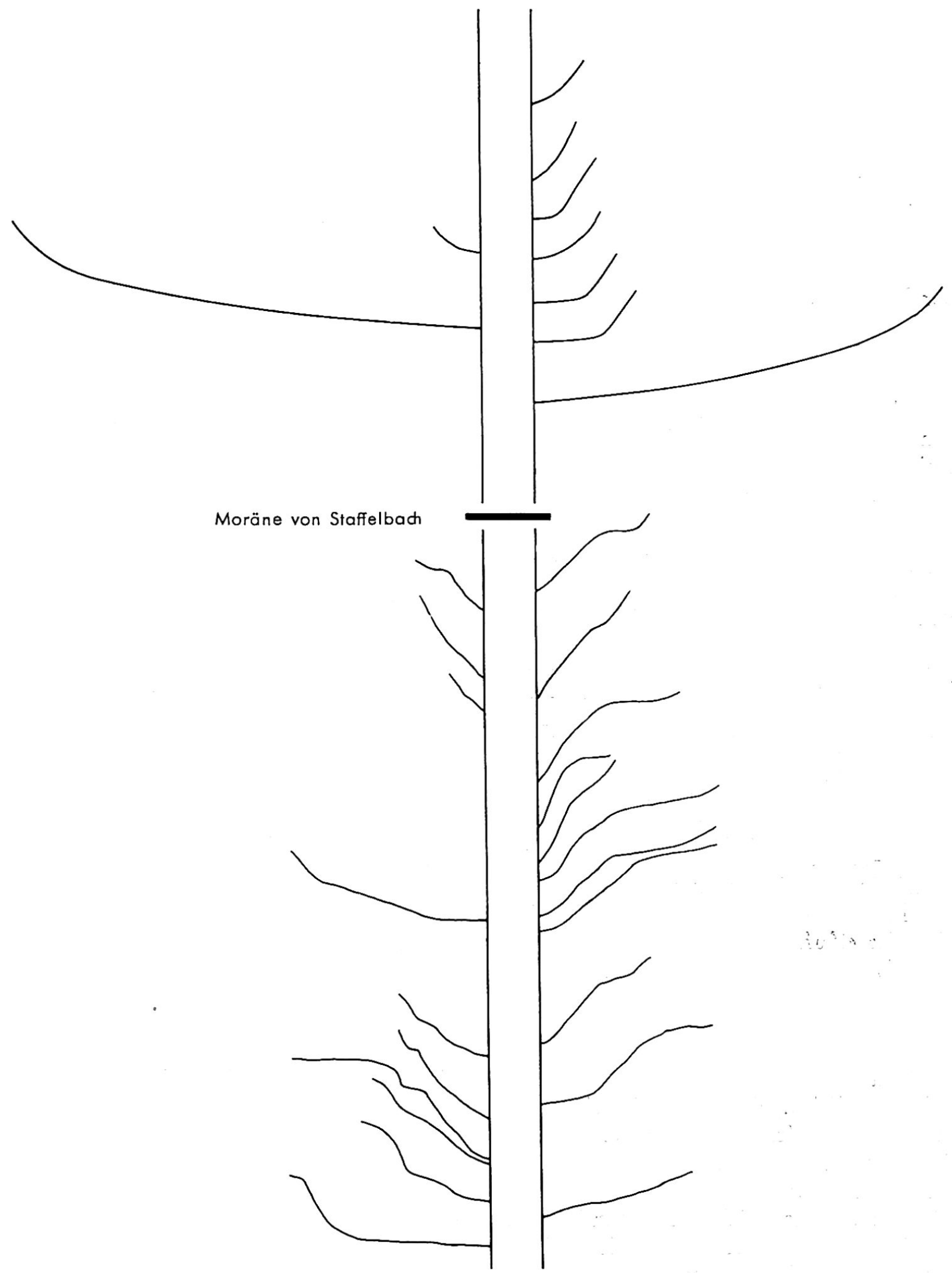

Abb. 4. Längsprofile der Suhrezufüsse von ihrer Quelle bis an den Rand der Talsohle

Molasse (schiefgestellte, wasserdurch- und undurchläßige Schichten) begünstigt wird. Die Längsprofile der Bäche in den Seitentälern (Abb.4) geben Aufschluß über die Erosionstätigkeit, wobei zwischen intra- und extramoränischem Gebiet wieder deutliche Unterschiede zu erkennen sind. Südlich der Endmoräne von Staffelbach fallenedie Bäche gegen die Ebene des Suhrentales steil ab; dagegen weisen sie auf einer Höhe von 
ca. $700 \mathrm{~m}$ ü. M. oft ein flacheres Teilstück auf. Dies wird von den hier vorhandenen Seitenmoränen bedingt, die als Ablagerungen der Würmeiszeit noch deutlich erkennbar sind. Häufig verwehren diese sogar den Suhrezuflüssen von den Höhen der Talhänge den direkten Weg und drängen ihnen vorübergehend eine talparallele Richtung auf. Als Beispiele seien die Bäche bei Wilihof, Triengen und Knutwil hervorgehoben. Die Zuflüsse aus den Seitentälern nördlich Staffelbach erreichen bald ein Niveau, das nur wenig über demjenigen der Suhre liegt, da sie ihre Steilstufe des weiter fortgeschrittenen Erosionsstadiums wegen immer im Talhintergrund besitzen.

Grundwasserstrom. Die fluvioglazialen Schotter der letzten Eiszeit, die den extramoränischen Talboden erfüllen, stellen einen idealen Grundwasserträger dar. Südlich der Moräne bei Staffelbach hingegen verhindern die wasserdurchläßigen Grundmoränen und alluvialen Böden die Bildung von zusammenhängenden, großen Wassermassen unter der Erdoberfläche. HUg hat nach diesen Überlegungen die Grenzen des Grundwasserstromes wie folgt gezogen (49): Der Nordrand des Moränenwalles bei Staffelbach bildet den südlichen Abschluß. Von hier erstreckt sich der Strom unter der ganzen Breite der Talsohle bis Suhr, wo er sich mit demjenigen aus dem Wynental vereinigt. Bei Buchs ergießt er sich sodann in die Niederterrassenschotter der Aare, die ihrerseits schon sehr reich an Grundwasser sind. Die Verengerung des Suhrentales bei Suhr bewirkt einen Aufstau des unterirdischen Wassers; deshalb ist es im Gebiet südlich des Gönhard in Form von zahlreichen Grundwasseraufstößen an die Oberfläche getreten. Diese waren für die landwirtschaftliche Bodennutzung natürlich sehr ungünstig. So haben sich die interessierten Kreise während des Weltkrieges 1939-45 entschlossen, das Gebiet einer Melioration zu unterziehen. Da dieser Eingriff eine vollkommene Umgestaltung des Landschaftsbildes hervorgerufen hat, soll das ganze Werk in einem besonderen Kapitel näher behandelt werden.

Wie gelangen die großen Wassermassen in den Boden? Eine bedeutende Rolle spielt das Niederschlagswasser, das direkt in die durchläßigen Schotter der Talsohle eindringt und so den Grundwasserstrom erreicht. Ebenso versickert häufig das Wasser der Bäche, die die Talhänge entwässern, kurz nachdem sie auf die Schotterebene hinausgetreten sind. Die eindrücklichsten Beispiele entfallen auf die Gegend von Kirchleerau-Staffelbach, wo sogar Bäche mit ansehnlicher Wasserführung allmählich verschwinden. Auch muß man annehmen, daß unter dem Talboden aus den Sandsteinen der Molasse Quellen heraustreten und so den Grundwasserstrom direkt speisen. Da also alle «Zuflüsse» des Grundwassers stark vom Wetter abhängig sind, erklären sich die Niveauschwankungen, die in Oberentfelden ungefähr $2 \mathrm{~m}$ betragen (45).

\subsection{Flora und Fauna}

Von der ursprünglichen Pflanzendecke ist im Suhrental nur ein geringer Teil erhalten geblieben, da das Gebiet einer intensiven land- und forstwirtschaftlichen Nutzung unterworfen wurde. Auf Grund der heutigen Waldbestände darf man annehmen, daß früher vor allem auf den Hügelzügen ein Mischwald vorherrschte, der sich hauptsächlich aus Buchen, Eichen, Rot- und Weißtannen zusammensetzte. Auf der zum Teil versumpften Talsohle mögen Schilf und andere feuchtigkeitsliebende Gräser üppig gedeiht haben. Heute säumen sie noch die unversehrt gebliebenen Bäche. Ebenso sind die Bäume und Sträucher, die an einstige Auenwälder erinnern, nur noch auf einen schmalen Uferstreifen beschränkt; am häufigsten vertreten sind Erlen, Eschen, Pappeln und Weiden. Die reiche Vegetation bietet natürlich die besten Voraussetzungen für die Entwicklung einer mannigfaltigen Tierwelt. Der Eingriff des Menschen in die Naturlandschaft bewirkt aber mit der Zeit einen allgemeinen Rückgang der frei lebenden Tiere. Rotwild, Hasen und Füchse hausen jedoch heute noch in den Wäldern. Das Federwild hingegen wird immer seltener, da die Brutmöglichkeiten in der heutigen Kulturlandschaft immer spärlicher werden. Deshalb werden in absehbarer Zeit die 


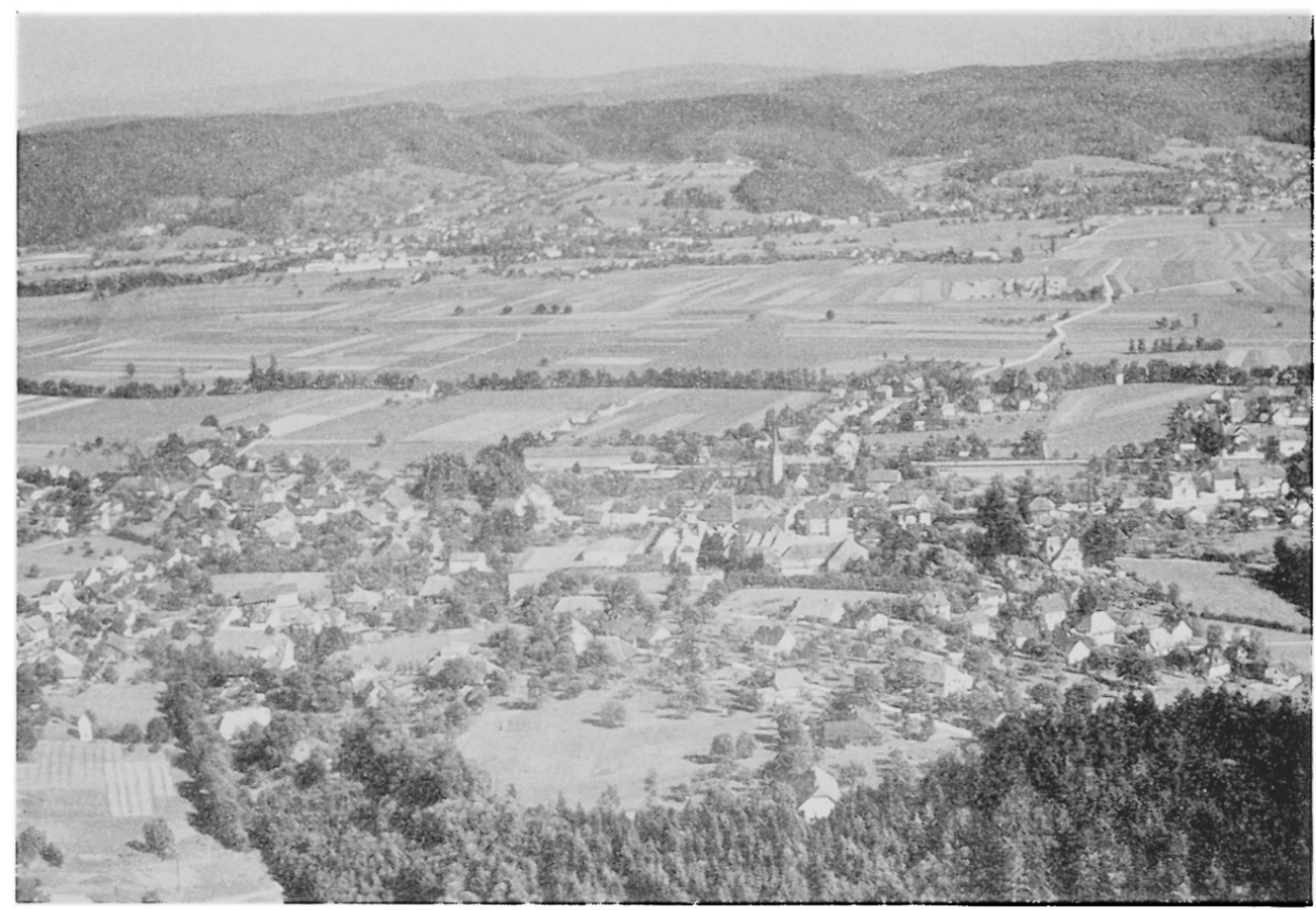

Abb. 5. Extramoränisches Suhrental. Im Vordergrund: Kölliken, im Hintergrund: Muhen (Aufnahme: Aerofoto Winterthur)

wenigen Wildenten und Reiher, die sich gelegentlich noch zur Brutzeit niederlassen, ebenfalls aus der Gegend verschwunden sein. Nicht viel besser ergeht es den Fischen, die immer mehr Mühe haben, einigermaßen unverschmutzte Gewässer zu finden.

\subsection{KULTURLANDSCHAFT}

\subsection{Siedlung}

\section{Der Verlauf der Besiedlung}

Im wesentlichen sind 3 verschiedene Epochen der Besiedlung zu unterscheiden, die in chronologischer Reihenfolge nachstehend einer näheren Betrachtung unterzogen werden.

Die Besiedlung in prähistorischer Zeit. Die ersten nachweisbaren Siedlungen fallen in die Zeit des Neolithikums (52). Die bevorzugte Siedlungform des seßhaft gewordenen Menschen war der Pfahlbau. Da diese Wohnstätten, die ihre Bewohner vor allerlei äußeren Gefahren schützen sollten, an seichte Uferstellen von Seen gebunden waren, treffen wir ihre Überreste im Untersuchungsgebiet bloß am Sempachersee in der Nähe von Schenkon und Sursee. Wie Stau в (57) berichtet, bestand die Siedlung aus 5-6 Pfahlwerken und dehnte sich über eine Fläche von ca. $9000 \mathrm{~m}^{2}$ aus. Sie soll nur in der neueren Steinzeit, also nicht mehr in der Bronce- und Eisenzeit wie andernorts, bewohnt gewesen sein. Die Fundgegenstände, vor allem Werkzeuge, aus diesen ersten Siedlungen sind im Museum Sursee aufbewahrt.

Die gallorömische Zeit. Bis heute sind im Suhrental, außer den bereits erwähnten Pfahlbauten, noch keine Anzeichen einer Besiedlung vor dem Einbruch der Römer sicher festgestellt worden. In Triengen glaubt man zwar einen der bekannten Grabhügel aus vorrömischer Zeit entdeckt zu haben. So können wir nicht mit Sicherheit 
entscheiden, ob bereits die Helvetier die Gegend zum Teil erschlossen hatten. Über römische Niederlassungen zeugen hingegen bis heute erhaltene Fundamente von $\mathrm{Ge}$ bäulichkeiten und Funde von Geräten und hauptsächlich von gebrannten Ziegelsteinen. Folgende Objekte konnten daher mit Sicherheit als von römischer Herkunft identifiziert werden:

- Einzelne Höfe in der Gegend von Sursee auf dem Endmoränenwall (47). Fundgegenstände sind im Museum Sursee der Öffentlichkeit zugänglich.

- Eine Villa in Triengen (56).

- Ein Gutshof bei Oberentfelden (56). Mit großer Wahrscheinlichkeit wurde die Gründung dieser Siedlung von der Legionsstadt Vindonissa aus veranlaßt, die bekanntlich noch weitere Betriebe verwaltete, um die Versorgung der Truppen sicherzustellen. Die Vereinigung für Heimatkunde des Suhrentales in Verbindung mit der Aargauischen Historischen Gesellschaft begann im Herbst 1936 mit den Ausgrabungen (45). Das Ergebnis war überraschend. Die etwa $50 \mathrm{~cm}$ unter der Erdoberfläche festgestellten Fundamente sind derart gut erhalten, daß sie eine vollkommene Rekonstruktion des Hofes zuließen. Die bis heute festgestellten $18 \mathrm{Häu-}$ ser waren in der Hauptsache an eine Umfassungsmauer im Abstand von etwa $25 \mathrm{~m}$ angebaut und wiesen eine Bodenfläche von 9,5 x 7,75 m auf. Der Gutshof in diesem Ausmaß und solcher Anordnung ist der einzige bis heute festgestellte in der Schweiz. Die Erbauung dürfte im 1. Jahrhundert n. Chr. erfolgt sein. Die überall vorgefundene Brandschicht weist darauf hin, daß die Anlage einem Brand zum Opfer fiel.

$V$ on der Germanisierung bis zur Gegenwart. Nach unbedeutenden Einbrüchen der Alemannen im 2. und 3. Jahrhundert ins gallo-römische Helvetien erfolgte im 5. Jahrhundert die endgültige Besiedlung dieses Gebietes (52). Auch über diese Epoche fehlen noch sichere Überlieferungen. Es ist jedoch erwiesen, daß die Alemannen die bereits bestehenden römischen Siedlungen mieden und mit ihren Strohhütten den Grundstein der heutigen Dörfer legten. Die ersten urkundlichen Belege über Siedlungen stammen aber erst aus dem 9. Jahrhundert und ergeben für unser Gebiet folgende Daten (47, $37,43)$ :

$\begin{array}{lrlr}\text { Kölliken } & 864 & \text { Triengen } & 1180 \\ \text { Hirschthal } & 893 & \text { Bottenwil } & 1189 \\ \text { Safenwil } & 893 & \text { Neuenkirch } & 1228 \\ \text { Uerkheim } & 893 & \text { Nottwil } & 1236 \\ \text { Ober-, Unterentfelden } & 965 & \text { Moosleerau } & 1248 \\ \text { Geuensee } & 996 & \text { Kirchleerau } & 1248 \\ \text { Sursee } & 1036 & \text { Wiliberg } & 1251 \\ \text { Oberkirch } & 1036 & \text { Schöftland } & 1254 \\ \text { Muhen } & 1045 & \text { Kulmerau } & 1259 \\ \text { Reitnau } & 1045 & \text { Attelwil } & 1300 \\ \text { Suhr } & 1045 & \text { Schloßrued } & 1347 \\ \text { Büron } & \text { ca. } 1100 & \text { Schmiedrued } & 1347 \\ \text { Eich } & 1106 & \text { Knutwil } & 13 . \text { Jahrh. } \\ \text { Sempach } & 1173 & \text { Holziken } & 1415 \\ \text { Schenkon } & 1173 & \text { Wilihof } & 1429 \\ \text { Schlierbach } & 1178 & \text { Staffelbach } & ? \\ \text { Winikon } & 1178 & & \end{array}$

Diese Tabelle zeigt, daß schon um 1400 ein fast vollständiges Bild der auch heute noch bestehenden Siedlungsplätze vorlag. Die meisten Siedlungen treten bereits als Dörfer auf. Ungefähr gleichzeitig bereichern neue Siedlungselemente in Form von 
Burgen und Klöstern die Landschaft. Das nachfolgende Verzeichnis dieser Bauten zeigt, inwiefern sie sich heute im Suhrental noch bemerkbar machen.

- Noch bewohnte Anlagen:

Schloß Rued, erbaut Ende 18. Jahrhundert (47)

Schloß Schöftland, erbaut 1660 (37)

Kloster Sursee, erbaut 1608 (43)

- Zerstörte Anlagen:

Ruine Scherenberg bei Safenwil

Ruine Büron, heute keine Überreste mehr vorhanden, da 1913 das Schulhaus an ihrer Stelle erbaut worden ist.

Burg Schenkon

\section{Das heutige Siedlungsbild}

Siedlungslage. Die Abb. 6 zeigt, wie der früher mit Wasser durchtränkte Talboden südlich der Staffelbacher Moräne auf die Siedler eine abstoßende Wirkung ausübte (55). Noch heute läßt der grundlose Boden hier kaum die Aufrichtung eines Hauses zu. Im unteren Suhrental dagegen, wo das Wasser im Niederterrassenschotter ungehindert versickern kann, stehen der Besiedlung des Talbodens keine Hindernisse im Wege. Wie aus dem Abschnitt «Hydrographie»zu ersehen ist, treten überall an den Hängen ergiebige Quellen an die Oberfläche, die man gerne als Trinkwasser benützt. In neuerer Zeit wird außerdem der Grundwasserstrom für die Trinkwasserversorgung herangezogen. Die fließenden Gewässer ersetzten früher die kostspieligen Kanalisationsanlagen. Dazu eigneten sich die vielen Seitenbäche besonders gut. Sie gaben deshalb auffallend häufig an der Stelle ihrer Einmündung auf die Talsohle zur Gründung einer Siedlung Anlaß. Besonders typische Beispiele bieten uns die Ortschaften Muhen (3 Seitentäler mit je einem Dorfteil), Hirschthal, Schöftland, Kirchleerau, Triengen, Büron und Geuensee.

Das Relief hat im Untersuchungsgebiet sicher einen entscheidenden Einfluß auf die Lage der Siedlungen ausgeübt. Eine Ebene bietet natürlich den Bewohnern große Vorteile, wie beispielsweise bequeme Zufahrt und einfachere Bebauung des Bodens (Landwirtschaft). Die Talsohle ist somit für eine intensive Besiedlung prädestiniert. Tatsächlich sind denn auch die Zentren von 31 der insgesamt 34 Gemeinden des Suhrentales an die Talsohle gebunden. Die restlichen 3, Kulmerau, Schlierbach, Wiliberg, verdanken ihre Gründung aber ebenfalls einer Verflachung des Geländes, die allerdings nur lokalen Charakter besitzt.

Das Klima endlich erweist sich für ein so kleines Gebiet mit Höhenunterschieden von höchstens $500 \mathrm{~m}$ als $\mathrm{zu}$ einheitlich, um die Siedlungslage entscheidend $\mathrm{zu}$ beeinflussen.

Zusammenfassend ist festzustellen, daß sich die Faktoren, die die Siedlungslage bestimmen, im Gebiet nördlich der Moräne in ihrer Wirkung ergänzten. Südlich davon hingegen mußte die Besiedlung auf den schmalen Übergangssaum zwischen dem feuchten Talboden und dem Hang beschränkt werden (Abb. 6). Die Schwemmfächer der Seitenbäche, die den knappen Siedlungsraum etwas ausweiten, erleichterten den Ausbau der früheren Niederlassungen zu ansehnlichen Ortschaften. Büron, Geuensee, Schenkon und Eich sind die hervorstechendsten Vertreter dieser Siedlungslage.

Weniger ausgeprägt wirkten wirtschaftliche Erwägungen bei der Bestimmung der Siedlungslage mit. Die Dreifelderwirtschaft verlangte natürlich schon eine zentrale Lage der Gebäude in Bezug auf den Wirtschaftsraum. Diesem Bedürfnis konnte aber, wie oben dargestellt, nur im untern Suhrental und auf den höher gelegenen Ebenen entsprochen werden. Folgende Dörfer lassen heute noch diese wirtschaftlich bedingte Lage deutlich erkennen: Suhr, Unterentfelden, Oberentfelden, Kölliken, Safenwil, Muhen, Holziken, Hirschthal, Schöftland, Kulmerau, Schlierbach, Wiliberg. 


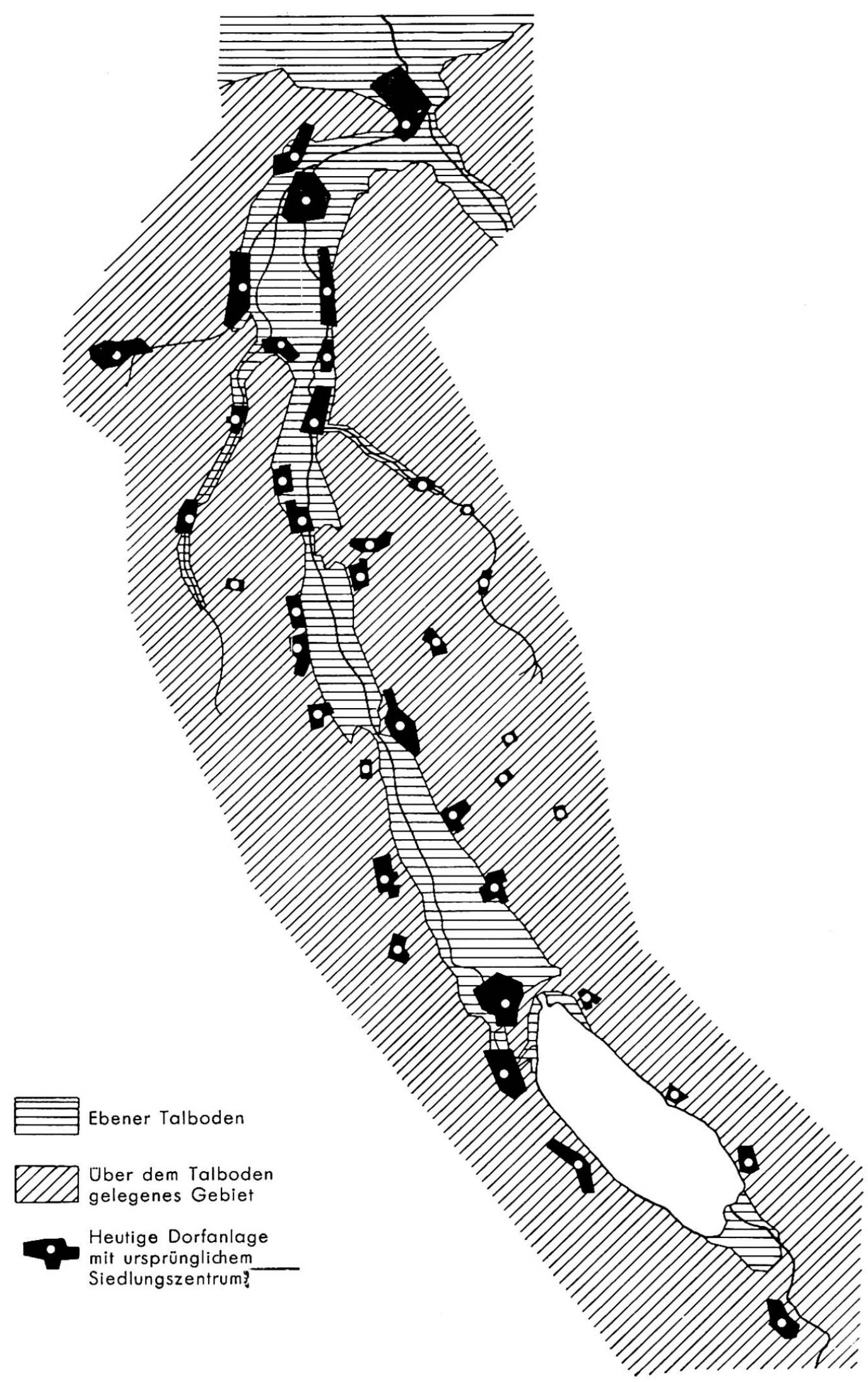

Abb. 6. Topographische Lage der Siedlungen

Für die in einer späteren Kolonisationszeit erfolgte Gründung von Weilern und Einzelhöfen (Uerkental, Ruedertal) kam die Rücksichtnahme auf die bereits bestehenden Dörfer und deren Wirtschaftsraum als weiterer lagebestimmender Faktor hinzu. 
Siedlungsformen. Das Suhrental weist alle Siedlungsformen vom Einzelhof bis zur Kleinstadt auf.

Der Einzelhof. Im Untersuchungsgebiet, wo sich im Laufe der Geschichte keine reinen Handelsplätze, Verkehrsorte oder andere landwirtschaftsfremde, selbständige Siedlungen bildeten, gilt der Einzelhof als Urtyp jeder Gebäudeagglomeration. Inı ganzen Tal ist diese Siedlungsart bis heute erhalten geblieben, sei es als Hof abseits des Dorfzentren oder als Glied der nachfolgend besprochenen Streusiedlung. Gründe, die zur Anlage eines Einzelhofes führen können, sind folgende: Kurze Distanzen zum Wirtschaftsgelände, was speziell bei der Überwindung von größeren Höhendifferenzen ins Gewicht fällt; keine Gefährdung der Leute und Tiere (Weidgang) durch den modernen Verkehr. Große Entfernung von Käserei, Spezereiladen, Schule, Kirche, Post usw. sind Nachteile, die bei den heutigen Verkehrsmitteln stark in den Hintergrund treten.

Als Beispiel der Streusiedlung soll nachfolgend die Gemeinde Uerkheim dargestellt werden (Abb. 7). Für das bessere Verständnis des gegenwärtigen Dorfbildes trägt die Darstellung seiner Entwicklung im Laufe der letzten 100 Jahre wesentlich bei. Dank der zuverläßigen Karte von Michaelis (5) kann der Stand der Besiedlung im Jahre 1844 bereits mit größter Genauigkeit erfaßt werden. Da in neuerer Zeit die Streusiedlung infolge intensiver Bautätigkeit im Dorfzentrum immer schlechter zu erkennen ist, erlangt dieses älteste Siedlungsbild besondere Wichtigkeit. Ein Blick auf den Entwicklungsplan zeigt, daß die Gemeinde bis 1844 noch eine reine Streusiedlung war. Nicht einmal die zentralen Dienste wie Kirche, Schulhaus und Spezereihandlung vermochten eine auffallende Häuserkonzentration hervorzurufen. Ebenso waren die beiden Haupttäler, Uerkental und Tal von Hinterwil, kaum dichter besiedelt als die Hänge und die höher gelegenen lokalen Verflachungen des Geländes. Naturgemäß bestehen die einzelnen Siedlungen ausschließlich aus Bauernhöfen. Die unzusammenhängenden Mischwaldparzellen verraten deutlich, daß das Gebiet vor der Erschließung vollkommen mit Wald bedeckt war. Heute bestockt er nur noch Steilhänge und unwegsame Gräben. Die gesamte Siedlungsanlage erinnert stark an diejenige des Napfgebietes. Nur bewirkt das mittlere Relief und die geringere Höhenlage eine erheblich größere Siedlungsdichte.

Siedlungsdichte Uerkheim um 1844 (Höhenlage im Mittel ca. $520 \mathrm{~m}$ ü. M.) :

Siedlungsdichte im Napfgebiet um 1950 (44):

15,5 Siedlungen $/ \mathrm{km}^{2}$

auf $1000 \mathrm{~m}$ Höhe: 3,34 Siedlungen $/ \mathrm{km}^{2}$

auf $900 \mathrm{~m}$ Höhe: 5,83 Siedlungen $/ \mathrm{km}^{2}$

auf $800 \mathrm{~m}$ Höhe: 12,50 Siedlungen $/ \mathrm{km}^{2}$

Aus der Entwicklung der Gemeinde von 1844 bis in die Gegenwart ist zu ersehen, da $\beta$ diese viel ausgeglichener verlief als diejenige von Oberentfelden (Abb. 10). $\mathrm{Da}$ keine Bahnverbindung besteht, sind die Bewohner größtenteils auf die spärliche eigene Industrie angewiesen. Die frühzeitige Gründung der bis vor kurzem einzigen Fabrik bewirkte ein stetiges Anwachsen des Dorfes. Diesen Entwicklungsvorgang veranschaulicht die nachstehende Tabelle.

$\begin{array}{rlr}\text { Anzahl Gebäude vor } & 1844: & 110 \\ \text { Anzahl Neubauten von } & 1845-1878: & 26 \\ 1879-1897: & 29 \\ 1898-1913: & 11 \\ 1914-1923: & 24 \\ 1924-1931: & 2 \text { (Krisenzeit) } \\ 1932-1942: & 16 \\ 1943-1952: & 13 \\ \text { Total: } & 230\end{array}$




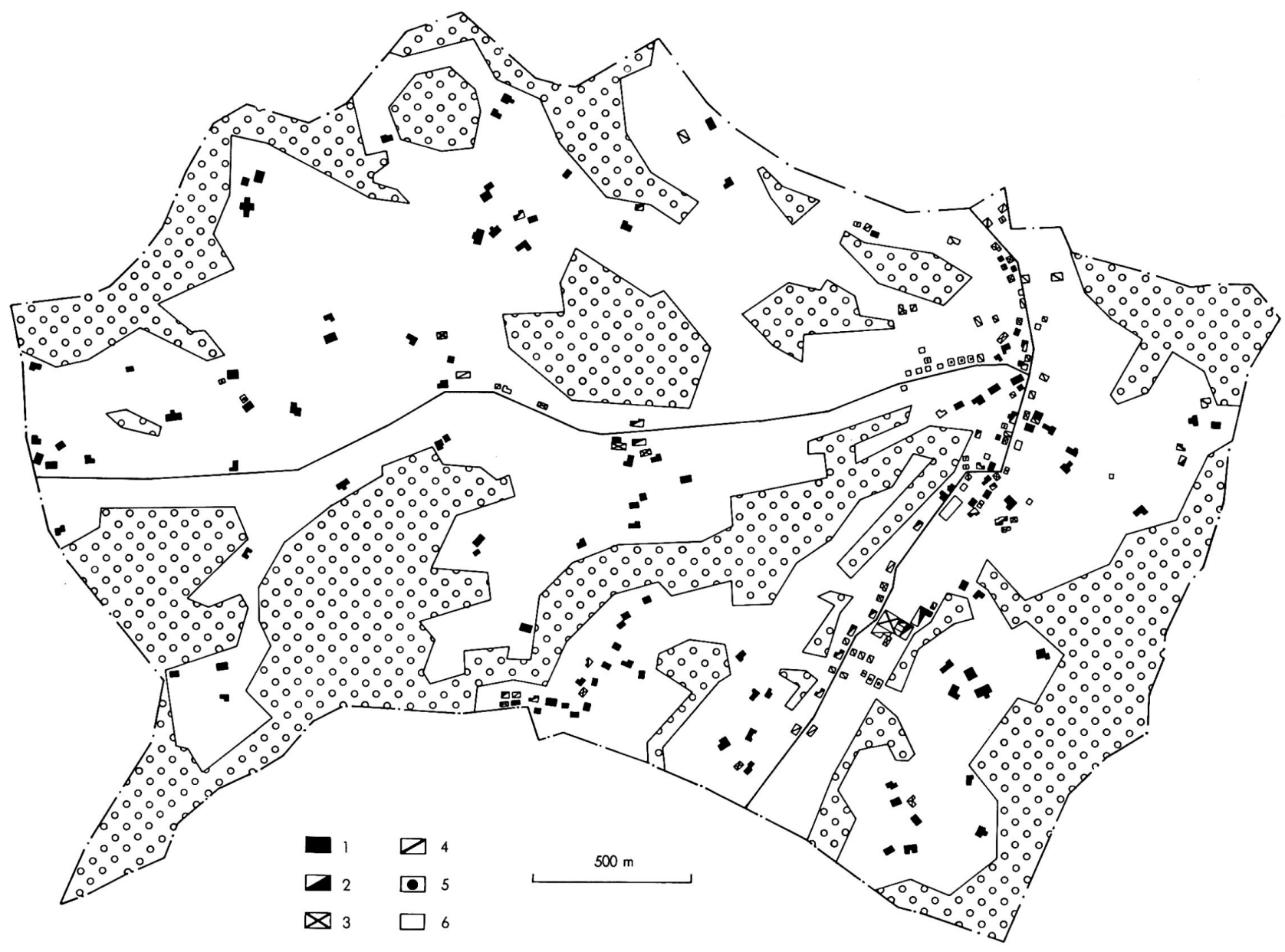


Verkehrstechnische Überlegungen dürften die Ërbauer der neueren Siedlungen, die vorwiegend aus reinen Wohnhäusern bestehen, bewogen haben, den ebenen Talgrund der Uerke als Standort zu wählen. Dies hatte zur Folge, daß die abgelegenen Einzelhofsiedlungen in ihrer ursprünglichen Form unangetastet blieben. Weitere Gemeinden mit typischer Streusiedlung sind Bottenwil, Wiliberg, Schloßrued und Schmiedrued.

Schloßrued bietet mit seiner geradezu mathematisch anmutenden regelmäßigen Verteilung der Höfe über das gesamte Gemeindeareal ein Musterbeispiel der Streusiedlung. Aus Abb. 8 geht auch der Vorgang der Erschließung des Tales sehr schön hervor. Beinahe jeder Hof muß als ein Rodungszentrum aufgefaßt werden, was dazu führte, daß der Wald in viele kleine Parzellen aufgelöst wurde. In Schloßrued besteht die Merkwürdigkeit, daß das Dorf 2 funktionelle Zentren besitzt. Diese werden aus den folgenden Diensten gebildet:

1.Zentrum: Gemeindeverwaltung, Schulhaus, Postgebäude, Gasthaus, Käserei, Mühle, Spezereihandlung und Werkstätten von Handwerkern, die zur Hauptsache landwirtschaftliche Geräte herstellen und reparieren (Schmiede, Sattlerei, Baugeschäft, Sägerei, Möbelschreinerei).

2. Zentrum: Kirche, Restaurant, Spezereihandlung.

Auf Grund dieser Zusammenstellung läßt sich auch gut die Bildung der beiden Zentren erklären. Zweifellos wäre die Kirche ebenfalls im ersten Zentrum erbaut worden, wenn nur die Leute von Schloßrued der Kirchgemeinde angehören würden. Diese umfaßt jedoch die Bewohner der ganzen Talschaft, die in der Kirchgemeinde Rued vereinigt sind. Da nun der Weiler «Kirchrued» ungefähr in der Mitte des Ruedertales liegt, wählte man diesen Standort für die Kirche. Somit erklärt sich auch die geringere Bedeutung dieses 2.Zentrums. Verständlicherweise beschränken sich die reinen Wohnhäuser auf die beiden Zentren, da sich deren Besitzer bloß nach den günstigen Verkehrswegen und der Nähe der Dienste richten müssen.

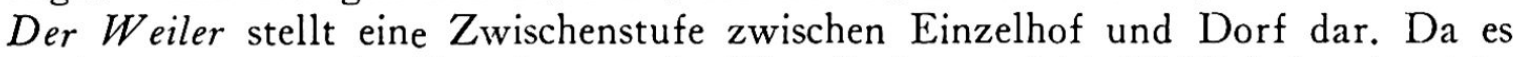
sich meistens nur um eine Erweiterung des Einzelhofes um 1 bis 20 Einheiten handelt, treffen obige Angaben im großen und ganzen auch für diese Siedlungsform zu. Im oberen Suhrental spielen die Weiler, wie später noch gezeigt wird, in der Gestaltung des Landschaftsbildes eine wichtige Rolle. Folgendes Verzeichnis offenbart, daß sie sich im luzernischen Talabschnitt insofern in der Richtung einer kommunalen Siedlung entwickelt haben, als sie zum Teil ebenfalls zentrale Dienste enthalten.

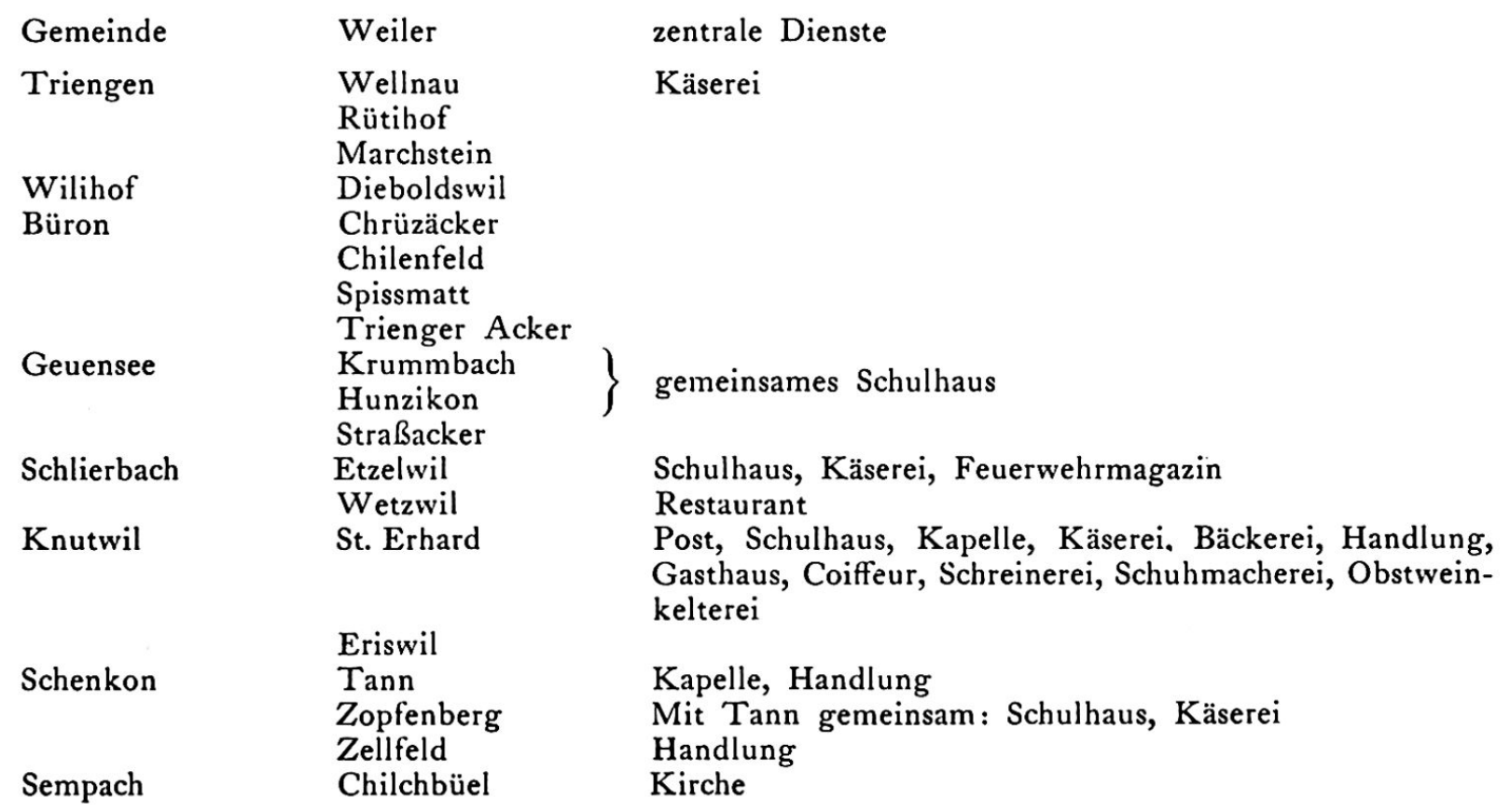




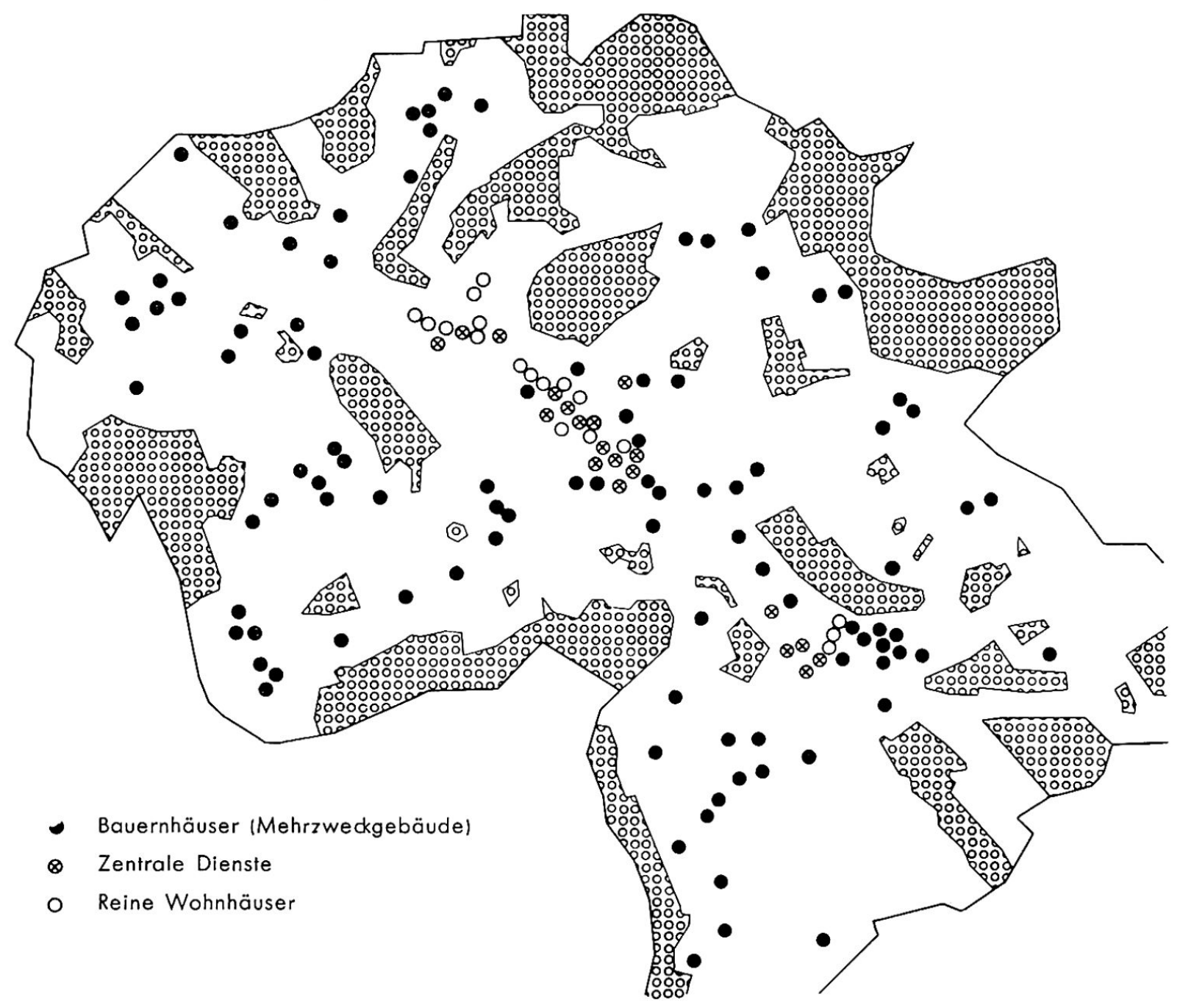

Abb. 8. Siedlungs- und Funktionsplan von Schloßrued. In der Mitte das Hauptzentrum, südöstlich davon das Zentrum der Kirchgemeinde

$\begin{array}{lll}\text { Neuenkirch } & \text { Adelwil } & \text { Kapelle } \\ \text { Rippertschwand } & \text { Kapelle, Käserei } \\ \text { Werligen } & \text { Käserei } \\ \text { Windblosen } & \text { Käserei } \\ \text { Wilistatt } & \text { Käserei } \\ \text { Hellbühl } & \text { Kirche, Handlung, Käserei } \\ \text { Lippenrüti } & \text { Handlung } \\ \text { Homel } & \\ \text { Hälfistägen } & \\ \text { u. a. m. }\end{array}$

Der Weiler St. Erhard verdankt seine Entwicklung der Durchgangsstraße BaselLuzern. Ihm würden zum selbständigen Gemeindewesen bloß noch die Verwaltung fehlen, da alle notwendigen Dienste vertreten sind.

Als Beispiel der Weilersiedlung wurde Schlierbach gewählt (Abb.9), da hier die ursprünglichen Verhältnisse nicht durch neuere Entwicklungstendenzen verwischt wurden; die Gemeinde ist noch heute ein reines Bauerndorf. Nur wenige Gewerbetreibende haben sich niedergelassen, um die Bevölkerung mit den notwendigsten Bedarfsartikeln zu versorgen. Die Siedlung zerfällt in 3 Teile, die äußerlich alle einem Haufendorf ähnlich sehen. Wie aber der Funktionsplan zeigt, könnten die einzelnen Häuseragglomerationen nicht selbständig bestehen, da ihnen wichtige zentrale Funktionen teilweise fehlen würden. Erst die Vereinigung der Weiler zur politischen Gemeinde ergibt ein harmonisches Ganzes. 


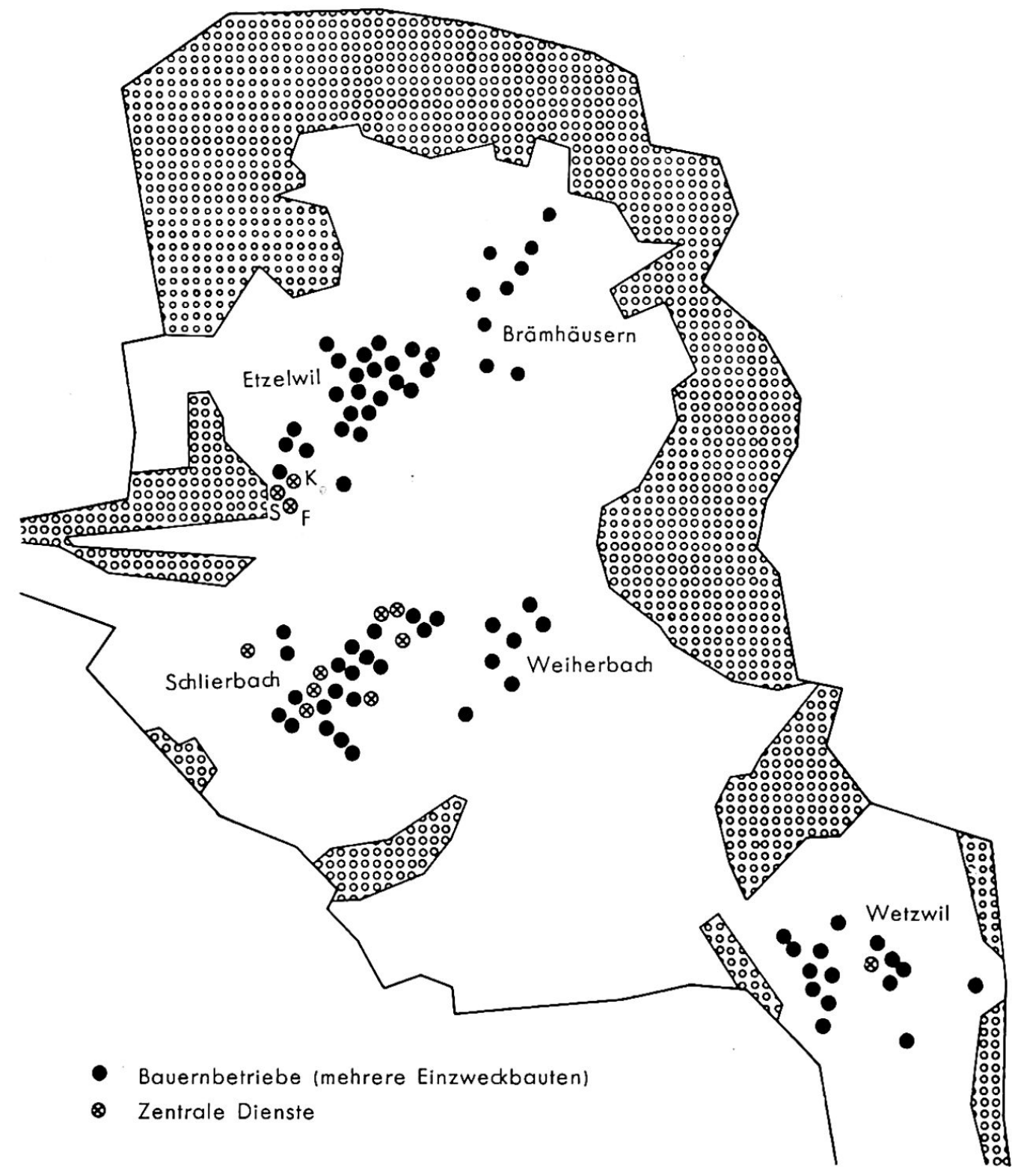

Abb. 9. Siedlungs- und Funktionsplan von Schlierbach. Aus der Lage von Schulhaus (S), Käserei $(\mathrm{K})$ und Feuerwehrmagazin $(\mathrm{F})$ geht hervor, daß sie nur für die Weiler Brämhäusern, Etzelwil, Schlierbach und Weiherbach bestimmt sind. Die Bewohner von Wetzwil benützen die entsprechenden Dienste des benachbarten Weilers Krummbach der Gemeinde Geuensee.

Auch die Verteilung des Waldes zeigt gegenüber der Streusiedlung ein ganz anderes Bild. Es ist offensichtlich, daß die wenigen ursprünglichen kleinen Rodungen konzentrisch vergrößert wurden. Nicht jeder Hof, sondern jeder Weiler muß als Rodungsmittelpunkt aufgefaßt werden.

Das Dorf nimmt im Suhrental die dominierende Stellung ein. Vor dem Einsetzen der Industrialisierung im letzten Jahrhundert handelte es sich ausnahmslos um reine Bauerndörfer. Da damals die Fläche des landwirtschaftlich nutzbaren Bodens der Größe der Niederlassung zweifellos eine bestimmte Grenze aufzwang, stellte sich ein Stillstand in der Entwicklung ein (siehe Entwicklungspläne Abb. 7 und 10). Mit der Ansiedlung von verschiedenen industriellen Betrieben entlang der neu gebauten Bahnlinien war der Bann gebrochen. So erlebten folgende Gemeinden seit der Jahrhundertwende eine sprunghafte Entwicklung: Suhr, Unterentfelden, Oberentfelden, Kölliken, Safenwil, Muhen, Hirschthal, Schöftland und Sursee. Die übrigen Ortschaften weisen noch heute ein Siedlungsbild auf, das nicht wesentlich von demjenigen um 1900 abweicht. 
Als Vertreter der geschlossenen Siedlung sei hier die Gemeinde Oberentfelden ausführlich behandelt (Abb. 10). Wie bei Uerkheim stammt das älteste Siedlungsbild aus dem Jahre 1844. Schon damals bestand die Gemeinde aus dem eigentlichen Zentrum, den Weilern «am Holz», «Wallenland» und «am Berg» und den Einzelhöfen im «Engstal». Die heutige Form des Dorfes (Haufendorf) war in ihren Grundzügen bereits vorhanden. Die auffallende Leere zwischen der Hauptsiedlung und den Weilern dürfte ihren Grund in der alten Dreizelgenwirtschaft haben, die ein Überbauen der einzelnen Zelgen nicht zuließ (48). Ihre Abschaffung um 1800 wirkte sich also auf das Dorfbild noch nicht stark aus. Das Gebiet der heutigen Uerke wurde der vielen Grundwasseraufstöße wegen ohnehin von Siedlungen gemieden. Der Dorfkern enthielt um diese Zeit bereits die zentralen Dienste wie Verwaltung, Schule, Kirche, Käserei, Kaufladen, Gasthof und gewerbliche Betriebe (37,45). Auch die ersten Gebäude der bedeutendsten Fabriken (Karton- und Bürstenfabrik) waren schon vorhanden. Während den 53 Jahren von 1844 bis 1897 sind nur 15 Neubauten, bestehend aus 3 Bauernhäusern, 8 Wohnhäusern und 4 Nebengebäuden, zu verzeichnen. Daraus muß geschlossen werden, daß die Entwicklung der Gemeinde unter den bestehenden Verhältnissen (keine Neuerschließung von Kulturland, wenig Verdienstmöglichkeiten in der Industrie) die möglichen Grenzen erreicht hatte. Auch der Bau der Nationalbahn (1878) vermochte diese Zustände vorerst noch nicht zu ändern.

Die Zeitspanne von 1897 bis 1906 leitete jedoch eine neue Epoche in der Entwicklungsgeschichte des Dorfes ein. Die Zahl von 41 Neubauten (24 Wohnhäuser, 12 Bauernhäuser, 5 industrielle oder gewerbliche Betriebe) während dieser kurzen Zeit bestätigt, daß neue Faktoren bei der Bestimmung des Dorfbildes mitzuwirken begannen. Die Eröffnung der Schmalspurbahn Aarau-Schöftland im Jahre 1901 gab sicher den Anstoß dazu, denn damit war endlich die schnelle Verbindung mit der Stadt Aarau geschaffen, die den Bewohnern die Arbeitsplätze in den dortigen industriellen Betrieben erschloß. Der Arbeiter war also nicht mehr gezwungen, seinen Wohnsitz in die Stadt zu verlegen, um dort dem Verdienst nachzugehen. Die Neugründung von Bauernbetrieben war die Folge der damals üblichen Erbteilungen (45). Dank der Umstellung auf die wirtschaftlichere Kleegraswirtschaft (siehe Seite 198) dürfte manchem Erblasser der Entschluß zur Aufspaltung seines Gutes leichter gefallen sein.

Die Periode von 1906 bis 1919 brachte keine neuen Entwicklungstendenzen. Die Erstellung von 65 Wohnhäusern, 10 Gebäuden der Industrie und des Gewerbes und eines Bauernhauses bezeugt, daß die Bautätigkeit ungefähr im gleichen Sinne angehalten hat. Schon jetzt fällt jedoch auf, daß sich nicht alle Dorfteile gleich entwickeln. Die Bevorzugung der Hauptsiedlung um das Dorfzentrum zur Erstellung von neuen' Wohnhäusern bedarf sicher keiner weitern Erklärung (zentrale Dienste). Auf den ersten Blick scheint es aber rätselhaft, da $\beta$ von den 4 weitern Siedlungsgebieten einzig der Weiler «am Holz» mit der Entwicklung Schritt halten konnte, während die übrigen mit einer Ausnahme überhaupt keine neuen Gebäude erhielten. «Am Holz» ist für Arbeiter in der Stadt eher noch günstiger gelegen als das Dorfzentrum. Vor allem übt die Haltestelle der Aarau-Schöftland-Bahn einen offensichtlichen Einfluß aus. Dies ist wiederum ein schönes Beispiel, wie ein scheinbar nebensächlicher Umstand bei der Gestaltung des Landschaftsbildes von großer Bedeutung sein kann.

Wie folgendes Verzeichnis der Neubauten zeigt, hielt die um die Jahrhundertwende einsetzende rege Bautätigkeit bis zur Gegenwart an.

1919-1931: 81 Wohnhäuser, 2 Bauernhäuser, 3 Gebäude für Industrie oder GeGewerbe

1932-1940: 54 Wohnhäuser, 1 Bauernhaus, 8 Gebäude für Industrie oder Gewerbe 1941-1952: 183 Wohnhäuser, 9 Gebäude für Industrie oder Gewerbe

Seit dem 2. Weltkireg, der verständlicherweise einen vorübergehenden Stillstand in der Entwicklung verursachte, nahm die Vergrößerung der Gemeinde geradezu 


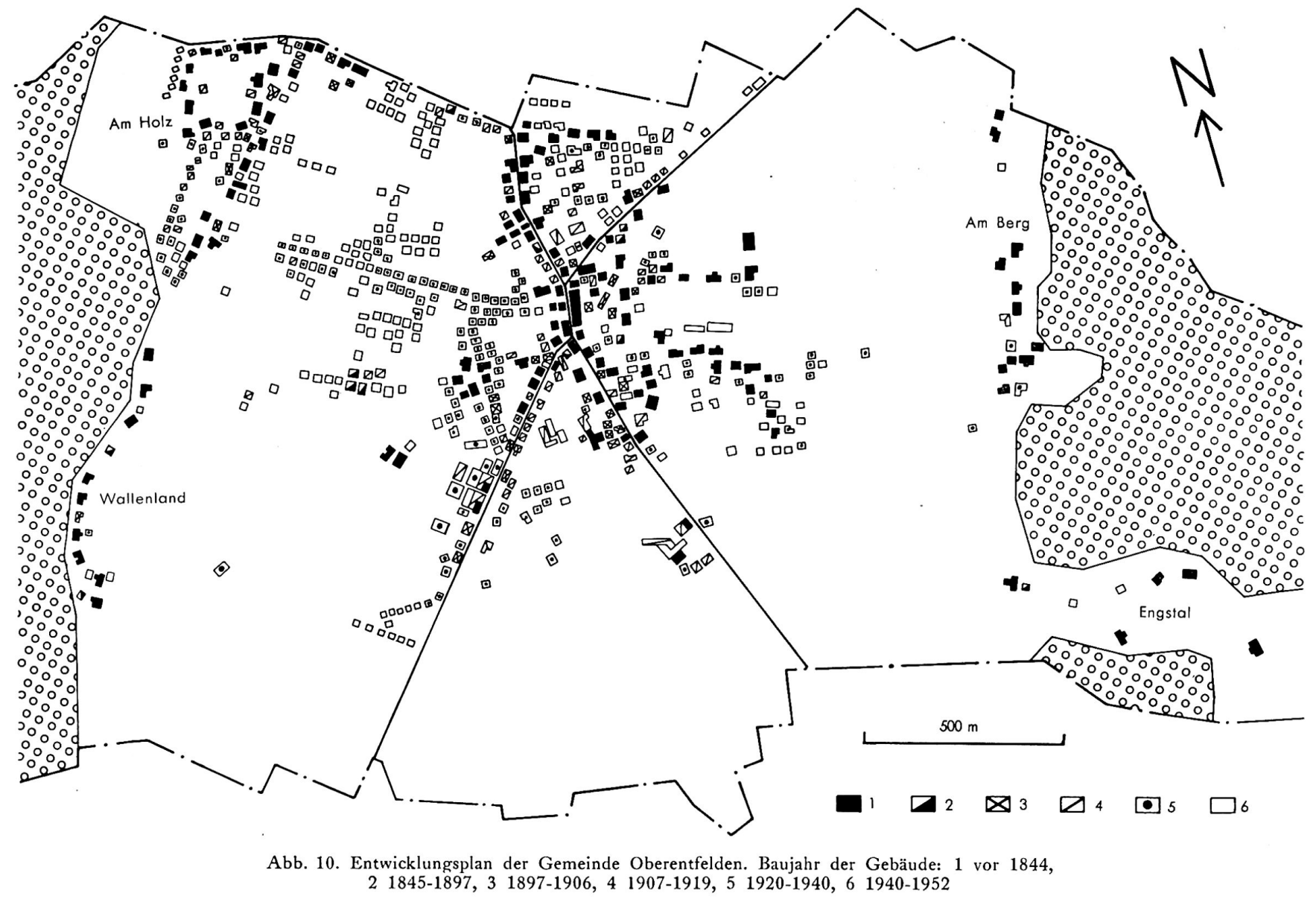


stürmische Formen an. Die Hochkonjunktur in der Industrie verwandelte die bäuerliche Gemeinde immer mehr in ein Siedlungsgebiet der Arbeiter und Angestellten. Noch heute hält diese Tendenz unvermindert an. Die Melioration des Gebietes westlich des Dorfkernes in den Jahren 1942/43 erschloß neues Siedlungsgebiet; die gleichzeitige Erstellung von guten Straßen leistete der Überbauung dieses Dorfteiles noch besonderen Vorschub. So wird in absehbarer Zeit der Weiler «am Holz» mit dem Dorfzentrum vollständig verschmolzen sein.

Die Stadt. Die einzigen Städte, Sempach und Sursee, wurden im Mittelalter zur Zeit der habsburgischen Herrschaft gegründet (35). Das Stadtrecht besitzt Sempach seit 1235, und Sursee erhielt es 1299. Ihr Schicksal hängt eng mit demjenigen der Handelsstraße von Basel über Luzern nach Italien, also dem Gotthardweg zusammen. Es war demnach auch seit ihrer Gründung eine der Hauptaufgaben, als Rastort den Reisenden und Fuhrleuten über Nacht Schutz und Erholung zu gewähren. Noch heute erinnern die großen Stallungen und die Gasthäuser an das betriebsame Leben vergangener Zeiten. Wie in andern mittelalterlichen Städten, siedelten sich auch hier innerhalb der sicheren Stadtmauern bald die Handwerker und Krämer an. Die bcinahe seit der Stadtgründung bestehenden Marktrechte förderten den Warenaustausch zwischen Stadt- und Landbevölkerung.

Erst das 19. Jahrhundert vermochte jedoch die Entwicklung der beiden Städte in neue Bahnen zu lenken. Während bis dahin beiderorts allgemein die gleichen Bedingungen herrschten, änderte sich das nun mit der Eröffnung der neuen Verkehrswege von Basel nach Luzern; denn sowohl die Eisenbahnlinie als auch die Autostraße bedienen nur Sursee. So ließen sich hier Geschäftsleute und Industrielle nieder, die der Stadt zu neuem Aufblühen verhalfen. In Sempach hingegen blieb die Entwicklung nicht nur stehen; es zeigten sich sogar deutlich rückläufige Tendenzen. Der althergebrachte Transitverkehr wurde in keiner Weise ersetzt. Es herrschen also heute noch ähnliche Zustände wie vor 100 Jahren.

Diese ungleichen Voraussetzungen spiegeln sich in der Bevölkerungsentwicklung der beiden Städte wieder (siehe Seite 217). Während die Bevölkerung Sempachs seit 1850 kaum zugenommen hat, verdreifachte sich diejenige von Sursee.

Die Formen der landwirtschaftlichen Gebäude. Die Grundform des Bauernhauses im aargauischen Suhrental ist das alte dreisäßige Stockhaus oder Strohhaus. Der Name gründet in der deutlichen Dreiteilung des Gebäudes in Wohnraum, Tenn und Stall, vielleicht auch in der des Wohntraktes in Stube, Küche und Nebenzimmer $(36,48)$. Über Tenn und Stall befinden sich Lagerräume für Heu und Getreide. Auch die Wagen- und Geräteschuppen sind meistens noch an die ohnehin vielgestaltigen Gebäude angebaut. Es sind also Mehrzweckbauten, wobei sich der First geradlinig und in gleicher Höhe über den Hauskörper hinzieht. Die Anordnung der einzelnen Räume erinnert stark an das «oberaargauische Bauernhaus». Als Bedachung diente ursprünglich Stroh, das aber mit wenigen Ausnahmen dem dauerhafteren Ziegeldach weichen mußte. Auch im luzernischen Suhrental trifft man verständlicherweise diese Bauform recht häufig an, da auch hier ursprünglich das dreisäßige Stockhaus als Vorbild diente. Bei der Umstellung der Betriebe auf fast reine Graswirtschaft Ende des 19. Jahrhunderts (siehe Seite 198) zeigte es sich aber, daß die Ausmaße der Heudielen und Ställe den neuzeitlichen Anforderungen nicht mehr gewachsen waren. Im luzernischen Gebiet, wo die durchschnittliche Fläche der Landwirtschaftsbetriebe bedeutend größer ist als im Aargau (siehe Seite 199), ist das Bedürfnis nach einer besseren Lösung des Raumproblems besonders groß. So entwickelte sich im Laufe der Zeit das «luzernische Gehöft», bei dem Wohnhaus und Scheune getrennt sind. Das Ökonomiegebäude ist geräumig und mit mehreren Ställen versehen. Häufig dient noch ein weiteres Gebäude als Wagen- und Geräteschuppen. Diese Bauart wirkt natürlich im Vergleich zum «Aargauer Bauernhaus» weniger als geschlossene Einheit. 

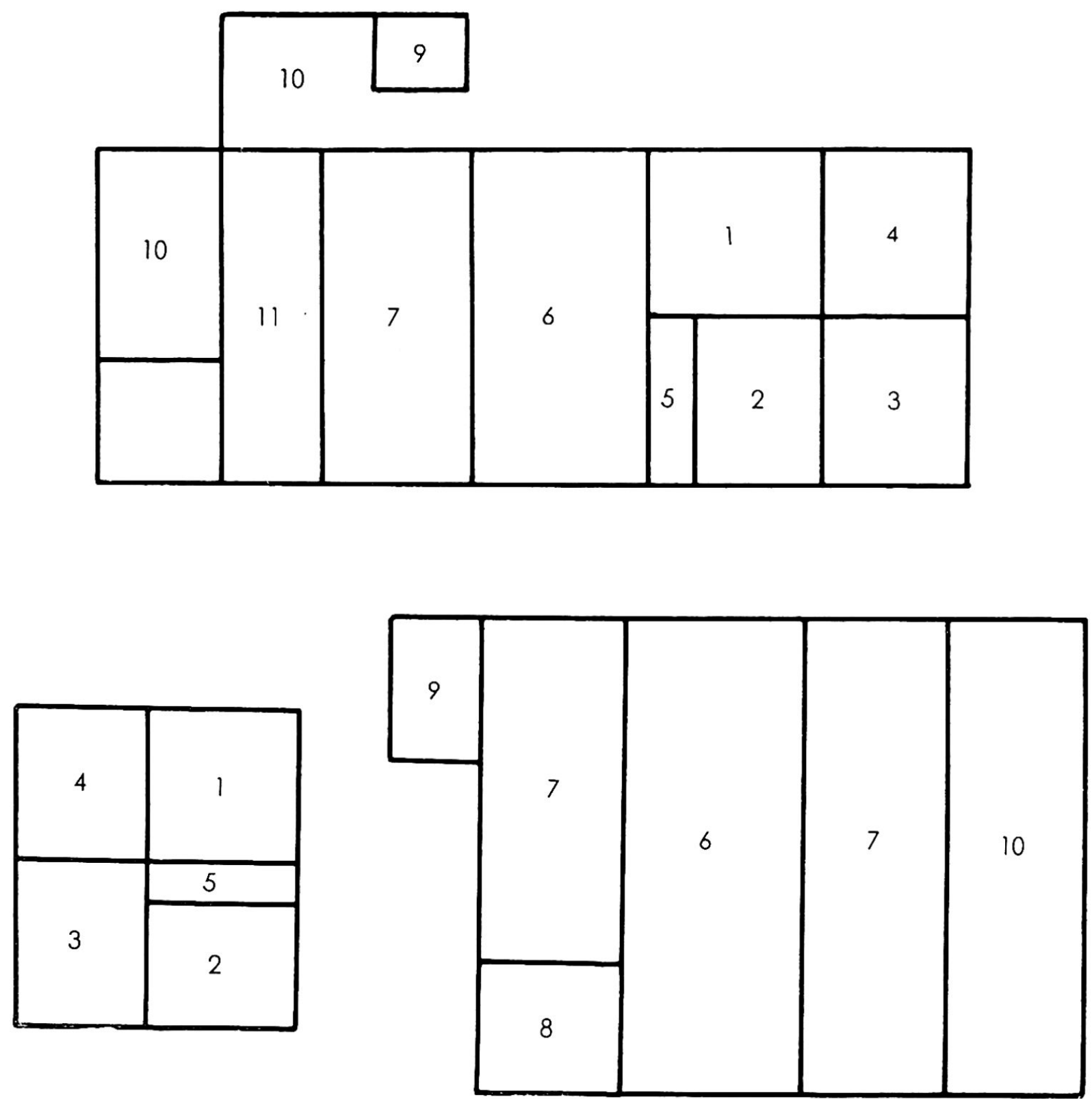

Abb. 11. Schematischer Grundriß der beiden Typen der landwirtschaftlichen Gebäude. Oben: Aargauer Bauernhaus, unten: luzernisches Gehöft. 1 Küche, 2 Stube, 3 Hinterstube (Schlafzimmer), 4 Vorratskammer, 5 Eingang (Wohnteil), 6 Tenne, 7 Kuhstall, 8 Pferdestall, 9 Schweinestall, 10 Geräteschuppen, 11 Futtertenne

Wenn wir die Vor- und Nachteile dieser beiden Bauarten einander gegenüberstellen, so heben sie sich doch fast auf, wie im folgenden ersichtlich ist.

Aargauer Bauernhaus (Mehrzweckgebäude)

Vorteile

Billige Erstellungskosten, weil weniger Material nötig.

Bequeme Arbeitsbedingungen, weil kurzer Weg von Wohn- zu Ökonomieräumlichkeiten.

Verbindungsweg nicht der Witterung ausgesetzt. Nachteile

Weniger große Räumlichkeiten für den Landwirtschaftsbetrieb.

Bei Brandausbruch beide Gebäudeteile gefährdet.

Störender Einfluß des Landwirtschaftsbetriebes auf die Wohnung.
Luzernisches Gehöft (Einzweckgebäude)

Nachteile

Teure Erstellungskosten, weil mehr Material nötig.

Die größere Distanz von Wohn- zu Ökonomiegebäude erschwert eine rationelle Arbeitseinteilung.

Verbindungsweg der Witterung ausgesetzt.

Vorteile

Große Räumlichkeiten für den Landwirtschaftsbetrieb.

Bei Brandausbruch nur ein Gebäude gefährdet.

Landwirtschaftsbetrieb stört das Leben in der Wohnung weniger. 


\subsection{Landwirtschaft}

\section{Die Landwirtschaft in früheren Zeiten}

Wie bereits festgestellt, war bis zum 18. Jahrhundert die Dreifelderwirtschaft das vorherrschende Bodennutzungssystem (48). Neben den Auswirkungen auf das Siedlungsbild fallen vor allem noch die häufigen Flurnamen auf, die mit dieser Wirtschaftsform in Zusammenhang stehen. Anhand dieser Namen kann heute noch die ehemalige Einteilung des Kulturlandes in die einzelnen «Zelgen» rekonstruiert werden. Beispiele: Oberentfelden: Schürlifeld

Oberfeld

Außerfeld

Büntlis (eingezäuntes Landstück für Gemüsepflanzungen) Schinhutmatten

Weltimatt

Geuensee: Bünten (wie Büntlis)

Allmend (gemeinsames Weideland)

Über die Wirtschaftsform in den Gebieten der Streusiedlung ist wenig bekannt, da keine sicheren Überlieferungen zur Verfügung stehen. Aus den Untersuchungen Howalds (48) geht hervor, daß in diesen Regionen eher die im Emmental heimische Egartenwirtschaft betrieben wurde. Er begründet diese Annahme mit den auf «Weid» endenden Flurnamen. In Wiliberg gibt es besonders gute Beispiele: «Farnweid», «Grabenweid», «Bärenweid».

\section{Die heutige Landwirtschaft}

Mit der Aufhebung der Dreifelderwirtschaft im Laufe des 18. Jahrhunderts (48) stellten sich bereits die jetzigen Verhältnisse in groben Zügen ein, die mit der Zeit allerdings noch verschiedene Entwicklungsstufen durchliefen. Die Aufhebung des Flurzwanges verlieh dem Bauer mehr Freiheit in der Bebauung seines Grundes. Das neue Bodennutzungssystem mit der Bezeichnung «verbesserte Dreifelderwirtschaft»kennzeichnete sich dadurch, daß der vermehrten Düngung zufolge die brachliegenden Grundstücke aus dem Landschaftsbild verschwanden. Der Fruchtwechsel eines Ackers wickelte sich nun wie folgt ab: Kartoffeln, Weizen, Roggen, Klee, Korn, Gerste. Nach der Gerste begann der sechsjährige Zyklus (Sechsfelderwirtschaft) von vorne. Neu war auch die Stallfütterung während des ganzen Jahres, wodurch der Bauer die Möglichkeit einer wirtschaftlicheren Auswertung des natürlichen Düngers erhielt.

Die vermehrte Einfuhr von billigem Getreide bewirkte um 1900 neuerdings eine Veränderung des Bodennutzungssystems. Diese bezweckte eine Intensivierung des Futterbaues und als Folge davon der Milchwirtschaft. Im sechsjährigen Fruchtwechselzyklus eines Grundstückes nimmt nun der Futterbau 3 Jahre in Anspruch, währenddem der Getreidebau stark zurückgedrängt wird. Die verschiedenen Kleearten, die mehrheitlich für den Futterbau herangezogen werden, haben die Bezeichnung «Kleegraswirtschaft» aufkommen lassen.

Um ein möglichst vollständiges Bild von der heutigen Landwirtschaft zu erhalten, werden in erster Linie die zur Verfügung stehenden Statistiken und die im Untersuchungsgebiet gemachten Beobachtungen auszuwerten sein.

\section{Betriebsverhältnisse}

Sehr aufschlußreich sind die Werte der mittleren Betriebsgröße (Tab. 1). Im allgemeinen - nur 5 Gemeinden bilden eine Ausnahme - vergrößern sie sich während der 26-jährigen Zeitspanne von 1929-1955 beträchtlich. Die gleichzeitige, zum Teil starke Verminderung der Bauernhöfe läßt folgende Entwicklungstendenz erkennen: Die kleinen, unwirtschaftlichen Betriebe werden allmählich aufgehoben und treten 
ihr Land den großen zur Nutzung ab. So erfährt die Landwirtschaft eine Konsolidierung, was in Zukunft sicher gute Auswirkungen haben wird. Auffallend sind ferner die unterschiedlichen Betriebsgrößenverhältnisse zwischen den aargauischen und den luzernischen Gemeinden. Die Betriebsareale sind in den letztern durchschnittlich um ca. 200 a größer. Dieser Unterschied beruht auf dem zwar ungeschriebenen Erbrecht der luzernischen, katholischen Bauernfamilien, wonach die Kinder nach Ableben der Eltern den Hof gemeinsam zu verwalten und zu bearbeiten haben. Niemals aber darf der Grundbesitz zerstückelt werden. Im Kanton Aargau hingegren teilten früher die Nachkommen, soweit es die Wirtschaftlichkeit zuließ, den elterlichen Besitz und gründeten neue Bauernhöfe.

Tab. 1: Die Betriebsverhältnisse im Suhrental (18)

\begin{tabular}{|c|c|c|c|c|}
\hline & $\begin{array}{r}\text { Landwir } \\
\text { in }\end{array}$ & $\begin{array}{l}\text { betriebe } \\
\text { en }\end{array}$ & Mittler & bsgröße \\
\hline & 1929 & 1955 & 1929 & 1955 \\
\hline (Suhr & 100 & 64 & 404 & 593 \\
\hline Unterentfelden & 57 & 33 & 248 & 274 \\
\hline Oberentfelden & 119 & 70 & 317 & 564 \\
\hline Muhen & 135 & 110 & 317 & 375 \\
\hline Kölliken & 131 & 112 & 335 & 334 \\
\hline Safenwil & 126 & 92 & 227 & 296 \\
\hline Holziken & 38 & 34 & 465 & 541 \\
\hline Hirschthal & 48 & 32 & 319 & 430 \\
\hline Schöftland & 86 & 49 & 357 & 572 \\
\hline Staffelbach & 91 & 89 & 451 & 473 \\
\hline Kirchleerau & 60 & 42 & 340 & 525 \\
\hline Moosleerau & 53 & 50 & 318 & 461 \\
\hline Attelwil & 36 & 27 & 454 & 574 \\
\hline Reitnau & 107 & 74 & 343 & 470 \\
\hline Uerkheim & 129 & 111 & 350 & 389 \\
\hline Bottenwil & 81 & 75 & 346 & 395 \\
\hline Wiliberg & 16 & 16 & 732 & 712 \\
\hline Schloßrued & 93 & 82 & 511 & 582 \\
\hline Schmiedrued & 138 & 124 & 442 & 532 \\
\hline Kulmerau & 41 & 34 & 437 & 513 \\
\hline Winikon & 66 & 63 & 603 & 651 \\
\hline Triengen & 126 & 111 & 482 & 541 \\
\hline Wilihof & 23 & 24 & 990 & 970 \\
\hline Schlierbach & 61 & 59 & 648 & 714 \\
\hline Büron & 93 & 89 & 364 & 440 \\
\hline Knutwil & 94 & 86 & 692 & 823 \\
\hline Geuensee & 75 & 70 & 631 & 731 \\
\hline Sursee & 54 & 46 & 707 & 688 \\
\hline Schenkon & 70 & 64 & 773 & 846 \\
\hline Oberkirch & 101 & 99 & 713 & 738 \\
\hline Eich & 50 & 47 & 975 & 1056 \\
\hline Nottwil & 99 & 103 & 968 & 929 \\
\hline Sempach & 59 & 57 & 1112 & 1301 \\
\hline Neuenkirch & 188 & 190 & 1047 & 1109 \\
\hline
\end{tabular}

\section{Bodennutzung}

Wie folgende Zusammenstellung zeigt, ist die Kulturfläche des Untersuchungsgebietes einer steten Abnahme unterworfen. Dies rührt daher, daß die Möglichkeiten der Neuerschließung von Kulturland erschöpft sind und die Überbauung des Areals mit Wohnhäusern, Industrie-, Verkehrsanlagen usw. der Landwirtschaft immer mehr Boden entreißt. Da sich die Abnahme für alle Gemeinden ungefähr gleich hoch beläuft, seien hier die Landverluste im gesamten Suhrental verzeichnet: 


$\begin{array}{lc} & \text { Kulturland ohne Wald } \\ \text { Im Jahre } 1912(27) & 16996,6 \text { ha } \\ \text { Im Jahre } 1923(12) & 16879,6 \text { ha } \\ \text { Im Jahre } 1952(12) & 16176,2 \text { ha }\end{array}$

Abnahme pro Jahr in der Periode 1912-23: 10,6 ha

1923-52: 24,2 ha

Wie erwartet, kommt in diesen Zahlen zum Ausdruck, daß der jährliche Verlust von Kulturland gegenüber früher sehr stark zugenommen hat.

Die Bepflanzung des Kulturareals gestaltet sich in allen Gemeinden des Untersuchungsgebietes ungefähr gleich. Der Anteil des offenen Ackerlandes an der gesamten Kulturfläche schwankt zwischen 20 und 35\%. Nachdem jedoch im Suhrental eine vielgestaltige Oberflächengeologie festgestellt wurde (Abb.2), könnte man auch eine ebenso differenzierte Bebauung des Bodens erwarten. Wie später noch gezeigt wird, richtet sich aber die Art der Bodennutzung mehr nach wirtschafts-politischen Gesichtspunkten (Nachfrage der Konsumenten, momentane Witschaftslage des Landes).

Wie die Konsultation der

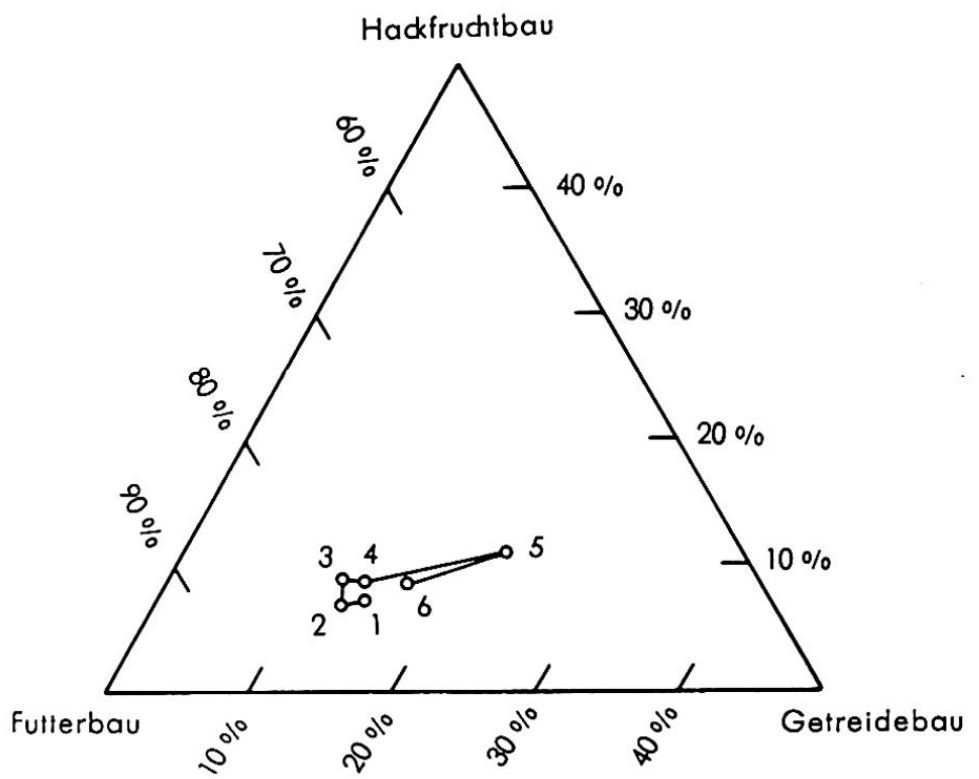

Abb. 12. Entwicklung der Kulturen von 1917 bis 1950 . 1: 1917, 2: 1929, 3: 1934, 4: 1939, 5: 1942, 6: 1950. Anbaustatistik von 1950 ergab, sind auch die Verhältnisse der Anbauflächen der wichtigsten Kulturpflanzen in allen Gemeinden ungefähr gleich. Der Futterbau dominiert überall $(60-80 \%)$ und der Getreidebau steht durchwegs an zweiter Stelle. Die Darstellung mit Dreieckskoordinaten veranschaulicht die Entwicklung der Kulturen im Suhrental (Abb. 12). $\mathrm{Da} \beta$ die Kriegsjahre eine gewisse Erschütterung eines über viele Jahre gleichbleibenden Verhältnisses verursachten, geht deutlich daraus hervor. Der Wert für das Jahr 1950 deutet aber an, daß das Vorkriegsstadium langsam wieder angestrebt wird.

Getreidebau. Die Entwicklung des Getreidebaues seit 1917:

\begin{tabular}{ccc} 
& \multicolumn{2}{c}{ Getreideanbaufläche } \\
$1917(26)$ & Subrental in ha & Schweiz in 100 ha \\
$1929(11)$ & 1923 & 1173 \\
$1934(11)$ & 1626 & 1183 \\
$1939(13)$ & 1576 & 1166 \\
$1942(13)$ & 1837 & 1369 \\
$1950(11)$ & 3909 & 1923 \\
& 2570 & 1653
\end{tabular}

Diese Zusammenstellung illustriert den Anstieg des Getreidebaues während der Kriegszeiten. Im Suhrental ist offenbar, verglichen mit dem schweizerischen Total, eine stärkere Intensivierung des Getreidebaues möglich. Der Bauer zieht aber den Futterbau vor, wenn er nicht durch Bundesbeschlüsse in seinem Handeln eingeschränkt wird. Die Ernteaussichten im Getreidebau sind aber keineswegs geringer als anderswo im schweizerischen Mittelland. 
Hackfruchtbau. Die Hackfrüchte sind im Suhrental vor allem durch Kartoffeln und Futterrüben vertreten. Der Anbau von Zuckerrüben und «Gelben Rüben» (Karotten) für den Handel ist sehr selten. Die Entwicklung des Hackfruchtbaues seit 1917:

\begin{tabular}{ccc} 
& \multicolumn{2}{c}{ Anbaufläche der Hackfrüchte } \\
Schweiz in 100 ha & Suhrental in ha & 612,5 \\
$1917(26)$ & 931 & 568,3 \\
$1929(11)$ & 866 & 780,1 \\
$1934(11)$ & 1085 & 1124,1 \\
$1939(13)$ & 1071 & 1070,8 \\
$1942(13)$ & 1533 & 904,9 \\
$1950(11)$ & 1273 &
\end{tabular}

Der Vergleich mit der Anbaufläche der ganzen Schweiz bestätigt, daß das Suhrental im Hackfruchtbau eigene Wege eingeschlagen hat. Ende der zwanziger Jahre hatte die Anpflanzung einen bemerkenswerten Tiefpunkt erreicht. Die Anbauvorschriften während der Kriegsjahre verursachten einen erstaunlichen Aufschwung. Seither sank aber die Anbaufläche wieder auf das Vorkriegsniveau zurück. Dies hebt wieder die Vorliebe des Suhrentaler Bauern zum Futterbau hervor, die sich in Zeiten einer gesicherten Versorgungslage der Schweiz voll entfalten kann.

Futterbau. Zum Futterbau zählen die Naturwiesen und die zur Kleegraswirtschaft gehörenden Kunstwiesen. Letztere setzen sich hauptsächlich aus den folgenden Pflanzen zusammen; Rotklee, Luzerne, Esparsette und Italienisches Raygras. Wie schon erwähnt, ist der Futterbau die vorherrschende Bodennutzungsart (Abb. 12). Die Voraussetzungen für eine ertragreiche Ernte sind vor allem feuchter Grund und gute Düngung. Das Regenwasser versickert aber auf der Ebene des Niederterrassenschotters im extramoränischen Suhrental ziemlich rasch; deshalb haben die Bauern früher das Wasser der Suhre besonders bei längeren Trockenzeiten zur künstlichen Bewässerung benützt. Nun sind aber in den Meliorationsgebieten die alten Bewässerungskanäle verschwunden (siehe Abschnitt 2.32). Dort bedient sich heute der Landwirt der sogenannten Berieselungsanlagen, die ebenfalls mit Suhrewasser gespiesen werden. Während aber die Arealstatistik des Jahres 1923 (12) für alle Gemeinden der extramoränischen Talsohle «Wässerwiesen» verzeichnet, fehlen diese im intramoränischen Gebiet vollständig. Aus folgenden Gründen kann der Landwirt im oberen Suhrental auf eine künstliche Bewässerung verzichten:

1. Das alluvial abgelagerte Oberflächenmaterial des Talbodens, ein Gemisch von feinem Sand und leichter, torfähnlicher, schwarzer Erde, ist ein guter Wasserspeicher, der auch die Verdunstung stark verzögert.

2. Die Grundmoränen verhindern das Versickern des Regenwassers in die Tiefe.

3. Das geringe Gefälle bewirkt eine langsame Oberflächenentwässerung.

Gemüsebau. Der Gemüsebau hat nie eine große Bedeutung erlangt. Da in unmittelbarer Nähe keine Großstadt liegt, die den Absatz von Frischgemüse sicherstellt, ist es verständlich, daß die Pflanzer bloß die Versorgung des eigenen Haushaltes anstreben.

Obstbau. Im Suhrental dominieren folgende Obstbaumarten: Apfel-, Birnen-, Kirschen-, Zwetschgen- und Pflaumenbäume. Der durchschnittliche Anteil an Bäumen pro Landwirtschaftsbetrieb ist in den einzelnen Gemeinden sehr unterschiedlich (Tab. 2). Verständlicherweise besitzen die größeren Betriebe der luzernischen Gemeinden fast ausnahmslos bedeutend mehr Bäume als im Aargau; denn der eigene Obstbedarf steigert sich der vermehrten Arbeitskräfte wegen. Die relativ großen Baumbestände von Suhr, Unterentfelden und Oberentfelden sind auf die Nähe der Stadt Aarau zurückzuführen, die den Absatz von Frischobst dieser Gemeinden sicherstellt. Die windgeschützte Lage des Ruedertales läßt besonders die Kirschen gut gedeihen; so ist man über die hohe Obstbaumdichte dieser Region kaum erstaunt. Bei der Verwertung des Obstes spielt natürlich die Selbstversorgung der Bauernfamilien mit Frischobst, Most 
und Branntwein eine wichtige Rolle. Obstverkauf kommt im allgemeinen nur bei einer guten Ernte in Frage. Der Obstbau bietet dem Bauer also keine sichere Verdienstmöglichkeit.

Die Bäume sind vorwiegend in Hofnähe, auf den für die tägliche Grünfütterung bestimmten Wiesen, plaziert. Sie beeinträchtigen so die maschinelle Bearbeitung des Bodens am wenigsten, da diese Parzellen nicht umgepflügt und als offenes Ackerland verwendet werden. Ganz selten stehen Obstbäume in der freien Flur.

Tab. 2 Obstbau in den Gemeinden 1951 (17)

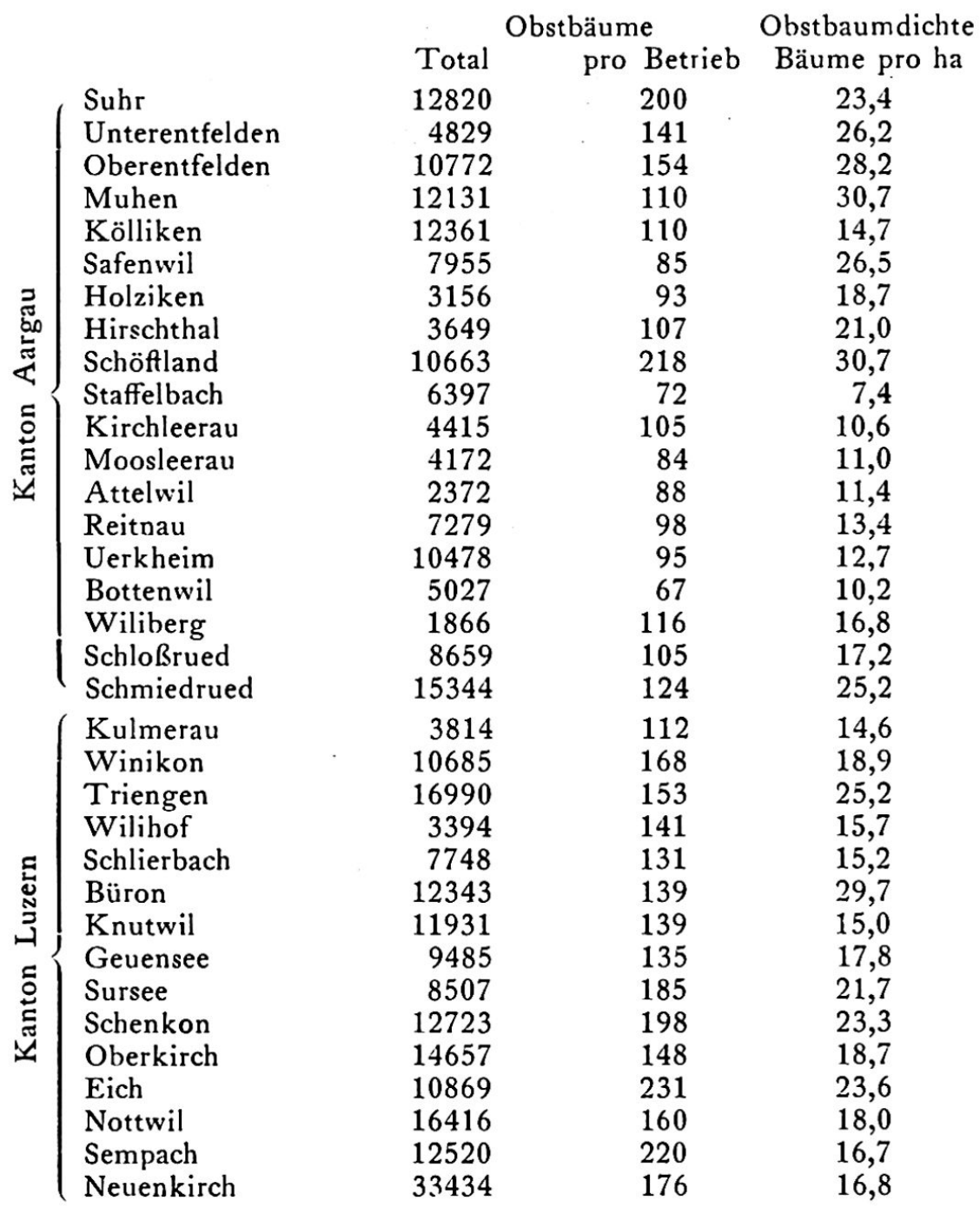

\section{Tierhaltung}

Der große Flächenanteil des Futterbaues am produktiven Land (Abb. 12) hebt die Bedeutung der Tierhaltung im Suhrental hervor. Als Gründe können folgende für die ganze Schweiz zutreffenden Verhältnisse angeführt werden:

1. Die Einfuhr von billigem Brotgetreide aus dem Ausland drängt die Inlandproduktion zurück.

2. Die 'Tierhaltung benötigt weniger Arbeitskräfte.

3. Der Futterbau ist weniger von der Witterung abhängig (Hagel, lange Regenperiode, Frost).

Rindvieh. Über die Rindviehhaltung in den einzelnen Gemeinden orientiert Tab. 3. Die relativ geringen Schwankungen der Viehdichte bestätigen die ausgeglichene Fruchtbarkeit des Bodens im Suhrental. Natürlich werden diese Zahlen noch von andern Faktoren beeinflußt, so z. B. vom Intensitätsgrad der Bodenbewirtschaftung, 
vom Verhältnis «Wiesland zu Ackerland» und von der Menge der Zukäufe von Futtermitteln. Offensichtlich hält die mittlere Anzahl Tiere pro Besitzer mit der Größe der Betriebe zusammen. Darin liegen die größeren Viehbestände in den luzernischen Gemeinden begründet; denn hier befinden sich auch die durchschnittlich umfangreicheren Höfe als im Aargau.

Tab. 3: Die Rindviehhaltung in den Gemeinden 1951 (16)

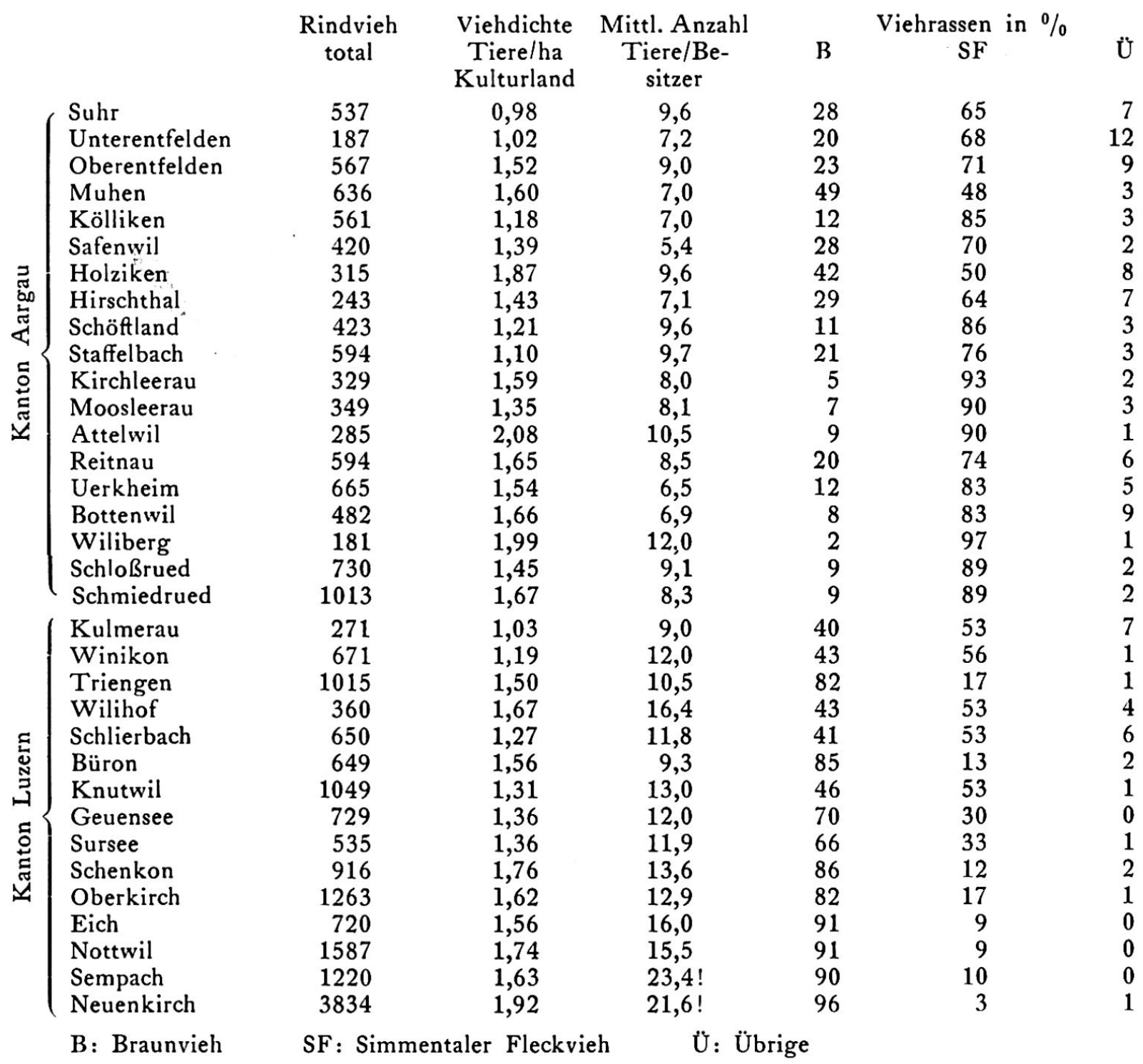

Wie aus der Tab. 3 zu ersehen, hält sich die Verteilung der Viehrassen ebenfalls an die Kantonsgrenze. Im luzernischen Suhrental überwiegt das Braunvieh, im aargauischen hingegen das Simmentaler Fleckvieh.

Die Art der Milchverwertung ist in den Gemeinden sehr verschieden (Tab.4). Im Vordergrund steht natürlich überall die Belieferung der Bevölkerung mit Frischmilch. In den Gemeinden des untern Suhrentales findet der gesamte Überschuß in Aarau als Konsummilch Absatz. Je nach Jahreszeit müssen noch entferntere Regionen zur Sicherung der Milchversorgung der Stadtbevölkerung herangezogen werden, da besonders im Winter die Produktion wesentlich geringer ist. Der kleinen Einwohnerzahl wegen vermag Sursee im oberen Suhrental nicht die gleiche Rolle wie Aarau zu spielen und Luzern liegt zu weit entfernt. Der nicht direkt verwertete Rest der Milch dient der Käse- und Butterbereitung in den Milchsammelstellen. Zusammenfassend sei festgestellt, daß im untern Gebiet des Tales die Frischmilchverwertung, im obern dagegen die Herstellung von Milchprodukten überwiegt. 
Tab. 4: Milchverwertung in den Gemeinden

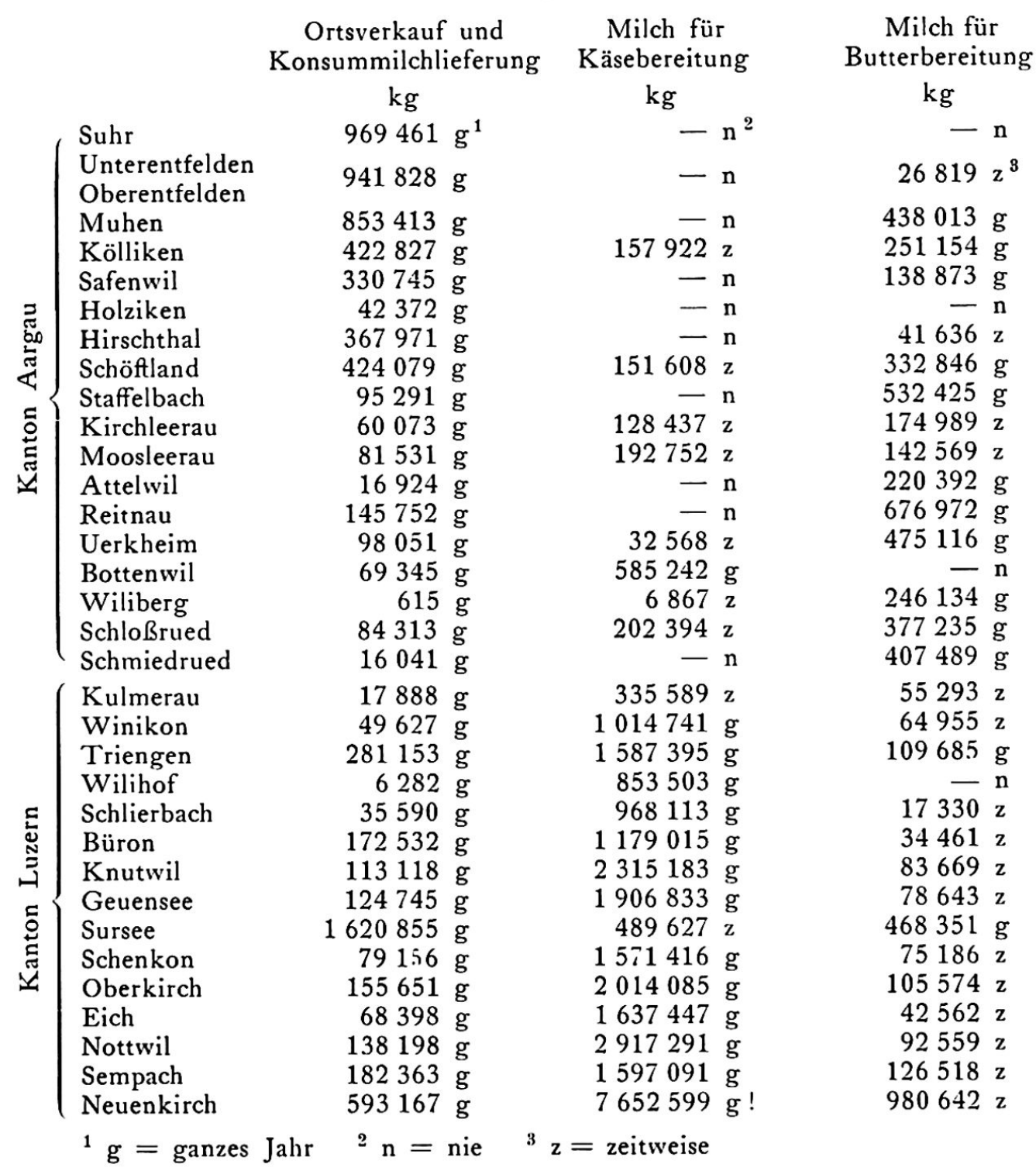

Pferde. Trotz der fortschreitenden Motorisierung der Landwirtschaft, kann sich das Pferd als Zugkraft behaupten. Die Bestände haben über die Kriegszeit sogar noch etwas zugenommen.

$\begin{array}{ll}1936 & 1835 \text { Pferde }(20) \\ 1946 & 1891 \text { Pferde (15) } \\ 1951 & 1683 \text { Pferde (16) }\end{array}$

Kleinvieh. Der Kleinviehhaltung kommt eine ganz geringe Bedeutung zu. Die Zahl der Ziegen beträgt für das ganze Untersuchungsgebiet nur 549, und auch die Schafe treten nur vereinzelt auf (375 Stück) (16).

\subsection{Forstwirtschaft}

Die unterschiedlichen geologischen Verhältnisse des Suhrentales bestimmen auch weitgehend die Verteilung des Waldes. Wie überall in der Schweiz drängten ihn auch hier die Besiedler auf die weniger fruchtbaren Regionen zurück. Deshalb beschränken sich die Waldflächen im extramoränischen Gebiet auf die Hügelzüge, wo die Molassegesteine direkt an die Oberfläche treten. Ebenso verhindert hier die steile Böschung jede landwirtschaftliche Nutzung. Die Talsohle dagegen weist ihrer Fruchtbarkeit wegen keine einzige Waldparzelle auf. Südlich der Moräne bei Staffelbach, wo die 


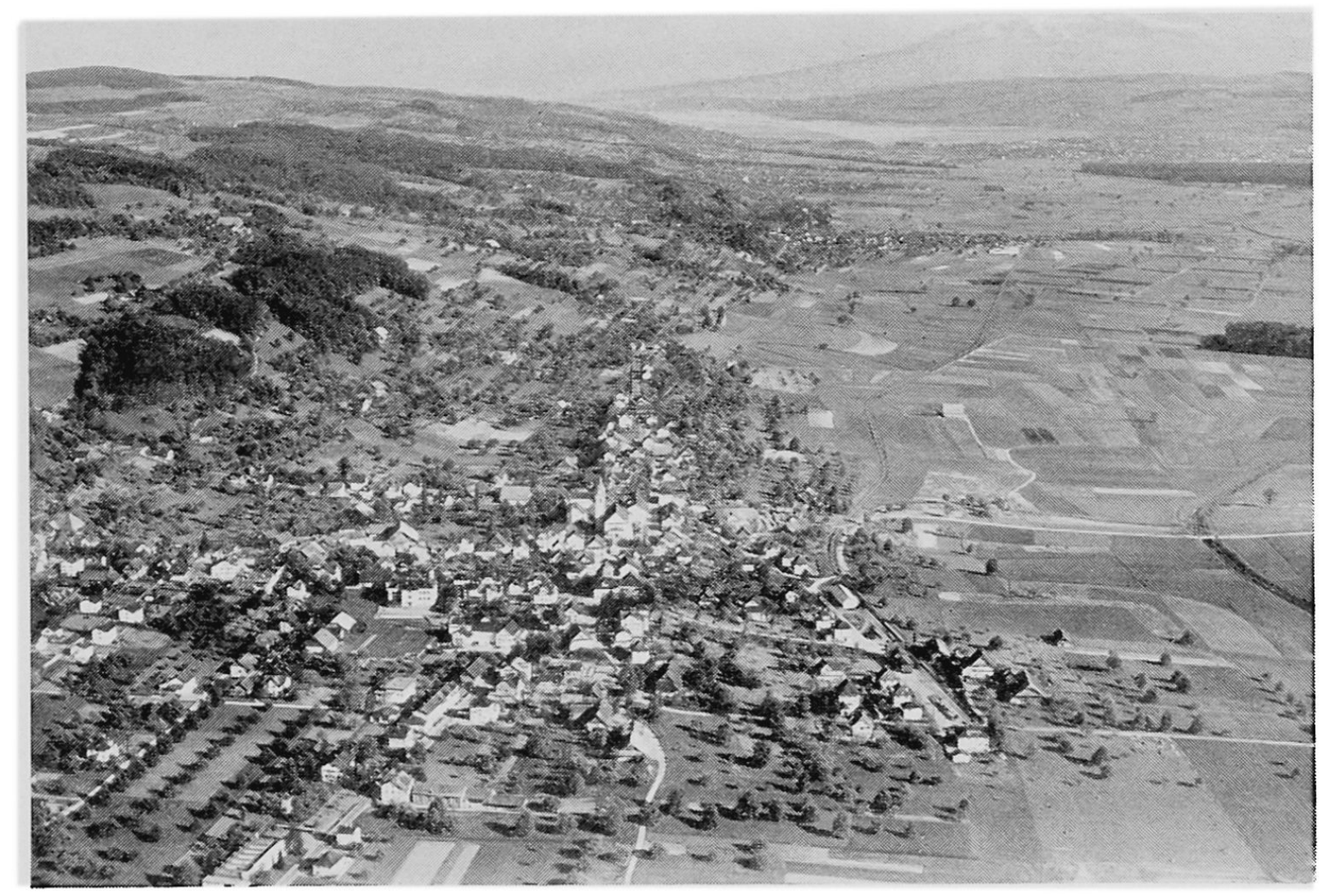

Abb. 13. Intramoränisches Suhrental. Im Vordergrund Triengen, im Hintergrund Sempachersee und rechts davon Sursee. (Aufnahme Swissair)

Hügelzüge mit Grund. und Seitenmoränenschotter bedeckt sind, war der Wald dem Zugriff der Ansiedler ausgeliefert. Dies erklärt wohl die relative Waldarmut der intramoränischen Gemeinden (Tab. 5). Im Gegensatz zum nördlichen Suhrental blieben aber hier oft größere Waldstücke auf der Talsohle bestehen. Sie bestocken vorwiegend grobsteinige Gletscherablagerungen, wie beispielsweise bei Triengen, Wilihof und Sursee.

\section{Tab. 5: Waldbestände in den Gemeinden (12)}

\begin{tabular}{|c|c|c|c|c|c|c|c|}
\hline & Suhr & 429 & 41 & & Kulmerau & 104 & 29 \\
\hline & Unterentfelden & 88 & 31 & & Winikon & 248 & 32 \\
\hline ป్ & Oberentfelden & 298 & 42 & & Triengen & 149 & 17 \\
\hline 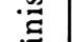 & Muhen & 260 & 37 & & Wilihof & 38 & 15 \\
\hline & Kölliken & 376 & 42 & $=$ & Schlierbach & 202 & 27 \\
\hline 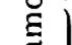 & Safenwil & 256 & 43 &. & Büron & 89 & 17 \\
\hline & Holziken & 107 & 37 & : & Knutwil & 116 & 12 \\
\hline & Hirschthal & 168 & 47 & & Geuensee & 74 & 11 \\
\hline & Schöftland & 259 & 41 & $\Xi^{\pi}$ & Sursee & 135 & 24 \\
\hline & Staffelbach & 259 & 29 & & Schenkon & 95 & 14 \\
\hline & Kirchleerau & 156 & 37 & & Oberkirch & 82 & 9 \\
\hline 氙 & Moosleerau & 88 & 23 & & Eich & 104 & 18 \\
\hline 든 & Attelwil & 57 & 26 & & Nottwil & 71 & 7 \\
\hline & Reitnau & 168 & 29 & & Sempach & 95 & 10 \\
\hline 엉 & Uerkheim & 253 & 36 & & Neuenkirch & 420 & 16 \\
\hline & Bottenwil & 189 & 37 & & & & \\
\hline & Wiliberg & 20 & 17 & & & & \\
\hline 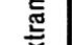 & Schloßrued & 165 & 23 & & & & \\
\hline & Schmiedrued & 179 & 20 & & & & \\
\hline
\end{tabular}


Die Wälder enthalten hautpsächlich Buchen, Rot- und Weißtannen; seltener sind Föhren, Eichen und Lärchen. Die Forstareale sind größtenteils Eigentum der Gemeinden oder der Kantone, die für eine fachgemäße Betreuung der Bestände sorgen. Nur selten besitzen Bauern kleine Waldparzellen. Wirtschaftlich kommt dem Wald insofern eine Bedeutung zu, als er den Brenn- und Nutzholzbedarf des Suhrentales vollständig zu decken vermag.

\subsection{Industrie und Handwerk}

\section{Industrie und Handwerk in früheren Zeiten}

Die Art der Betriebe mußte sich früher nach den Ansprüchen der einheimischen Bevölkerung richten, da der Verkauf der Produkte der schlechten Verkehrsverhält-

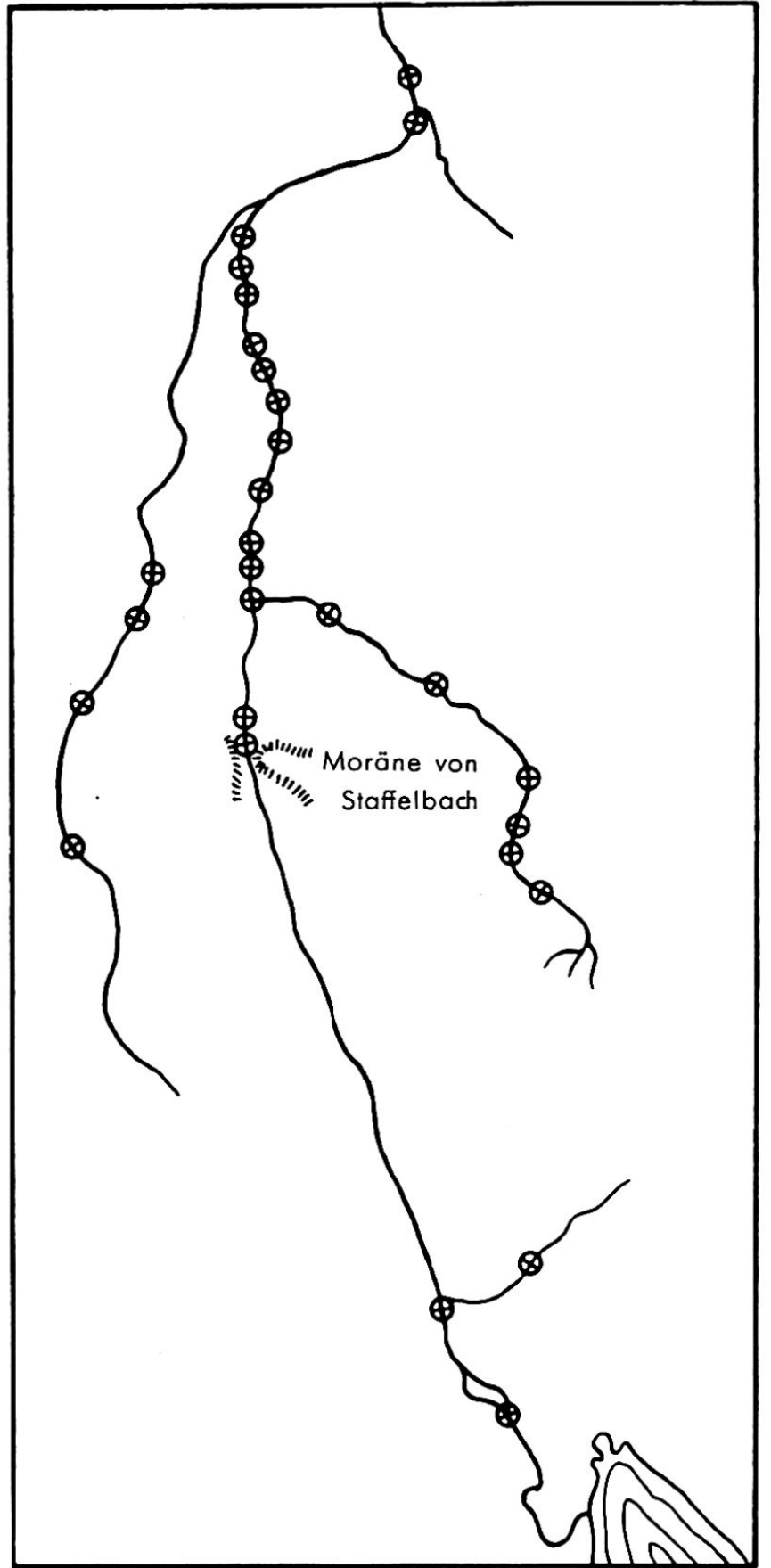

Abb. 14. Nutzung der Wasserkräfte im Suhrental. Südlich der Moräne von Staffelbach werden 3 Betriebe (Kreis) mit eigener Wasserkraft versorgt, nördlich davon dagegen deren 25. nisse wegen nach anderen Gebieten noch nicht in Frage kam. Der im Suhrental vorherrschende Erwerbszweig, die Landwirtschaft, begründet das frühzeitliche Auftreten des Schmiede- und Wagnergewerbes. Die Notwendigkeit der Verarbeitung der taleigenen Produkte lie $\beta$ auch bald Mühlen und Sägereien entstehen, die als erste Formen des fabrikmäßigen Betriebes zu betrachten sind. Sie waren natürlich vor der Einführung der Elektrizität an genügende, einheimische Wasserkräfte gebunden. Die Gewässer des Untersuchungsgebietes eignen sich aber zur Gewinnung natürlicher Energie sehr unterschiedlich, da vielerorts außer der nötigen $W$ assermenge auch das Gefälle fehlt. Wie auf Grund des Längsprofiles der Suhre (Abb. 3) zu erwarten ist, sind die Möglichkeiten vor allem im intramoränischen Teil des Flüsschens sehr beschränkt. Es überrascht deshalb kaum, daß hier bloß eine Mühle und eine Sägerei erbaut wurden. Eine weitere Mühle kam in Geuensee an den Krummbach zu stehen. Ein Staubecken und die Ausnützung von ca. $20 \mathrm{~m}$ Höhendifferenz dienen noch heute zur Kompensation der geringen Wasserführung des Bächleins. Das größere Gefälle der Suhre nördlich von Staffelbach sowie der Ruederchen und der Uerke begünstigten dagegen den Bau von zahlreichen Wasserwerken. Die Reliefgegensätze bestimmten also im Suhrental weitgehend den Standort der ersten industriellen Betriebe. Die Abb. 14, welche die jetzigen Verhältnisse der lokalen Wasserkraftausnützung dar- 
stellt, offenbart, daß die ehemals gewählte Lage der Betriebe an den Flüssen beibehalten wurde. Im Gegenteil, es machten sich sogar noch weitere Unternehmen die natürlichen Wasserkräfte zu Nutze.

\section{Das heutige Gewerbe}

unterscheidet sich von demjenigen anderer Gegenden kaum. Den allgemeinen Bedürfnissen entsprechend entfallen folgende Betriebe mit wenigen Ausnahmen auf alle Gemeinden: Schmiede, Wagnerei, Sattlerei, Schuhmacherwerkstätte, Küferei, Käserei, Bäckerei, Metzgerei, Restaurant, Coiffeursalon, Kolonialwarenhandlung. Etwas seltener ist natürlich das Handwerk des Maurers, Zimmermannes, Dachdeckers, Müllers, Uhrmachers und anderer vertreten.

\section{Die Industrie der Gegenwart}

zeichnet sich im Untersuchungsgebiet vor allem durch ihre Vielfalt aus. Die bereits bestehenden Betriebe an der Suhre wurden zum Teil zu ansehnlichen Fabriken erweitert. Beispiele sind die Handelsmühle in Schöftland und die Sägerei in Attelwil. Der Aufschwung der Industrie in der Schweiz hat dem Suhrental noch zahlreiche neue Betriebe beinahe aller Wirtschaftszweige gebracht. Die Entwicklung ist ungefähr ana$\log$ derjenigen der übrigen Schweiz verlaufen. Die folgende Tabelle gibt einen Überblick über die letzten 25 Jahre (28).

$\begin{array}{lccc}\text { Jahr } & \text { Betriebe } & \text { Arbeiter } & \text { Arbeiter pro Betrieb } \\ 1929 & 67 & 3651 & 53 \\ 1937 & 76 & 3370 & 44 \\ 1949 & 95 & 4107 & 43\end{array}$

Der Einfluß der Krise in den dreißiger Jahren kommt durch eine merkliche Abnahme der Zahl der Beschäftigten zum Ausdruck. Die Betriebe hingegen nehmen in der gleichen Zeit um $9 \mathrm{zu}$, sodaß die durchschnittliche Arbeiterzahl pro Betrieb von 53 auf 44 sinkt. In der Kriegs- und Nachkriegszeit erlebte dann die Industrie einen allgemeinen Aufschwung; die Folge war eine starke Zunahme der Betriebe und der Arbeitnehmer. Das gleichbleibende Verhältnis der Arbeiter pro Betrieb könnte aber einen Stillstand im Ausbau der einzelnen Fabriken vermuten lassen. Daß dem nicht so ist, geht aus nachfolgender Tabelle hervor (28).

\begin{tabular}{cccc} 
Jahr & In Fabrikbetrieb & \multicolumn{2}{c}{ Durchschnittliche Leistung } \\
& installierte Leistung & pro Betrieb & pro Arbeiter \\
1929 & 4717 PS & 70,5 PS & 1,3 PS \\
1937 & 5687 PS & 74,8 PS & 1,7 PS \\
1949 & 13733 PS & 144,5 PS & 3,4 PS
\end{tabular}

Mit dem Einsetzèn der Hochkonjunktur nach Kriegsende sind die menschlichen Arbeitskräfte immer gesuchter geworden. Um dennoch die Produktion steigern zu können, haben die Unternehmer die Mechanisierung ihrer Betriebe stark vorangetrieben. So haben sich die Durchschnittswerte der installierten Leistungen pro Betrieb und pro Arbeiter von 1937 bis 1949 etwa verdoppelt. Die Industrie im Suhrental hielt also mit den neuesten Entwicklungen Schritt und paßte sich weitgehend den neuzeitlichen Ansprüchen an, um in dieser Weise die Voraussetzungen für eine Weiterentwicklung in der Zukunft zu schaffen.

Der Grad der Industrialisierung in den einzelnen Gemeinden wird weitgehend von der Güte der Verkehrsverhältnisse, dann von lokalen Energiequellen, von den verfügbaren Arbeitskräften und anderem mehr bestimmt. Abb. 15 gibt Aufschluß über den Grad der Industrialisierung in den einzelnen Gemeinden. Die Förderung der Industrie durch die Bahnen ist offensichtlich. Suhr, Oberentfelden, Kölliken, Safenwil, an der Linie Aarau-Zofingen gelegen, sowie Muhen und Schöftland als Stationen der AarauSchöftland-Bahn besitzen die bedeutendsten Industrieniederlassungen im aargauischen 


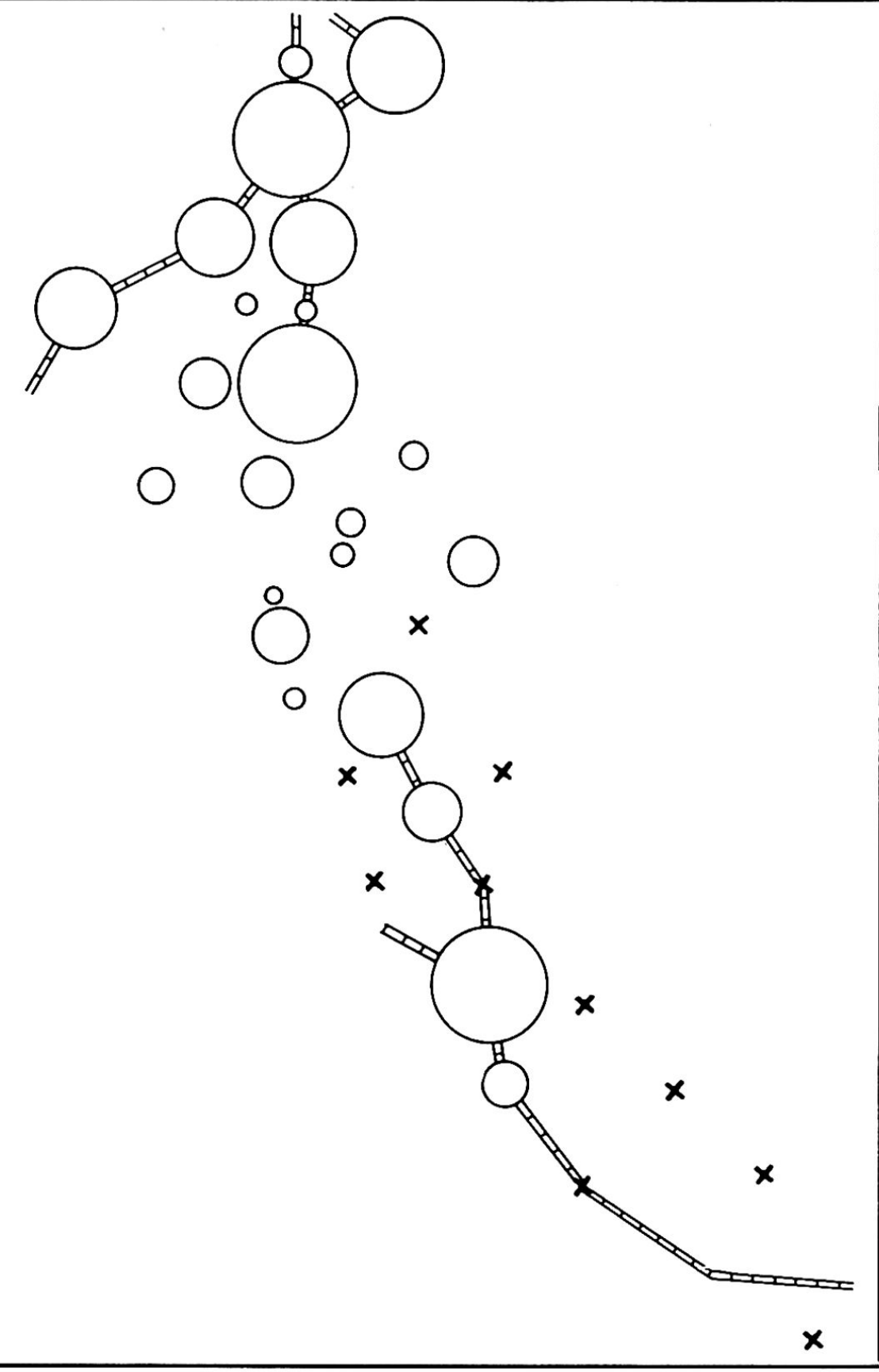

Abb. 15. Die Industrie in den Gemeinden (28). Die Kreisfläche ist proportional der beschäftigten Arbeitskräfte. Die mit Kreuz bezeichneten Gemeinden besitzen keine Industrie.

Suhrental. Im Kanton Luzern spielen Sursee, Büron und Triengen dieselbe Rolle. Immerhin muß hervorgehoben werden, da $\beta$ die Sursee-Triengen-Bahn wie auch die Durchgangslinie Olten-Sursee-Luzern nicht die gleich günstigen Auswirkungen, wie sie die andern Bahnen verzeichnen, zur Folge gehabt haben. So besitzen Knutwil, Geuensee, Schlierbach, Wilihof, Kulmerau, Schenkon, Nottwil, Eich, Sempach und Neuenkirch überhaupt keinen fabrikmäßigen Betrieb, obwohl sie unweit von Stationen dieser Bahnen entfernt liegen. Es muß aber berücksichtigt werden, daß hier die ersten Ansätze einer Industrialisierung aus früherer Zeit (Mühlen, Sägereien usw.) fehlen.

\section{Die Industrie in den Gemeinden}

Die wichtigsten Betriebe. Fast jede Ortschaft hat andere Verhältnisse in Bezug auf die Art der Industrie.

Suhr: Metall-, Holzindustrie, Strickereien, Textildruckerei, Butterzentrale. Oberentfelden: Schuhfabriken, Bürstenfabrik, Papierfabrik, Holzindustrie, Wattenfabrik, Strickerei. 
Muhen: $\quad$ Papierfabrik, Bürstenfabrik, Bandweberei.

Kölliken: $\quad$ Färberei, Ziegelei.

Safenwil: Holzindustrie, Strickerei.

Schöftland: Kleiderfabriken, Schuhfabriken.

Uerkheim: Berufskleiderfabrik, Buntweberei.

Triengen: Überkleiderfabrik, Tuchwarenfabrik, Wäschefabrik.

Sursee: Holz-, Metallindustrie, Kleiderfabrik.

Heimindustrie in Muhen. In Muhen findet man ein Beispiel, wie ein vorübergehend aufblühender Industriezweig wesentliche Veränderungen im Landschaftsbild zur Folge hatte, die noch heute als auffällige, aber vollkommen fremdartige Merkmale erscheinen. Als Vertreter der 3 Seitentäler, in denen der erwähnte Einfluß nachweisbar ist, sollen die besonderen Verhältnisse des Schwabistales näher dargestellt werden. Die nun folgenden Ausführungen stützen sich auf die Aussagen von Frau Lüscher, einer 85-jährigen Einheimischen.

$\mathrm{Zu}$ Beginn des 18.Jahrhunderts war das Schwabistal bloß von ein paar Bauern besiedelt. Um $1750 \mathrm{kam}$ dann im Gebiet des heutigen aargauischen Mittellandes dic Baumwollweberei auf, die damals als Hausindustrie betrieben wurde. Auch im Schwabistal waren die Leute über diese neue zusätzliche Erwerbsmöglichkeit froh. Die heranwachsenden Kinder mußten nicht mehr in der Fremde dem Verdienst nachgehen, denn in jedem Bauernhaus sorgten Webstühle für die nötige Arbeit. Bei der Übergabe des Hofes an eine neue Generation teilten die Eltern das Land unter ihre Kinder auf. Diese bauten wieder neue Häuser, die jedoch ganz nach dem neuen Erwerbszweig, der Baumwollindustrie, ausgerichtet waren. Die Landwirtschaft spielte nur noch eine

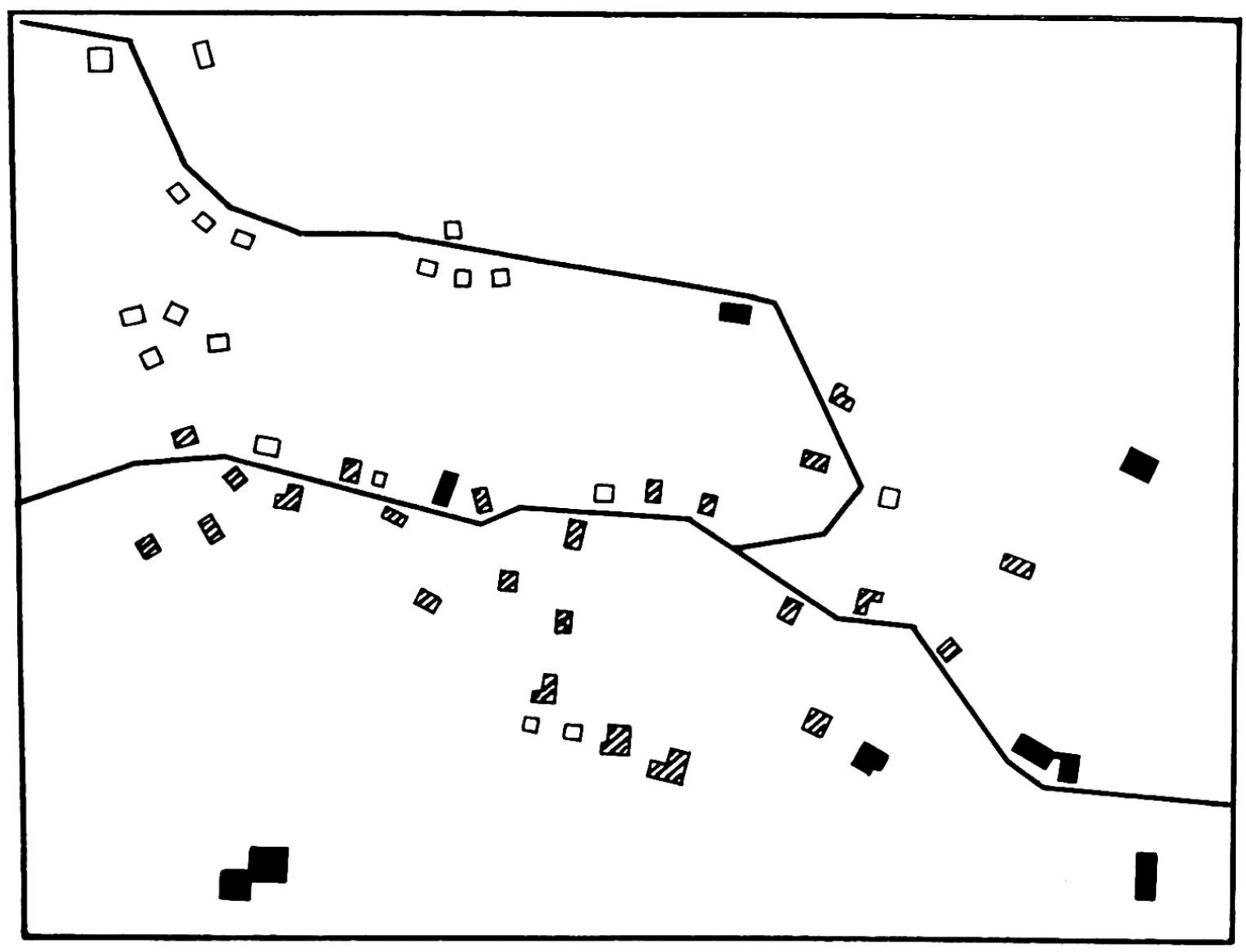

Abb. 16. Die Funktion der Gebäude in Schwabistal (Gemeinde Muhen). Schwarz: Bauernhaus eines hauptberuflichen Landwirtes. Schraffiert: Bauernhaus eines nebenberuflichen Landwirtes. Weiß: Reines Wohnhaus. 


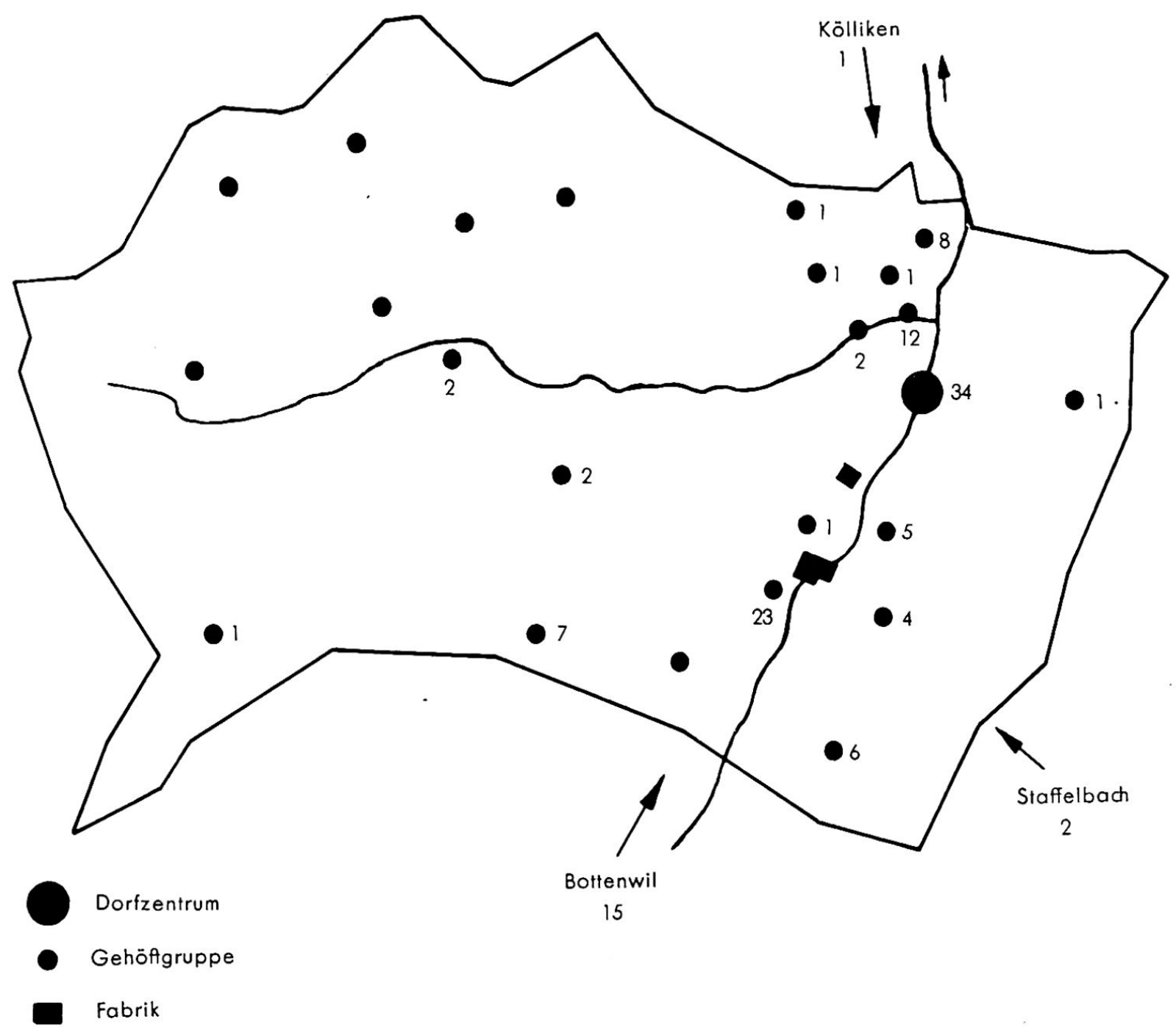

Abb. 17. Herkunft der Arbeiter der industriellen Betriebe in Uerkheim. Die Zahl der Arbeiter ist bei ihrem Wohngebiet vermerkt.

nebensächliche Rolle. Es kam schließlich so weit, daß einzelne Landbesitzer nur noch eine Kuh halten konnten, was knapp für die Selbstversorgung der Familie ausreichte. Als dann um die Mitte des 19. Jahrhunderts die Baumwollweberei als Heimarbeit infolge der Einführung der mechanischen Webstühle aufgehoben wurde, suchten die Leute in den eben aufkommenden Industriebetrieben eine neue Beschäftigung. Die merkwürdigen Besiedlungsverhältnisse sind jedoch bis heute erhalten geblieben. Der Funktionsplan des Schwabistales (Abb. 16) zeigt die heutigen Zustände: 7 Landwirte üben ihr Gewerbe noch heute hauptberuflich aus. Ihre Vorfahren sind also den allgemeinen Entwicklungstendenzen nicht gefolgt. Hingegen erweisen sich 24 Betriebe eindeutig als Besitz eines nebenberuflichen Bauern. 'Trotz vielen Aufteilungen des Kulturlandes blieb eine ziemliche Arrondierung des Grundbesitzes erhalten. Die relativ große $Z$ ahl von 17 reinen Wohnhäusern datiert durchwegs aus neuerer Zeit. Offenbar ziehen die Leute die ruhige, windgeschützte Lage des Schwabistales dem Dorfzentrum an der Durchgangsstraße vor.

Herkunft der Arbeiter der industriellen Betriebe in Uerkheim. Wie aus dem Abschnitt 1.121 hervorgeht, dominierte in der Gemeinde Uerkheim früher eindeutig die Streusiedlung. Obwohl die ursprünglichen Siedlungsverhältnisse heute etwas verwischt sind, ist es interessant festzustellen, wo die Arbeiter der beiden Fabriken wohnen (Abb. 17). Verständlicherweise haben die meisten im Dorfzentrum oder in einem Weiler, der sich in unmittelbarer Nähe der Fabriken befindet, ihren Wohnsitz. Die Bauernhöfe 
in Hinterwilertal jedoch weisen ganz sonderbare Verhältnisse auf. Einzig die Betriebe am Nordhang können noch Arbeitskräfte an die Fabriken abgeben. Die südexponierten Güter bieten den Besitzern also bedeutend bessere Existenzmöglichkeiten, da sie ertragreicher und auch verhältnismäßig groß sind (nach Aussage eines einheimischen Bauern). Von den Nachbargemeinden sticht einzig Bottenwil mit 15 Arbeitern hervor, die täglich nach Uerkheim pendeln.

Die Industrie in den Seitentälern. Überraschenderweise ließen sich in den beiden Seitentälern viele Kleinbetriebe nieder. Ihre Unternehmer erkannten jedoch, daß in den abgelegenen Ortschaften billige Arbeitskräfte zu finden sind, da den Leuten anderweitige Beschäftigung fehlt. Bezeichnenderweise sind es denn auch meistens Filialfabriken von größeren, auswärtigen Betrieben. Aus dem gleichen Grunde ließen die Bally-Schuhfabriken in verschiedenen Häusern des Ruedertales mechanische Webstühle einrichten. Diese Bewohner stellen nun als sogenannte Heimarbeiter Schuhnestel her.

\subsection{Verkehr}

Die Entwicklung der Verkehrsverhältnisse im Suhrental weist gegenüber derjenigen des übrigen Mittellandes keine wesentlichen Unterschiede auf. Vor dem Bau der Bahnen wickelte sich der Verkehr ausschließlich auf der Straße ab, da die Wasserführung der Suhre zu gering ist, um sie auch nur mit kleinen Schiffen befahren zu können.

\section{Das Straßennetz}

Die beiden wichtigsten Straßen mit gesamtschweizerischer Bedeutung berühren das Suhrental im nördlichen bzw. südlichen Teil. Sie dienen hauptsächlich dem Fernverkehr: Die Hauptstraße Nr. 1, die den Bodensee mit dem Genfersee verbindet und über Zürich, Bern nach Genf führt, gilt als wichtigste Ost-West-Verbindung des Landes. Sie berührt die Gemeinden Suhr, Oberentfelden, Kölliken und Safenwil und benützt die flachen Übergänge des untern Suhrentales nach den Nachbartälern. Eine ähnliche Aufgabe erfüllt die Straße Nr.2 in nord-südlicher Richtung von Basel nach Luzern und über den Gotthard. Sie gelangt vom Wiggertal nach Sursee, folgt dem linken Sempacherseeufer und verläßt das Untersuchungsgebiet südlich Neuenkirch. Die eigentliche Talstraße von Aarau nach Sursee besitzt mehr regionale Bedeutung. Da sie jedoch das $T$ al in seiner ganzen Länge durchzieht und beinahe alle Gemeinden erfaßt, dient sie der einheimischen Bevölkerung

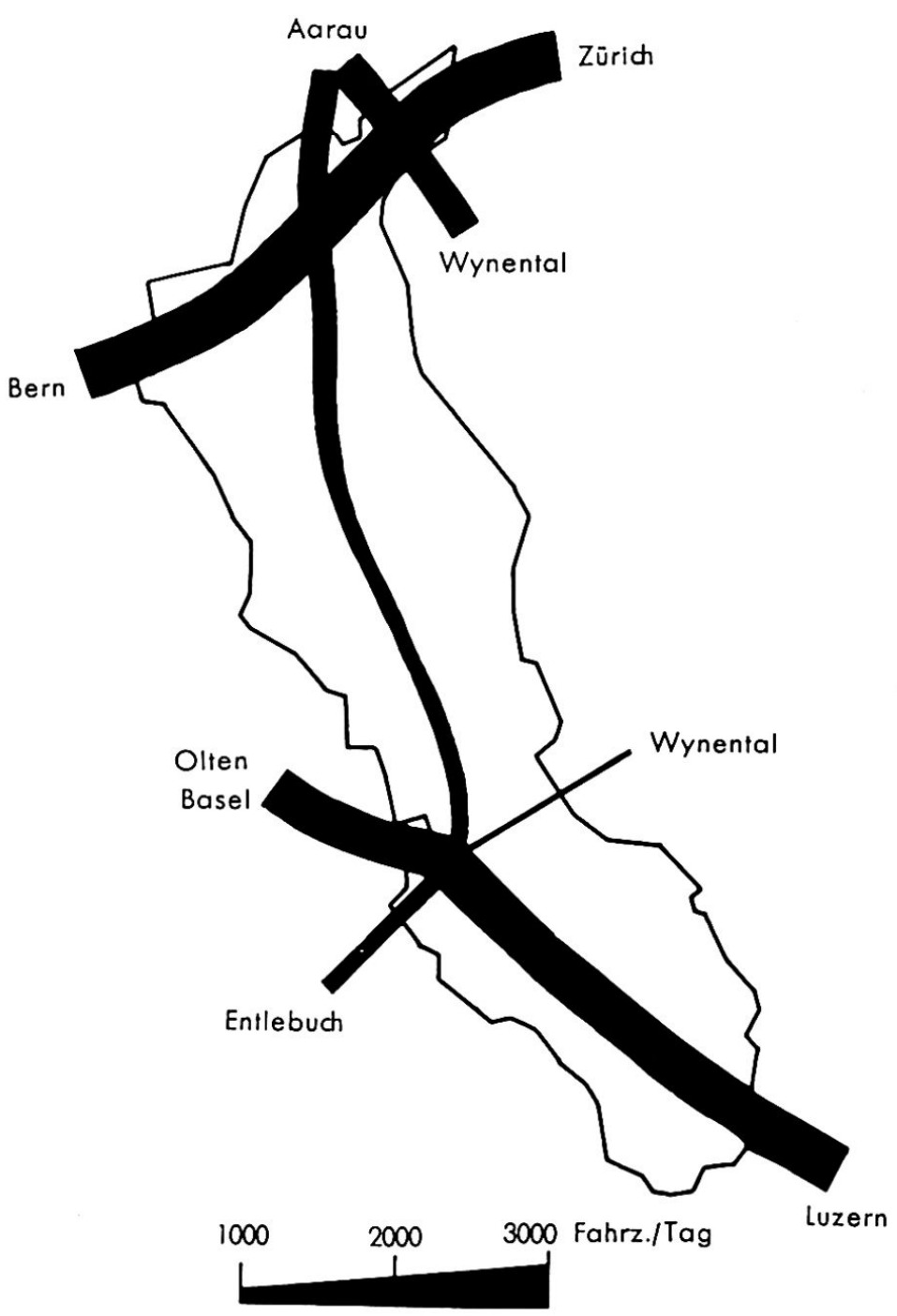

Abb. 18. Der Fahrzeugverkehr auf den Straßen des Suhrentales im Jahre 1955. 
besser als obgenannte Fernverbindungen. Ähnlich verhält es sich mit den Talstraßen des Uerkentales und des Ruedertales. Beide überwinden den Talabschluß und führen nachher in die Nachbartäler, Wigger- bzw. Wynental; sie können daher ebenfalls als Durchgangsstraßen bezeichnet werden.

Um das Bild zu vervollständigen, seien noch die bedeutendsten Übergänge über die Hügelzüge erwähnt, die das Suhrental mit den Nachbartälern verbinden. Der Böhler, welcher von Schöftland nach Unterkulm führt, und der Übergang von Schenkon nach Menziken über Beromünster sind als $\mathrm{Paßstraßen} \mathrm{sehr} \mathrm{gut} \mathrm{ausgebaut.} \mathrm{Die}$ Straße von Reitnau nach Reiden bildet außer den bereits erwähnten Hauptstraßen Nr. 1 und 2 die wichtigste Querverbindung ins Wiggertal.

Die Entwicklung des Straßenverkehrs (Tab. 6) nahm besonders in neuerer Zeit stürmische Formen an: Von 1949 bis 1955 haben sich die Frequenzen auf den Hauptstraßen rund verdreifacht, sodaß diese an verkehrsreichen Tagen den Anforderungen oft nicht mehr gewachsen sind. Der dringend notwendige Bau von Autobahnen dürfte aber in dieser Region noch längere Zeit auf sich warten lassen.

Tab. 6: Die Entwicklung des Fahrzeugverkehrs auf den Hauptstraßen des Suhrentales (19). Die Zahlen bedeuten das Total der Fahrzeuge pro Tag.

Suhr-Safenwil (Zürich-Bern)

Knutwil-Neuenkirch (Basel-Luzern)

Sursee-Entlebuch

Aarau-Oberentfelden

Oberentfelden-Schöfland

Triengen-Sursee

Sursee-Wynental

Aarau-Suhr

$\begin{array}{cc}1928 / 29 & 1936 / 37 \\ 443 & 828 \\ 448 & 908 \\ - & 719 \\ - & 330 \\ 290 & 296 \\ - & 320 \\ 198 & 251 \\ 227 & 254\end{array}$

$1948 / 49$

1042

1033

988

539

289

385

299

694
1955

3268

3309

915

1766

1279

861

553

\section{Das Eisenbahnnetz}

Wie das nachfolgende Verzeichnis zeigt, ist das Suhrental relativ reichlich mit Bahnen versehen. Trotzdem besteht bei den Bewohnern die Auffassung, daß die Verkehrsmittel den Anforderungen nicht nachkämen. Die Gründe liegen in der kurzsichtigen Eisenbahnpolitik am Ende des 19. Jahrhunderts. Es war vor allem die eigensinnige Einstellung und die fehlende Weitsicht der Eisenbahngesellschaften, die eine durchgehende Bahnverbindung im Suhrental verhinderten. Speziell nachteilig wirkt sich für den Güterverkehr der Umstand aus, daß die Bahnen verschiedene Spurbreiten aufweisen.

Linie

1. Olten-Luzern

2. Aarau-Zofingen

3. Aarau-Wettingen

Aarau-Schöftland (AS) 1901

5. Wynentalbahn (WTB) 1904

6. Sursee-Triengen

$\mathrm{N}=$ Normalspur
Übersicht über die Bahnen im Suhrental (23)

$\begin{array}{cc}\text { eröffnet } & \text { Spur } \\ 1856 & \mathrm{~N} \\ 1877 & \mathrm{~N} \\ 1877 & \mathrm{~N} \\ 1901 & \mathrm{~S} \\ 1904 & \mathrm{~S} \\ 1912 & \mathrm{~N}\end{array}$

Mit Bahnhöfen in

Sursee, Oberkirch, Nottwil, Sempach-Neuenkirch

Suhr, Oberentfelden, Kölliken, Safenwil

Suhr

Unter-, Oberentfelden, Muhen, Hirschthal, Schöftland Suhr

Sursee, Geuensee, Büron, Triengen

Über die Leistung der einzelnen Bahnen orientiert die nachfolgende Tabelle, worin die Anzahl Züge in beiden Richtungen enthalten sind. Diese richten sich natürlich in erster Linie nach den Bedürfnissen der Bevölkerung, aber auch nach dem Leistungsvermögen des vorhandenen Rollmaterials (Sursee-Triengen-Bahn).

\section{Linie}

Olten-Luzern (SBB)

Aarau-Zofingen (SBB)

Aarau-Wettingen (SBB)

Aarau-Schöftland (AS)

Aarau-Menziken (WTB)

Sursee-Triengen (ST)
Anzahl Personenzüge

in beiden Richtungen (10)

Sonntags Werktags

$14 * 15 *$

1214

1214

$20 \quad 24$

1923

$8 \quad 8$ 
Obige Tabelle zeigt, daß alle Linien der SBB ungefähr die gleiche Frequenz aufweisen. Die geringe Zahl der Züge der Sursee-Triengen-Bahn ist darauf zurückzuführen, daß dieses Unternehmen hauptsächlich bäuerliche Gemeinden berührt. Da noch heute die gleichen Anforderungen wie zur Zeit der Gründung an diese Bahn gestellt werden, mußte auch das Rollmaterial vorläufig nicht modernisiert werden. Bei normalen Verhältnissen wird der Verkehr von nur einem Zug bewältigt, der wie folgt zusammengesetzt ist: Ein zweiachsiger Wagen mit querliegendem Dampfkessel, Gepäck- und Postabteil dient als Triebwagen. $Z_{\text {wei }}$ weitere zweiachsige Wagen übernehmen den Personentransport. Daneben besitzt das Unternehmen noch zwei Dampflokomotiven, welche aber nur bei Revisionsarbeiten des Triebwagens eingesetzt werden. Die beiden Straßenbahnen hingegen profitieren von der großen Zahl der Pendelwanderer, die in der nahen Stadt Aarau ihrem Verdienst nachgehen. Die meisten Züge verkehren deshalb am frühen Morgen, über den Mittag und am Abend. Der Umstand, daß die Spurbreite dieser beiden Bahnen derjenigen der SBB nicht entspricht, wirkt sich für den Güterverkehr nachteilig aus, da die Fracht umgeladen werden muß. Um doch eine gewisse Vereinfachung zu erzielen, haben die WTB in Suhr und die AS in Oberentfelden ein Anschlußgeleise an die SBB. Die großen Güterwagen der Normalbahnen werden dort auf sogenannte Rollschemel montiert und können somit auch auf dem Schmalspurgeleise verkehren.

Die nachfolgenden statistischen Tabellen und Abbildungen orientieren über den Personen- und Güterverkehr. Während jedoch die SBB über jede Station Aufschluß geben können, ist das für die Privatbahnen unmöglich, da das Zugspersonal ebenfalls Fahrkarten abgibt.

Tab. 7: Der Personen- und Güterverkehr auf den SBB-Stationen im Jahre 1958 (29)

$\begin{array}{lrc}\text { Abgegangene Personen } & \begin{array}{c}\text { Güterumschlag } \\ \text { in t }\end{array} \\ \text { Suhr } & 35645 & 33822 \\ \text { Oberentfelden } & 23743 & 11290 \\ \text { Kölliken } & 45250 & 4942 \\ \text { Safenwil } & 41467 & 6229 \\ \text { Sursee } & 68318 & 49394 \\ \text { Oberkirch } & 5980 & - \\ \text { Nottwil } & 11438 & 3277 \\ \text { Sempach-Newenkirch } & 29270 & 19656\end{array}$

Tab. 8: Der Personen- und Güterverkehr auf den Privatbahnen und der Postautomobillinie Schöftland - Triengen (39)

\begin{tabular}{cccccr}
$\begin{array}{l}\text { Durchschnitt } \\
\text { der Jahre }\end{array}$ & \multicolumn{3}{c}{ Beförderte Personen } & \multicolumn{2}{c}{ Beförderte Güter in $t$} \\
& AS & Auto & ST & AS & ST \\
$1903-12$ & 329353 & & & 16700 & \\
$13-14$ & 352518 & & 128050 & 23740 & 10000 \\
$15-21$ & 436317 & & 117077 & 23340 & 15270 \\
$22-27$ & 405510 & 13182 & 144997 & 22260 & 12470 \\
$28-33$ & 396777 & 23482 & 137659 & 24340 & 10640 \\
$34-39$ & 286661 & 23645 & 84304 & 19390 & 7840 \\
$40-44$ & 596693 & 34471 & 122186 & 20790 & 14230 \\
$45-49$ & 1183717 & 54630 & 148057 & 27540 & 14830 \\
1950 & 1108683 & 42413 & 133629 & 31039 & 9435 \\
1951 & 1158636 & 44816 & 141415 & 32565 & 9116
\end{tabular}

Bei allen Unternehmen kommt deutlich zum Ausdruck, daß die Kriegsjahre die Frequenzen günstig beeinflußten, was wohl mit den Einschränkungen für den Motorfahrzeugverkehr zusammenhängt. Bemerkenswert ist ferner die stürmische Entwicklung des Verkehrs auf der Aarau-Schöftland-Bahn (Pendelwanderer). Die Frequenzen der Sursee-Triengen-Bahn hingegen erfuhren im Laufe von 38 Jahren eine nur ge- 

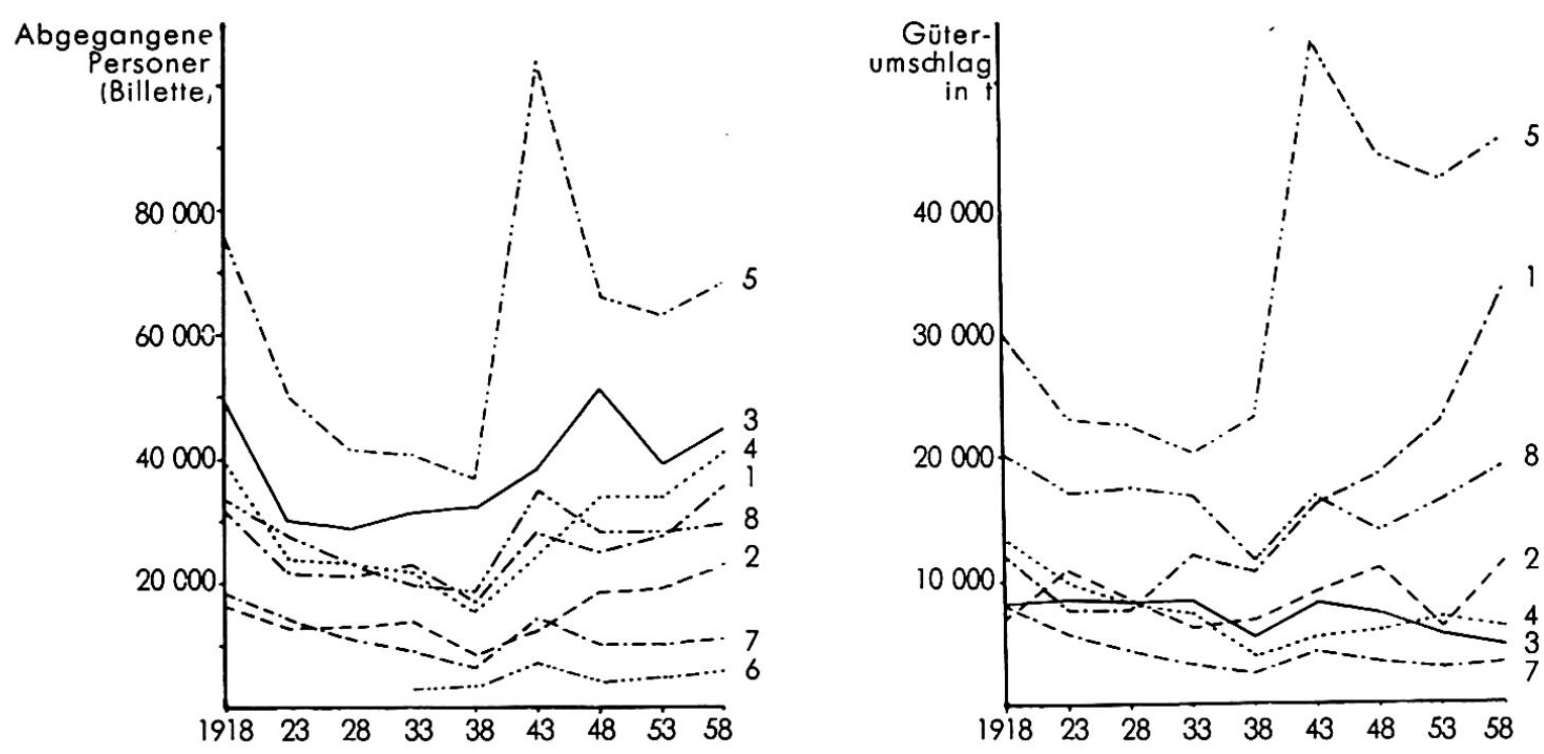

Abb. 19. Die Entwicklung des Personenverkehrs (links) und des Güterverkehrs (rechts) auf den Stationen der SBB. 1 Suhr, 2 Oberentfelden, 3 Kölliken, 4 Safenwil, 5 Sursee, 6 Oberkirch, 7 Nottwil, 8 Sempach-Neuenkirch.

ringe Zunahme. Die vergleichsweise aufgeführten Zahlen der Postreisenden auf dem bahnlosen Zwischenstück bestätigen, daß das Automobil das Verkehrsproblem im mittleren Talabschnitt nicht lösen kann; sollten doch theoretisch die Werte zwischen denjenigen der AS und ST liegen. So wären beispielsweise im Jahre 1951 anstelle der 44816 Reisenden rund $650000 \mathrm{zu}$ erwarten. Das Postautomobil vermag also bloß etwa $7 \%$ des vorhandenen Verkehrsvolumens zu bewältigen.

\section{Die Postautomobilverbindungen}

haben im Suhrental eine zweifache Bedeutung:

a) Sie überbrücken das bahnfreie Talstück zwischen Schöftland und Triengen.

b) Sie verbinden die abgelegenen Ortschaften mit den Bahnstationen.

Übersicht über die Postautomobilrouten

1. Schöftland - 'Triengen: 6 Kurse pro Tag; Platzzahl 25-29; hält an in Schöftland, Wittwil, Staffelbach, Kirchleerau, Moosleerau, Attelwil, Reitnau, Winikon, Triengen.

2. Schöftland - Walde: 4 Kurse pro Tag; Platzzahl 17-21; hält an in Schöftland, Schloß-, Schmiedrued, Walde.

3. Kölliken - Bottenwil: 4 Kurse pro Tag; Platzzahl 16-21; hält an in Kölliken, Uerkheim, Bottenwil.

4. Bottenwil - Reiden: 3 Kurse pro Tag; Platzzahl 24-28; hält an in Bottenwil, Moser Säge (bei Wiliberg).

5. Reinach - Walde: Kurse nur an Markttagen in Reinach, Samstags und Sonntags; Platzzahl 8.

6. Sursee - Beromünster : 8 Kurse pro Tag; Platzzahl 24-28; hält an in Sursee, Schenkon.

7. Sursee - Buchs: 4 Kurse pro Tag; Platzzahl 17-21, hält an in Sursee, St. Erhard, Knutwil.

8. Sempach Station - Eich: 13 Kurse pro Tag; Platzzahl 25; hält an in Sempach Station, Sempach, Eich.

9. Emmenbrücke - Neuenkirch: 2 Kurse pro Tag; Platzzahl 25-29; hält an in Neuenkirch. 
10. Luzern - Emmenbrücke - Ruswil: 14 Kurse pro Tag; Platzzahl 20-30; hält an in Hellbühl (Neuenkirch).

Diese große $\mathrm{Zahl}$ von regelmäßig befahrenen Routen täuscht wohl eine gute Erschließung des ganzen Gebietes vor. Die Verschiedenheit der Verkehrsmittel bedingt aber ein oft mehrmaliges Umsteigen, verbunden mit Wartezeiten. Daher verzichten die Leute häufig auf eine nicht absolut notwendige Reise. Berufstätige hingegen verlegen ihren Wohnort in die Gemeinde ihres Arbeitgebers.

Über die in jüngster Zeit unternommenen Bestrebungen, die ungenügenden Verkehrsverhältnisse des Tales zu verbessern, gibt der Abschnitt 2.4 der vorliegenden Arbeit Aufschluß.

\subsection{Bevölkerung}

\section{Die Bevölkerung im allgemeinen}

Die im Laufe dieser Arbeit dargestellten, örtlich bedingten Unterschiede im Bereiche der Landwirtschaft, der Industrie und des Verkehrs spiegeln sich ebenfalls in der Bevölkerungsstruktur deutlich wider. Schon allein die Einwohnerzahlen der Gemeinden lassen Rückschlüsse auf die Anwesenheit von Fabriken zu, die wiederum eine günstige Verkehrslage vorziehen. So bestätigt das Suhrental einmal mehr, daß die einzelnen Landschaftselemente unter sich in enger Beziehung stehen.

Wie zu erwarten ist, liegen die großen Ortschaften am untern, respektive am obern Ende des Tales. Nur Schöftland und Triengen als Bahnendstationen und regionale Zentren machen in dieser Beziehung eine Ausnahme. Die kleinen, bäuerlichen Gemeinden mit meistens weniger als 1000 Einwohnern finden sich im mittleren Talabschnitt und in den Seitentälern.

Auch die Volksdichte variiert von Gemeinde zu Gemeinde ziemlich stark, wie Abb. 20 zeigt. Die dünnbesiedelten Gebiete im mittleren Talabschnitt heben sich deutlich von den industriereichen Orten ab. Besonders eindrücklich wird die Stellung von Sursee als Verwaltungs-, Handels-, Verkehrs- und Industriezentrum des luzernischen Gebietes veranschaulicht.

\section{Vergleich der Volksdichten}

Volksdichte im Suhrental (ganzes Gebiet): $186 \mathrm{Ew} . / \mathrm{km}^{2}$

Volksdichte im aargauischen Suhrental: $226 \mathrm{Ew} . / \mathrm{km}^{2}$

Volksdichte im luzernischen Suhrental: $149 \mathrm{Ew} . / \mathrm{km}^{2}$

Volksdichte im Kanton Aargau: $\quad 214 \mathrm{Ew} . / \mathrm{km}^{2}$

Volksdichte im Kanton Luzern: $\quad 149 \mathrm{Ew} . / \mathrm{km}^{2}$

Volksdichte in der Schweiz: $\quad 114 \mathrm{Ew} . / \mathrm{km}^{2}$

\section{Bevölkerungsentwicklung}

Aus der Tab. 9 geht deutlich hervor, daß sich die Bevölkerungsentwicklung verschiedener Teilgebiete ungefähr analog vollzogen hat. Dies erlaubt, die Gemeinden in einzelne Gruppen zusammenzufassen, um trotz der Vielzahl eine übersichtliche Darstellung geben zu können.

1. Gruppe: Die Gemeinden des aargauischen Suhrentales mit Bahnverbindung: Suhr, Unterentfelden, Oberentfelden, Muhen, Kölliken, Safenwil, Holziken, Hirschthal, Schöftland.

Alle diese Gemeinden besitzen in der 2. Hälfte des 19. Jahrhunderts ziemlich stabile Bevölkerungszahlen. Dies beweist, daß die bestehenden Existenzmöglichkeiten bereits um 1850 erschöpft waren. Viele Einwohner sahen sich daher gezwungen, ihre engere Heimat zu verlassen, um in der Fremde dem Verdienst nachzugehen. Diese Verhältnisse änderten sich mit der Eröffnung der Bahnen. Die Nationalbahn vermochte zwar vorerst die Bevölkerungsentwicklung von Suhr, Oberentfelden, Kölliken 


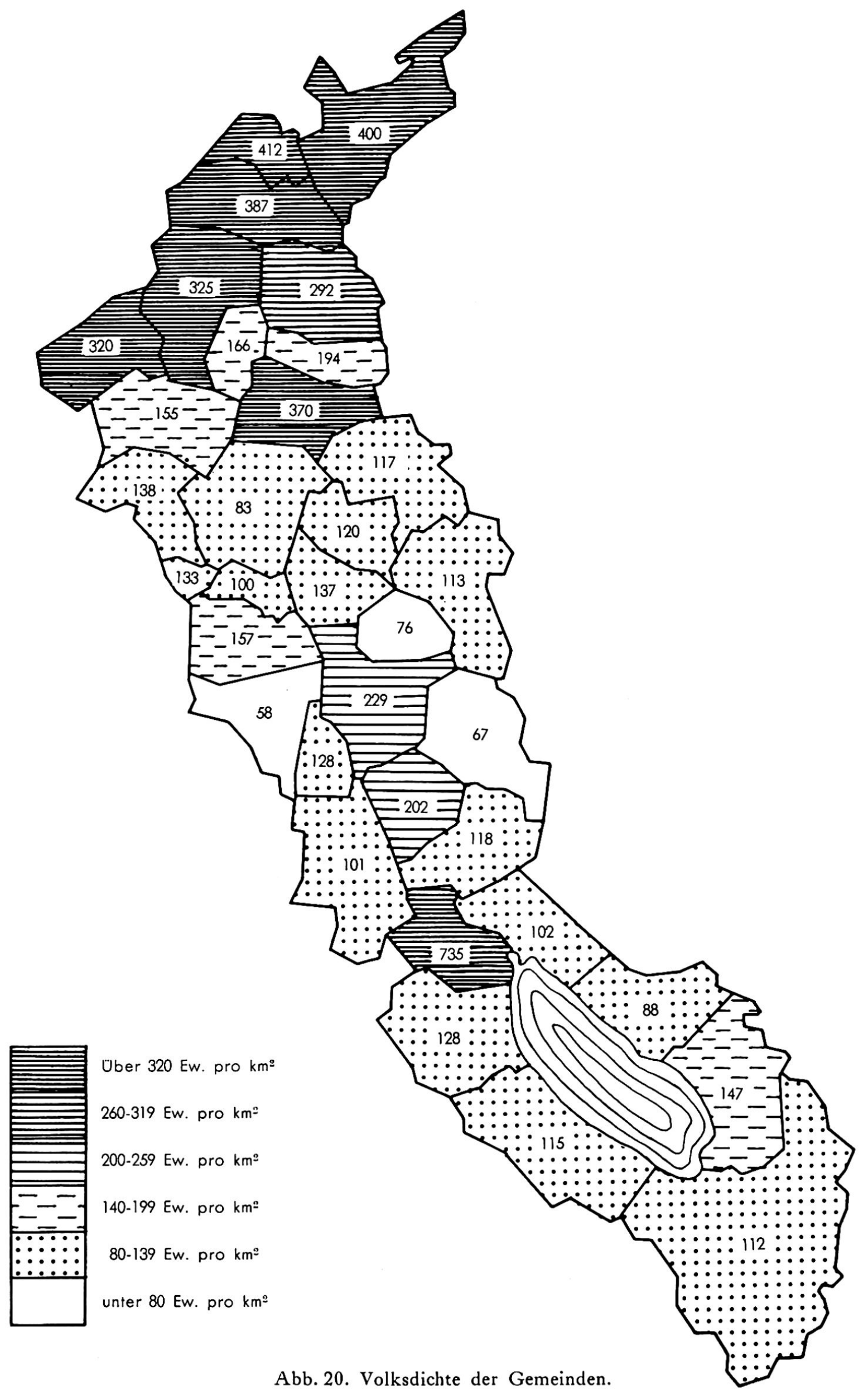


Tab.9: Die Einwohnerzahlen der Gemeinden 1850-1950 (30)

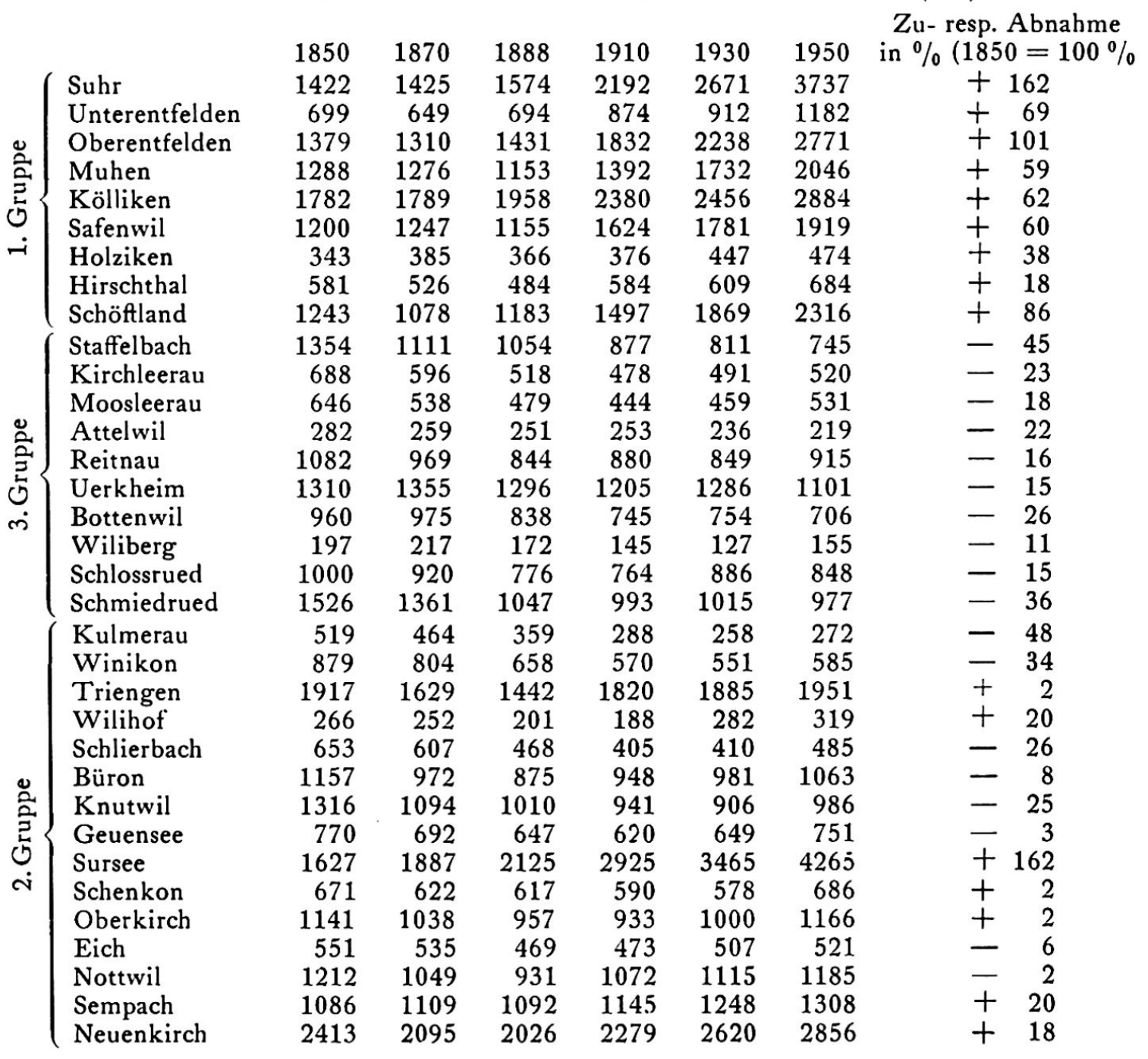

und Safenwil nur schwach positiv zu beeinflussen; es war also eine gewisse Anlaufzeit notwendig. Mit der Eröffnung der beiden Schmalspurbahnen um die Jahrhundertwende setzte dann die Zunahme der Bevölkerung für alle Gemeinden geradezu stürmisch ein. Diese völlig veränderten Entwicklungstendenzen wurden hauptsächlich von folgenden neuen Voraussetzungen hervorgerufen:

a) Die einheimischen Industrieunternehmen konnten sich nun ungehindert entwickeln; denn dem Herantransport von Rohstoffen, sowie dem Versand der Erzeugnisse standen jetzt keine Schwierigkeiten mehr im Wege.

b) Die Pendelwanderer nach der Stadt Aarau, wo die Industrie einen besonders starken Aufschwung erlebte, erreichten nun mühelos ihre Arbeitsplätze. Immer mehr Leute zogen es deshalb vor, in einem Dorf zu wohnen und täglich nach der Stadt zu reisen.

2. Gruppe: Die luzernischen Gemeinden: Kulmerau, Winikon, Triengen, Wilihof, Schlierbach, Büron, Knutwil, Geuensee, Schenkon, Sursee, Oberkirch, Eich, Nottwil, Sempach, Neuenkirch.

Die Bevölkerungsentwicklung der luzernischen Gemeinden beschrieb seit 1850 eine leicht fallende Kurve. Erst in neuerer Zeit ist die Einwohnerzahl bei fast allen Ortschafter wieder im Steigen begriffen. Auffällig ist aber, daß sich bei den Gemeinden mit Stationen der Sursee-Triengen-Bahn kaum ein Unterschied gegenüber den andern feststellen läßt. Der unbedeutende Einfluß, den diese Bahn auf die obere Talschaft ausübt, kommt also auch hier deutlich zum Ausdruck. Hingegen überrascht, daß die moderne Durchgangslinie Olten-Luzern in den von ihr berührten Gemeinden Ober- 
kirch, Nottwil, Sempach und Neuenkirch nur einen geringen Einfluß auf die Bevölkerungsentwicklung ausüben konnte. So blieb der rein bäuerliche Charakter der Sempacherseegegend bis heute erhalten. Die einzige Ausnahme bildet die Stadt Sursee, die wie die Gemeinden der ersten Gruppe seit dem Bahnanschluß eine sprunghafte Entwicklung durchmachte.

3. Gruppe: Die aargauischen Gemeinden ohne direkte Bahnverbindung: Staffelbach, Kirchleerau, Moosleerau, Attelwil, Reitnau, Uerkheim, Bottenwil, Wiliberg, Scl.loßrued, Schmiedrued.

Charakteristisch für alle diese Gemeinden ist der andauernde Rückgang der Bevölkerung. Tatsächlich brachten die letzten 100 Jahre aber auch keine neuen Arbeitsmöglichkeiten oder wesentliche Verbesserungen der Verkehrsverhältnisse. Im Gegentcil: Die Modernisierung der Landwirtschaftsbetriebe verdrängte viele Hilfskräfte. Die Bevölkerungsentwicklung befolgte also die gleichen Tendenzen wie sie bei der 2 . Gruppe festgestellt wurden. Die Zweckmäßigkeit der Ausscheidung dieser 3. Gruppe kommt jedoch Seite 219 besser zum Ausdruck.

\section{Berufsstruktur}

Im Suhrental geht die Entwicklung der Berufsstruktur, die hauptsächlich von der einheimischen Industrie und der Verkehrslage der Gemeinden (Pendelwanderer) bestimmt wird, ungefähr parallel zur Bevölkerungsentwicklung. So sollen auch hier die Verhältnisse wieder gruppenweise dargestellt werden.

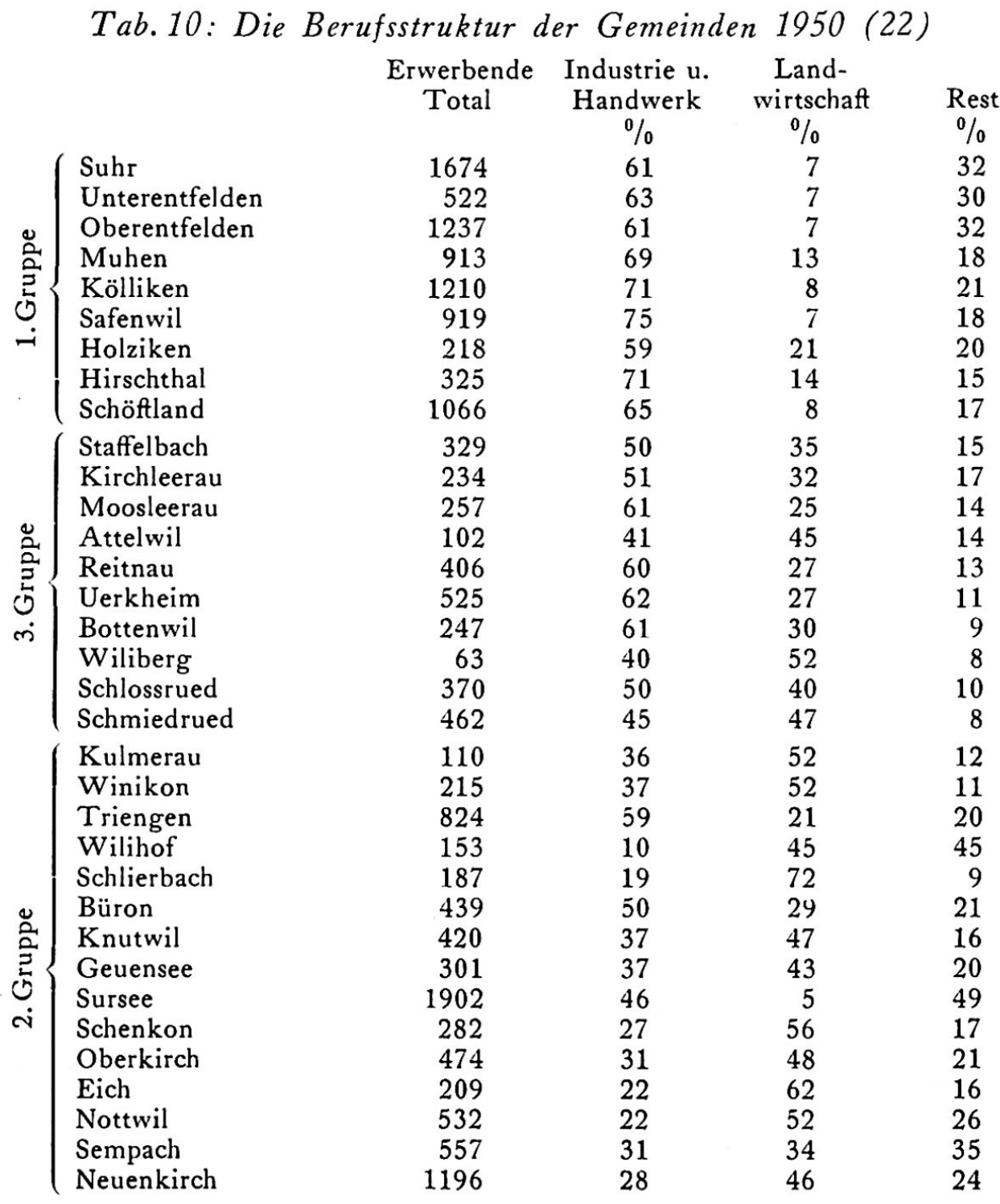


Die Gemeinden der 1. Gruppe weisen im Jahre 1950 eine relativ einheitliche Struktur auf. Die intensive Industrialisierung und die günstige Verkehrslage drängten die Landwirtschaft stark in den Hintergrund, sodaß sie nur noch etwa $10 \%$ aller $\mathrm{Er}$ werbenden beschäftigt. Der Anteil der Industriearbeiter und Handwerker beträgt hingegen durchschnittlich $68 \%$.

Auch die Gemeinden der 2. Gruppe weisen gegenseitig eine große Ähnlichkeit auf. Der im Landschaftsbild deutlich erkennbare bäuerliche Charakter dieser Gegend wird durch die Berufsstruktur bestätigt. Die in der Landwirtschaft beschäftigten Bewohner betragen in diesen Gemeinden 50 und mehr Prozent. Nur Sursee, Büron und Triengen machen auf Grund ihrer bevorzugten Lage insofern eine Ausnahme, als der Anteil von Industrie und Handwerk etwas größer ist.

Die Dörfer der 3. Gruppe zeigen eine Berufstruktur, die ungefähr dem Durchschnitt der beiden andern Gruppen entspricht. Sie kann mit folgenden mittleren Werten charakterisiert werden:

$\begin{array}{ll}\text { Landwirtschaft } & 37 \% \\ \text { Industrie und Handwerk } & 50 \% \\ \text { Rest } & 13 \%\end{array}$

Aus den Resultaten der Volkszählungen von 1910 bis 1950 geht hervor, daß die Entwicklung der Berufsstruktur in allen Gemeinden die gleichen Tendenzen befolgt. Bezeichnend ist der stete Rückgang der Landwirtschaft, wovon natürlich die andern Kategorien profitieren. Dabei besteht zwischen den Ortschaften des aargauischen und denjenigen des luzernischen Suhrentales der Unterschied, daß in den ersteren die $\mathrm{Zu}$ nahme der Industriearbeiter und Handwerker, in den letzteren hingegen die des Restes deutlich überwiegt.

\section{Pendelwanderung}

$\mathrm{Da}$ sich die großen Fabrikbetriebe auf wenige Gemeinden beschränken, müssen viele Arbeiter der industriearmen Orte täglich einen auswärtigen Arbeitsplatz aufsuchen. So gibt beispielsweise die Berufsstruktur für Hirschthal und Unterentfelden über $60 \%$ Beschäftigte in Industrie und Handwerk an, obwohl diese beiden Orte nur unbedeutende industrielle Betriebe besitzen. Die unveröffentlichten Zahlen des Eidgenössischen statistischen Amtes (Tab. 11) zeigen, daß alle Gemeinden relativ viele Wegpendler beheimaten. Als Aufnahmezentren dieser auswärts beschäftigten Arbeiter kommen die verkehrsbegünstigten Orte des untern Talgebietes, also Suhr, Oberentfelden und Schöftland, sowie Sursee in Betracht. Außerdem spielen die beiden Kantonshauptstädte eine überragende Rolle, da sie als Industrie- und Handelszentren große Anziehungskraft besitzen. Auch ist vor allem Aarau verkehrstechnisch sehr günstig gelegen; denn die beiden Schmalspurbahnen widmen sich speziell der raschen Personenbeförderung. Mit 1557 Arbeitern aus dem Suhrental ist es der weitaus wichtigste Arbeitsort für dessen Bevölkerung. Luzern vermag wohl der größeren Entfernung wegen nur noch 166 Pendler anzulocken.

Die Zahlen über die Weg- und Zupendler geben auch Aufschluß über die Bedeutung der Gemeinden als zentraler Ort. Mit 4 Ausnahmen weisen alle ein. Pendelwandererdefizit auf, was einmal mehr die Unselbständigkeit der kommunalen Gebilde bestätigt. Wie erwartet nehmen Schöftland und Sursee als Markt-, Handels- und Industrieorte eine Sonderstellung ein: Sie weisen als einzige eine große Mehrzahl an $\mathrm{Zu}$ pendlern auf.

Die Entwicklung der Pendelwanderung, wie sie aus den Vergleichszahlen von 1910 hervorgeht, vollzog sich insofern sehr einseitig, als sich das Pendelwandererdefizit in 29 Gemeinden vergrößerte. So blieben heute von den ehemals 8 Ortschaften mit einem 
Tab. 11: Pendelwanderung

\begin{tabular}{|c|c|c|c|c|c|c|}
\hline & \multicolumn{2}{|c|}{ Zupendler } & \multicolumn{2}{|c|}{ Wegpendler } & \multicolumn{2}{|c|}{ Zupendler - Wegpendler } \\
\hline & 1910 & 1950 & 1910 & 1950 & 1910 & 1950 \\
\hline Suhr & 106 & 422 & 354 & 815 & -248 & -393 \\
\hline Unterentfelden & 4 & 54 & 210 & 322 & -206 & -268 \\
\hline Oberentfelden & 37 & 446 & 276 & 457 & -239 & -11 \\
\hline Muhen & 35 & 120 & 80 & 412 & -45 & -292 \\
\hline Kölliken & 43 & 105 & 270 & 523 & -227 & -417 \\
\hline Safenwil & 162 & 114 & 80 & 373 & +82 & -259 \\
\hline Holziken & 5 & 13 & 48 & 115 & -43 & -102 \\
\hline Hirschthal & 8 & 17 & 93 & 202 & -81 & -185 \\
\hline Schöftland & 230 & 507 & 14 & 162 & +216 & +345 \\
\hline Staffelbach & 3 & 71 & 94 & 85 & -91 & -14 \\
\hline Kirchleerau & 30 & 8 & 16 & 74 & +14 & -66 \\
\hline Moosleerau & 2 & 9 & 35 & 99 & -33 & -90 \\
\hline Attelwil & 3 & 12 & 24 & 25 & -21 & -13 \\
\hline Reitnau & 35 & 55 & 4 & 75 & +31 & -20 \\
\hline Uerkheim & 103 & 27 & 115 & 209 & -12 & -182 \\
\hline Bottenwil & - & 9 & 85 & 137 & -85 & -128 \\
\hline Wiliberg & - & 4 & - & 25 & - & -21 \\
\hline Schlossrued & 5 & 7 & 24 & 99 & -19 & - 92 \\
\hline Schmiedrued & 3 & 13 & 13 & 57 & -10 & -44 \\
\hline Kulmerau & - & - & 12 & 29 & -12 & -29 \\
\hline Winikon & 7 & - & 7 & 43 & - & -43 \\
\hline Triengen & 23 & 73 & 15 & 61 & + & +8 \\
\hline Wilihof & 4 & 1 & 2 & 13 & + & -12 \\
\hline Schlierbach & - & - & 1 & 17 & -1 & -17 \\
\hline $\begin{array}{l}\text { Büron } \\
\text { Büli }\end{array}$ & 8 & 77 & 21 & 65 & -13 & $+\quad 12$ \\
\hline Knutwil & 2 & 15 & 26 & 90 & -24 & -75 \\
\hline Geuensee & 1 & 5 & 31 & 85 & -30 & -80 \\
\hline Sursee & 193 & 480 & 8 & 149 & +185 & +331 \\
\hline Schenkon & 3 & 2 & 22 & 59 & -18 & -57 \\
\hline Oberkirch & 4 & 47 & 29 & 101 & -25 & -54 \\
\hline Eich & - & 1 & 2 & 12 & -2 & -13 \\
\hline Nottwil & 1 & 6 & 1 & 62 & - & -56 \\
\hline Sempach & 3 & 22 & 21 & 71 & -18 & -49 \\
\hline Neuenkirch & 15 & 30 & 5 & 152 & +10 & -122 \\
\hline
\end{tabular}

Zupendlerüberschuß nur noch deren 4. Die fortschreitende Industrialisierung strebt offenbar nach einer Schwerpunktbildung in wenigen Orten.

\section{Konfessionen}

Die Konfessionen im Suhrental sind verständlicherweise wie in der übrigen Schweiz historisch bedingt. Da während der Reformation das aargauische Gebiet unter bernischer Herrschaft gestanden hat, haben alle Gemeinden gezwungenermaßen den neuen Glauben angenommen. Im Kanton Luzern hingegen ist die katholische Konfession unverändert beibehalten worden.Wie Tab. 12 bestätigt, sind die Gegensätze in beiden Kantonsgebieten überaus klar. Die dominierende Konfession hat in den einzelnen Gemeinden um 90\% und mehr Anhänger. Praktisch können also die Ortschaften des Suhrentales in konfessioneller Hinsicht als homogen bezeichnet werden. Die Entwicklung des Verhältnisses «Protestanten zu Katholiken» gestaltet sich dementsprechend sehr einfach. Seit 1910 haben sich beispielsweise nur Verschiebungen von höchstens $6 \%$ eingestellt.

Landschaftlich kommt der Glaubensunterschied deutlich zum Ausdruck. Das protestantische Suhrental besitzt außer den Kirchen keine äußeren Wahrzeichen, die mit der Religion zusammenhängen. Im luzernischen Teil hingegen begegnet man besonders an vielbegangenen Stellen wie Straßenkreuzungen, Brücken usw. sehr häufig Kapellen oder Wegkreuzen. 
Tab.12: Die Konfessionen in den Gemeinden 1950 (22)

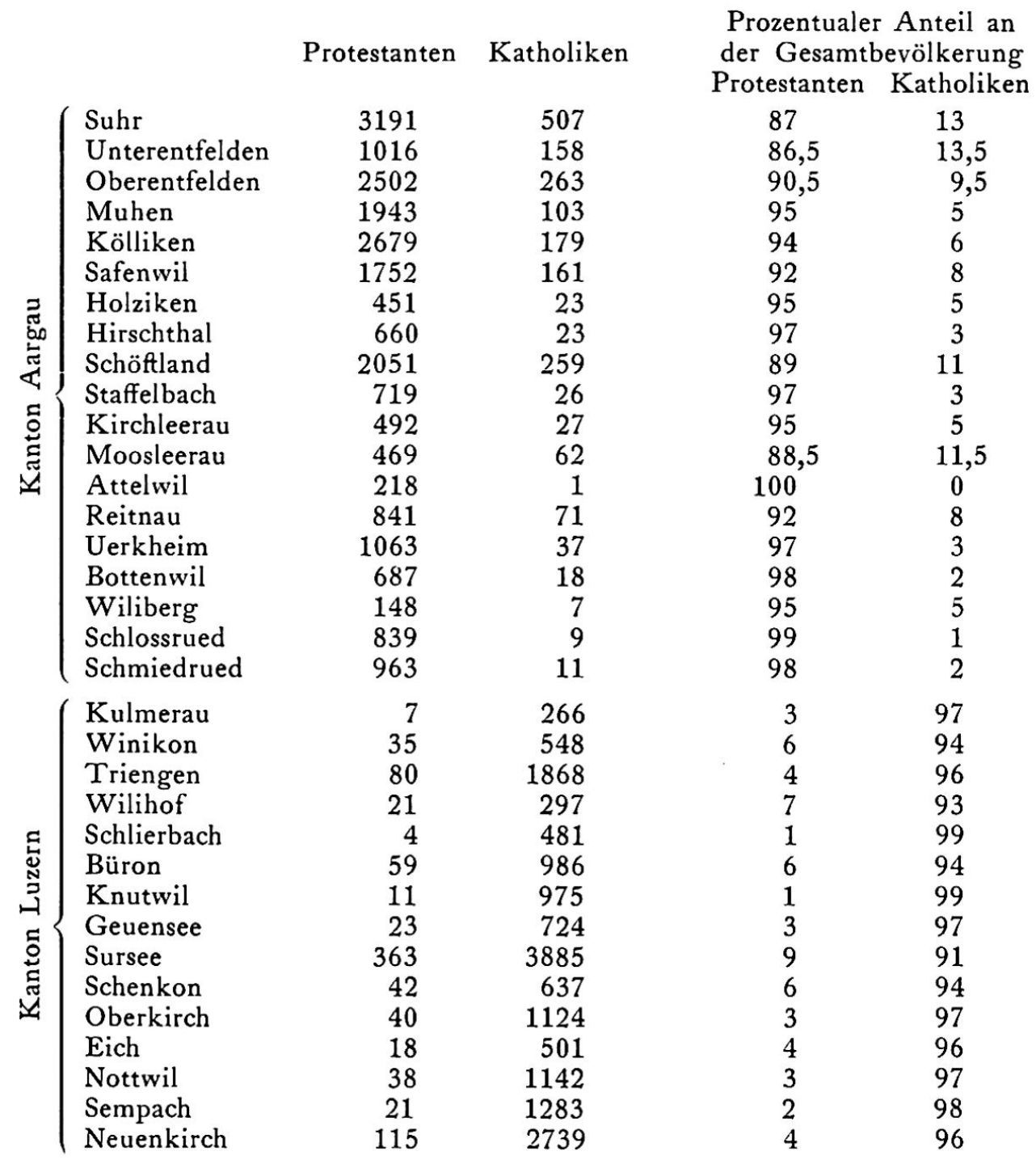

\section{Einleitung}

\subsection{DIE TEILLANDSCHAFTEN}

In diesem Abschnitt soll versucht werden, einzelne charakteristische Merkmale bestimmter Gebiete festzuhalten. Dies soll dann ermöglichen, einzelne Teillandschaften des Suhrentales auf Grund ihrer unterschiedlichen Merkmale zu umgrenzen und als typische Individuen zu kennzeichnen. Als Grundlage dienen die Ergebnisse der Untersuchungen im Abschnitt 1.1. Die Aufgabe besteht nun darin, den Einflußbereich eines typischen Landschaftselementes festzustellen. Die Lösung dieses Problems wird nicht leicht sein, denn nur selten bestehen gut erfaßbare Grenzen; viel häufiger wird es so sein, daß die einzelnen 'Typen allmählich ineinander übergehen. Außerdem müssen die Gemeindegrenzen berücksichtigt werden, weil die Statistiken nur für ganze Ortschaften aufgestellt wurden. Um das ganze Vorhaben nicht zu kompliziert zu gestalten, werden blo $\beta$ die auffallendsten Unterscheidungsmerkmale herausgegriffen. Am Schlu $\beta$ (Abschnitt 1.22) sollen dann die Gebiete mit gleichen Elementen zu einem einzigen Landschaftstyp zusammengefaßt werden.

\section{Relief}

\subsection{IN D IVID UEN}

Die Grenze zwischen dem intra- und dem extramoränischen Relieftyp ist in der Natur durch den weitesten Vorstoß der letzten Vergletscherung nach Norden klar 
gezeichnet. Also trennt die Moräne bei Staffelbach 2 Talabschnitte, die in ihrem Relief einen ausgesprochen unterschiedlichen Charakter aufweisen. Die Begrenzung der beiden Gebiete zeigt Abb. $23^{1}$.

\section{Hydrographie}

Auch hydrographisch zerfällt das Untersuchungsgebiet in die beiden intra- und extramoränischen Teillandschaften.

Intramoränisches Gebiet

Seitentäler wenig ausgeprägt

Ablenkung der Bachläufe durch Seiten-

moränen
Extramoränisches Gebiet

Seitentäler tief eingeschnitten

Bäche fließen auf dem direktesten Weg in die Suhre

\section{Siedlungslage}

Die Lage der Ortschaften hängt sehr stark vom Relief und der Hydrographie ab. Es überrascht deshalb nicht, wenn sich das Suhrental auch nach diesem Merkmal in die gleichen 2 Gebiete aufteilen läßt wie unter 1. und 2. (Abb. 23). Es sind folgende Unterschiede festzustellen:

a) Intramoränische Siedlungslage: Die Dörfer liegen am Hang und erheben sich demzufolge etwas über den Talboden.

b) Extramoränische Siedlungslage: Die Dorfzentren sind deutlich an den Talboden gebunden.

\section{Siedlungsformen}

Im Untersuchungsgebiet finden sich folgende Siedlungsformen: Einzelhofsiedlung, Weilersiedlung, Haufendörfer und Städte. Die beiden Städte ergeben aber keinen besonderen Landschaftscharakter. Sie können eher als Dorf (mit Weiler) mit Stadtrecht betrachtet werden. Auch die Unterteilung der Haufendörfer in solche mit oder ohne Weiler erweist sich als wenig sinnvoll. Wohl zerfallen im luzernischen Teil die Ortschaften geradezu beispielhaft in Hauptdorf und ein bis mehrere Weiler. Dies beeinflußt aber den Charakter des Landschaftsbildes kaum, da die Weiler für den Aussenstehenden als ein kleines, selbständiges Haufendorf erscheinen, das tatsächlich auch einzelne zentrale Dienste beherbergt. Endlich sei noch darauf hingewiesen, daß auch die aargauischen Gemeinden des Haupttales oft weilerähnliche Häusergruppen abseits des eigentlichen Dorfkernes besitzen, wie folgende Beispiele bestätigen:

\section{Suhr: $\quad$ Suhrester}

Oberentfelden: Am Berg, Am Holz, Wallenland

Staffelbach: Wittwil, Ufem Chalt

Damit ergeben sich also die beiden Typen der Einzelhof- oder Streusiedlung und der Haufendorfsiedlung. Ihre gegenseitige Abgrenzung gestaltet sich einfach: In den beiden großen Seitentälern der Uerke und der Ruederchen (Gemeinden Uerkheim, Bottenwil, Wiliberg, Schloßrued, Schmiedrued) dominiert die Streusiedlung, im übrigen Suhrental dagegen die Haufendorfsiedlung. Im Uerkental sind die ursprünglichen Verhältnisse durch den intensiven Wohnungsbau in neuerer Zeit jedoch etwas verwischt worden. Das funktionelle Zentrum wächst nämlich immer mehr zu einem eigentlichen Dorfkern heran, wie wir ihn in den Haufendörfern antreffen. Im Ruedertal hingegen blieb die reine Streusiedlung bis heute praktisch unberührt.

Im Gegensatz zum übrigen extramoränischen Suhrental sind in den beiden Seitentälern mit Streusiedlung auch die Hänge und Höhen besiedelt worden. Es wäre nun aber falsch zu glauben, die Einzelhöfe seien ein typisches Merkmal der höher gelege-

1 Um alle Grenzen der typischen Merkmale gesamthaft überblicken zu können, sind die entsprechenden Abbildungen am Schluß dieses Abschnittes zusammengefaßt. 
Abb. 21. Hypsographische Kurven der Gemeindeareale von Schloßrued (oben) und Schlierbach (unten)
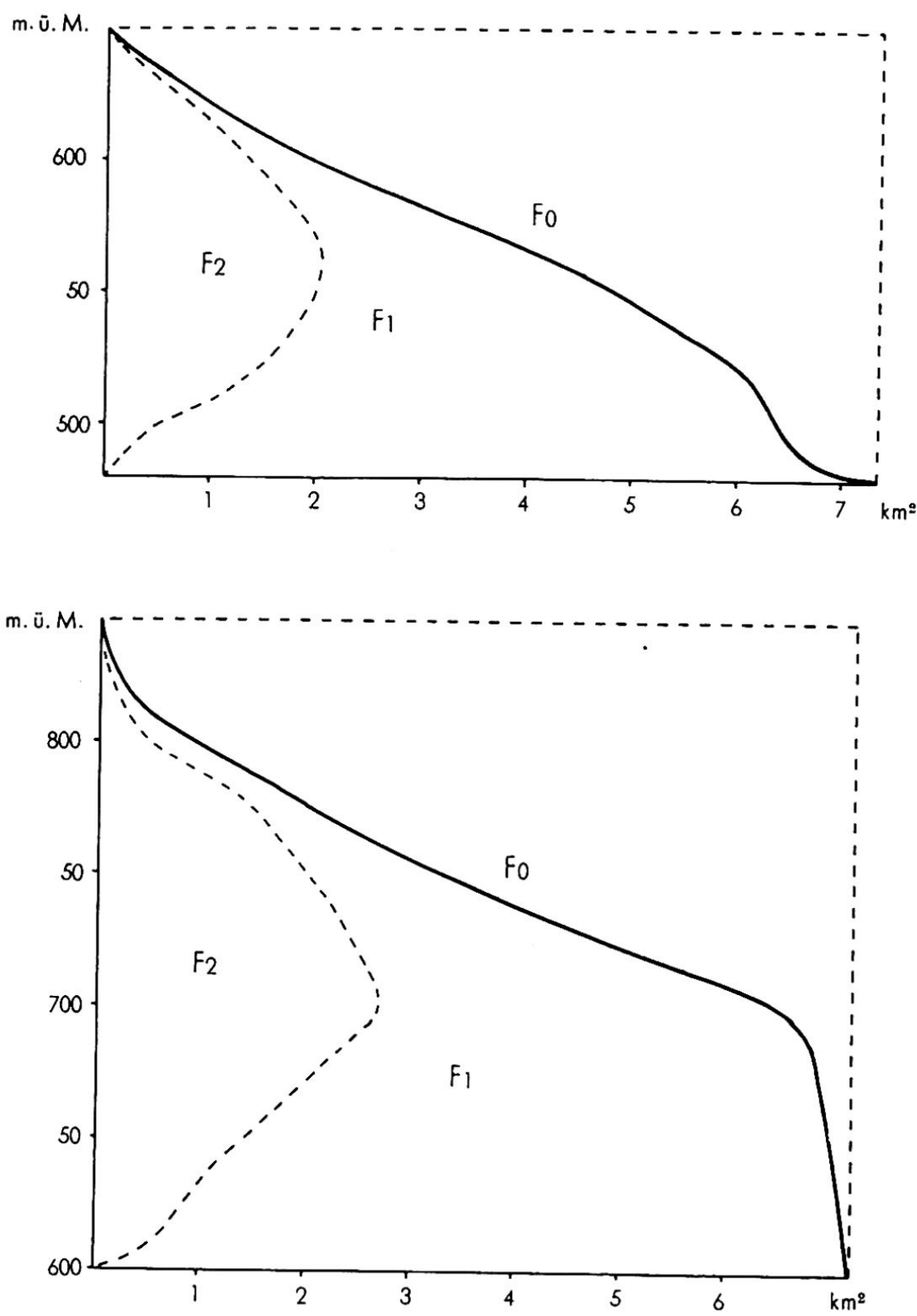

nen Gebiete. Dies beweisen die Gemeinden Kulmerau und Schlierbach, die südlich an das Ruedertal anschließen. Beide Ortschaften liegen über dem Haupttal und haben sich dennoch in einem gewissen Sinne zu Haufendörfern entwickelt. Wie der Siedlungs- und Funktionsplan von Schlierbach (Abb.9) zeigt, setzt sich die Gemeinde aus mehreren «Haufen» zusammen. Die Gründe, warum im luzernischen Hügelland nicht wie im benachbarten Ruedertal die Einzelhofsiedlung entstand, sind sehr undurchsichtig. Sicher spielt der große zeitliche Unterschied der Besiedlung eine wesentliche Rolle. Das Gebiet von Schlierbach und Kulmerau wurde nämlich rund 200 Jahre vor dem Ruedertal besiedelt, das nach Howald (48) als eines der letzten Täler des Aargau vom Menschen erschlossen wurde. Um die Mitbestimmung des Reliefs in der Art der Besiedlung genau feststellen zu können, werden nachfolgend die Kotenstreuung und der Relieffaktor der Gemeindeareale von Schloßrued und Schlierbach miteinander verglichen (42).

Berechnung. Die zur Berechnung der Kotenstreuung und des Relieffaktors notwendigen hypsographischen Kurven sind in Abb. 21 aufgezeichnet. Sie wurden durch planimetrisches Ausmessen der Höhenschichten mit der Aequidistanz $10 \mathrm{~m}$ ermittelt. 


$$
\begin{aligned}
& \text { Relieffaktor } \mathrm{k}=2 \sqrt{2 \mathrm{~J}-\mathrm{w}_{\mathrm{m}}{ }_{\mathrm{m}}} \\
& \text { Kotenstreuung } \mathrm{r}=\mathrm{h} \sqrt{2 \mathrm{~J}-\mathrm{w}_{\mathrm{m}}{ }_{\mathrm{m}}}=\frac{\mathrm{k} \cdot \mathrm{h}}{2} \\
& \mathrm{w}_{\mathrm{m}}=\frac{\mathrm{F}_{1}}{\mathrm{~F}_{0}} \quad \mathrm{~J}=\frac{\mathrm{F}_{2}}{\mathrm{~F}_{0}} \quad \mathrm{~h}=\text { maximale Kotendifferenz }
\end{aligned}
$$

Schloßrued:

$$
\begin{array}{lll}
\mathrm{F}_{0^{-}}=1,759 & \text { Einheiten } & \\
\mathrm{F}_{1}=0,896 & \mathrm{k}=0,558 \\
\mathrm{~F}^{2}=0,297 & \text { Einheiten } & \\
\mathrm{h} & \mathrm{r}=75,4 \mathrm{~m} \\
\mathrm{~h}=270 \mathrm{~m} &
\end{array}
$$

Schlierbach:

$$
\begin{array}{lll}
\mathrm{F}_{0}=2,292 & \text { Einheiten }^{2} & \mathrm{k}=0,316 \\
\mathrm{~F}_{1}=1,379 & \text { Einheiten }^{2} & \mathrm{r}=38,45 \mathrm{~m} \\
\mathrm{~F}_{2}=0,445 & \text { Einheiten } & \\
\mathrm{h}=243 \mathrm{~m} &
\end{array}
$$

Diskussion. Schon die hypsographischen Kurven der beiden Gemeindeareale zeigen in ihrem Verlauf einen großen Unterschied. Bei Schloßrued zeichnet sich die flache Talsohle deutlich ab, obwohl sie flächenmäßig einen geringen Anteil am Gesamtgebiet hat. Sodann ist die stetige Steilheit der Talhänge geradezu auffallend. Deutliche Terrassen, die zu einer engeren Besiedlung Anlaß geben könnten, fehlen. Die Streusiedlung ist folglich allein schon aus der hypsographischen Kurve verständlich. Für das Gebiet der Gemeinde Schlierbach gelten ganz andere Verhältnisse. Die Steilstufe von 600$700 \mathrm{~m}$ Meereshöhe umfaßt nur einen kleinen Teil der Gesamtfläche. Dann geht die Kurve plötzlich in ein relativ ebenes Teilstück über, das bis gegen $800 \mathrm{~m}$ anhält. Oberhalb dieser Höhe wird das Gelände wieder allmählich steiler. Die terrassenähnliche Verflachung des Geländes hat natürlich die Bildung der geschlossenen Siedlung stark begünstigt. Auch die streng mathematische Erfassung der Oberflächenformen ergibt ungefähr das gleiche Resultat. Im Gebiet von Schloßrued ist das Relief bedeutend stärker gegliedert als in der Gemeinde Schlierbach. Die entsprechenden Relieffaktoren zeigen diesen Unterschied sehr deutlich.

Die Umgrenzung der beiden nach der Siedlungsform einheitlichen Gebiete ist aus Abb. 24 ersichtlich.

\section{Bauart der Bauernhäuser}

Auch die Bauernhäuser eignen sich im Suhrental sehr gut für die Ausscheidung ähnlicher Gebiete. Die beiden verschiedenen Hausformen halten sich in ihrer Verbreitung an die Kantonsgebiete. Die Landwirte im aargauischen Teil besitzen mit ganz seltenen Ausnahmen Mehrzweckgebäude. Auch im luzernischen Gebiet herrscht diese Bauweise vor. Die Minderzahl der getrennt gebauten Häuser (Einzweckbauten) verleiht jedoch dem Dorfbild einen ganz andern Charakter. Abb. 22 illustriert die Verhältnisse im Grenzraum der Gemeinden Reitnau und Winikon. In Reitnau befindet sich nur ein Bauernbetrieb, bei dem der Wohnteil vom Oekonomiegebäude getrennt ist. Jenseits der Kantonsgrenze, in Winikon, beträgt der Anteil der Mehrzweckbauten immer noch $77 \%$. Da die luzernischen Gehöfte aber oft aus mehreren Gebäuden bestehen, erscheint ihr Anteil bei der Betrachtung des Dorfbildes bedeutend größer zu sein. In den übrigen Ortschaften des luzernischen Suhrentales ist das gegenseitige Verhältnis der beiden Bauarten ungefähr 3:1 oder eher zu Gunsten der luzernischen Gehöfte verschoben. Es sei hier noch besonders betont, daß nicht die Unterschiede der Naturlandschaftselemente wie Relief, Hydrographie usw. die Bauart bestimmten, sondern allein die Kantonszugehörigkeit der Gemeinden maßgebend ist. Abb. 25 orientiert über die Abgrenzung der entsprechenden Areale. 


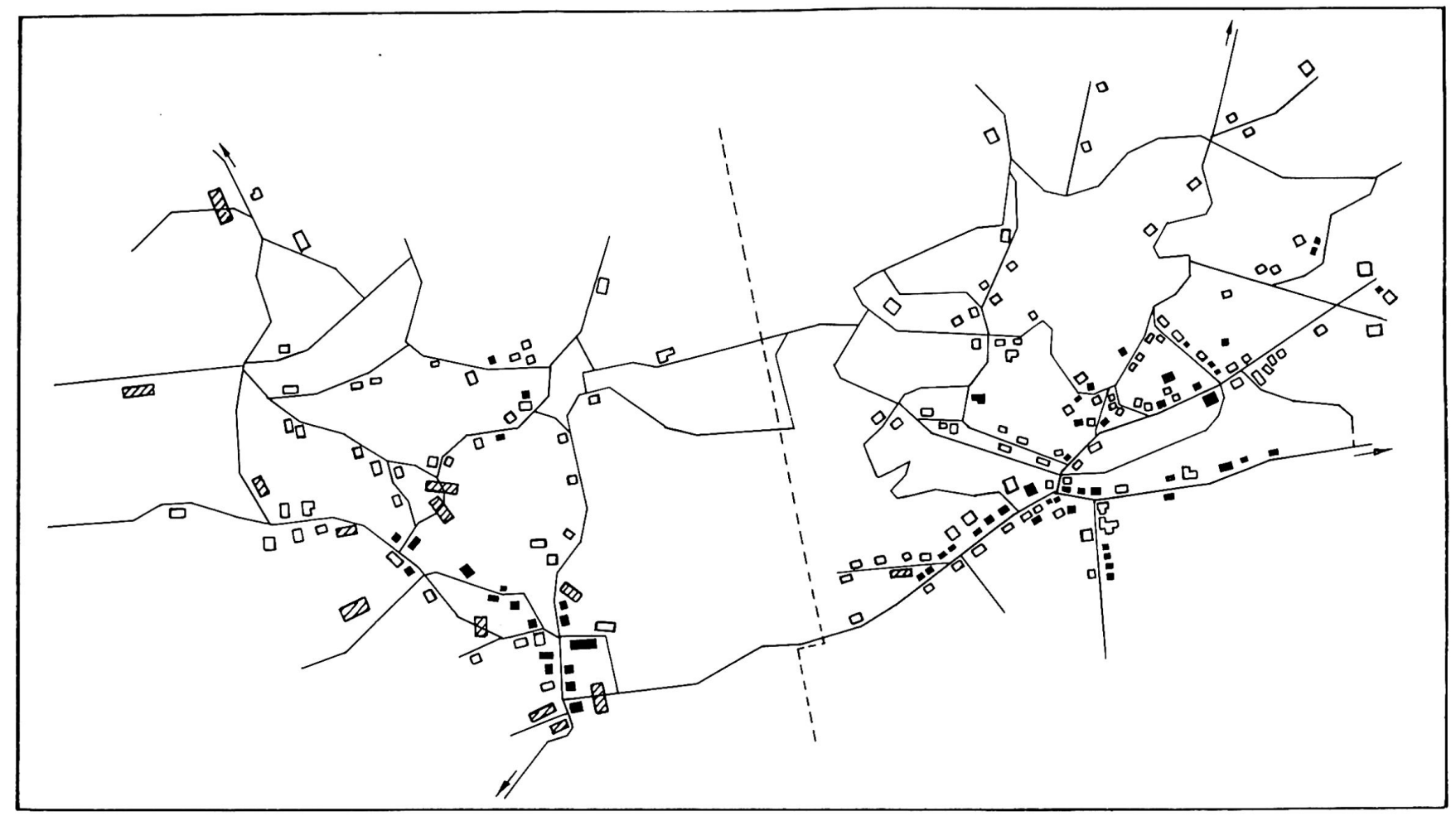

Abb. 22. Die Bauart der Bauernhäuser in den Gemeinden Reitnau und Winikon.

Weiß: Aargauer Bauernhaus (Mehrzweckgebäude), schraftiert: Luzernisches Gehöft (Einzweckbauten) Schwarz: Übrige Gebäude. 


\section{Betriebsgrößenverhältnisse}

Nach der Tab. 1 lassen sich klare Unterschiede zwischen einzelnen Gebieten in der mittleren Größe der Landwirtschaftsbetriebe feststellen. Für die Zusammenfassung der Gemeinden mit großen oder kleinen Betrieben soll ein mittlerer Flächeninhalt von 600 a als Grenze angenommen werden. Danach zerfällt das Suhrental wieder in 2 Gebiete. Die luzernischen Gemeinden weisen mehrheitlich Durchschnitte über 600 a und die aargauischen unter 600 a auf. Wie vorauszusehen war, zeigt die Analyse nach Betriebsgrößen eine gewisse Analogie mit derjenigen nach Haustypen. Der $\mathrm{Zu}-$ sammenhang der luzernischen Bauart mit den durchschnittlich etwas größeren Betrieben gegenüber dem aargauischen Suhrental ist also offensichtlich.

Bei den insgesamt 19 aargauischen Gemeinden bildet nur Wiliberg mit durchschnittlich 712 a pro Betrieb die Ausnahme. Es ist aber auch verständlich; denn in diesem vom modernen Verkehr abseits gelegenen Dorf stellt die Landwirtschaft den wichtigsten Erwerbszweig dar. Im luzernischen Teil des Tales gibt es 3 Ausnahmen, indem Kulmerau mit 513 a, Triengen mit 541 a und Büron mit 403 a pro Betrieb unter dem angenommenen Grenzwert liegen (Abb. 26).

\section{Anzahl Tiere (Rindvieh) pro Betrieb}

Die Anzahl Tiere auf den Bauernhöfen richtet sich natürlich nach der Fläche des Kulturlandes. So ist es verständlich, daß die Unterteilung des Untersuchungsgebietes nach der mittleren Anzahl Tiere pro Betrieb das gleiche Resultat ergibt wie bei den Betriebsgrößenverhältnissen. Auf die aargauischen Gemeinden entfallen durchschnittlich weniger als 11 Tiere pro Besitzer (Tab. 3). Wiederum bildet Wiliberg die einzige Ausnahme. Kulmerau, Triengen und Büron dagegen weisen als Sonderfälle im luzernischen Gebiet als einzige weniger als 11 Tiere pro Besitzer auf (Abb. 26).

\section{Künstliche Bewässerung}

Auch die künstliche Bewässerung hängt zusammen mit dem Relief und den geologischen Verhältnissen. Im intramoränischen Gebiet, in den Tälern der Ruederchen und der Uerke und in Safenwil fehlen die Bewässerungsanlagen aus hauptsächlich 2 Gründen :

a) Der Boden vermag dort das Regenwasser besser zu speichern.

b) Die Topographie erschwert die Einrichtung von Bewässerungskanälen.

Die extramoränische Talsohle ist stark wasserdurchläßig. Da zudem die Erstellung von künstlichen Bewässerungsanlagen keine besonderen Schwierigkeiten bietet, sind sie im untern Suhrental stark verbreitet. Abb. 27 veranschaulicht die einzelnen Gebiete.

\section{Forstwirtschaft}

Die im Abschnitt 1.123 über die Waldungen gemachten Feststellungen haben ergeben, daß sich die Verteilung der Waldareale stark nach dem Relief richtet. So ergeben sich die gleichen Landschaftsindividuen, wie sie Abb. 23 darstellt.

\section{Ausnützung der natürlichen Wasserkräfte}

Wie Abb. 14 bestätigt, bestehen zwischen dem intra- und dem extramoränischen Gebiet große Unterschiede in Bezug auf die Möglichkeit der Ausnützung natürlicher Wasserkräfte. Südlich von Staffelbach ist es des geringen Gefälles der Suhre wegen nur an 2 Stellen gelungen, die Wasserkraft auszunützen. Nördlich der Moräne dagegen liegen an der Suhre wie auch an der Uerke und der Ruederchen zahlreiche kleine Wasserwerke, die größtenteils Mühlen und Sägereien treiben. Die bereits in Abb. 23 dargestellten markanten Unterschiede der Gebiete südlich und nördlich der Moräne bei Staffelbach werden wiederum bestätigt. 

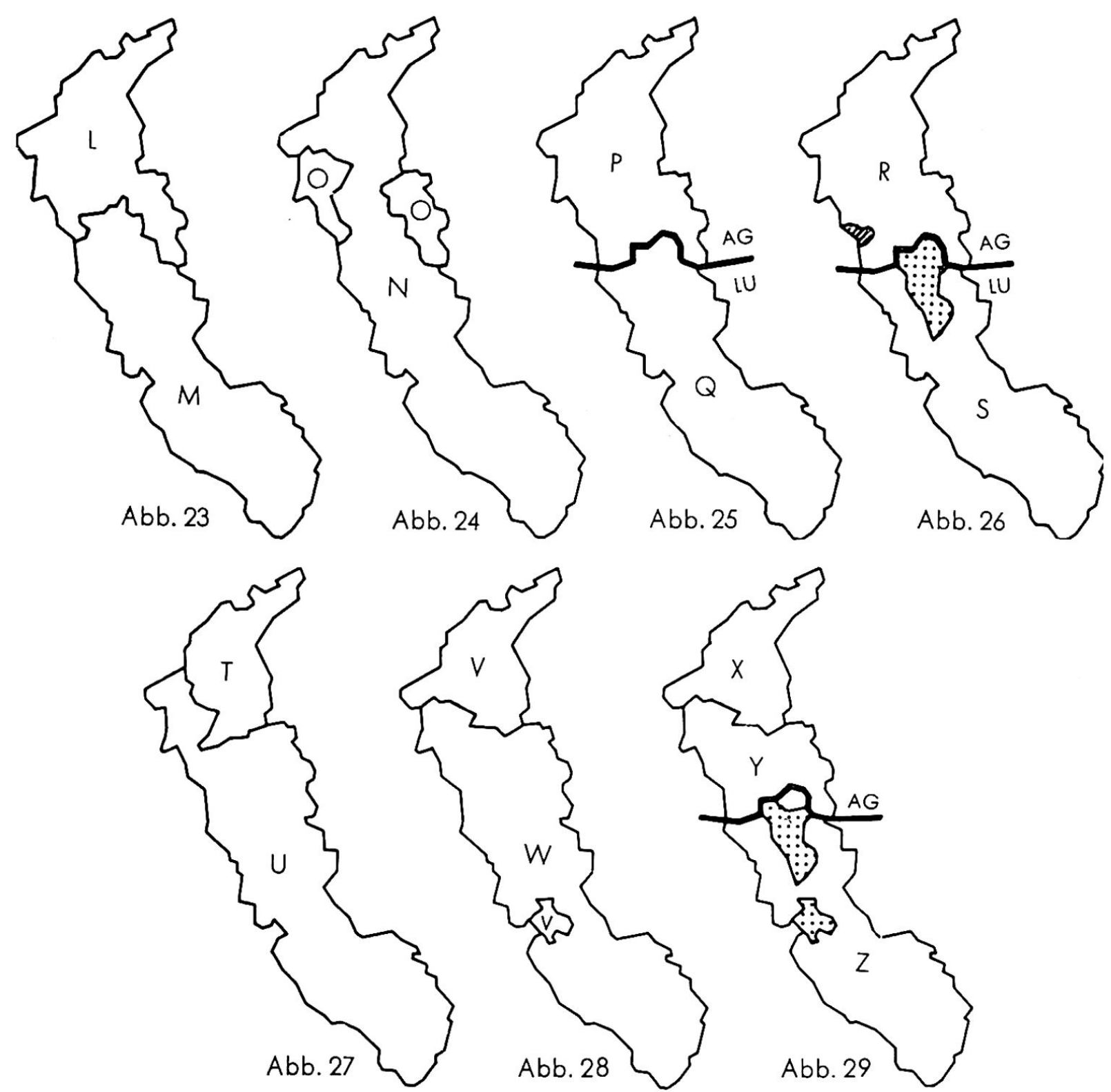

Abb. 23. r. Relief. L: Extramoränisches Gebiet. M: Intramoränisches Gebiet. 2. Hydrographie. L: Seitentäler markant. M: Seitentäler wenig ausgeprägt. 3. Siedlungslage. L: Dorfzentren liegen auf der Talsohle. M: Dorfzentren liegen am Hang. o. Waldverteilung. L: Hänge und Höhen vorwiegend bewaldet. M: Hänge und Höhen vorwiegend landwirtschaftlich bebaut. 1o. Wasserkräfle. L: 25 Wasserwerke. M: 2 Wasserwerke auf dem Talboden.

Abb. 24. 4. Siedlungsformen. N: Haufendörfer. O: Streusiedlung.

Abb. 25. 5. Bauart der Bauernhäuser. P: Praktisch alles Mehrzweckgebäude. Q: ${ }^{1 / 3}$ und mehr der Bauernbetriebe haben getrennt gebaute Gebäude (Einzweckgebäude). 13. Konfessionen. P: Über $86,5 \%$ der Einw. protestantisch. Q: Über $90 \%$ der Einw. katholisch.

Abb. 26. 6. Betriebsgrößenverhältnisse. R: Aarg. Suhrental: Betriebe durchschnittlich kleiner als 600 a. Ausnahme: Wiliberg (schraffiert). S: Luzern. Suhrental: Betriebe durchschnittlich größer als 600 a. Ausnahmen: Kulmerau, Triengen, Büron (punktiert). 7. Anzahl Tiere pro Betrieb. R: Durchschnittlich weniger als 11 Stück Großvieh pro Betrieb. Ausnahme: Wiliberg (schraffiert). S: Durchschnittlich mehr als 11 Stück Großvieh pro Betrieb. Ausnahmen: Kulmerau, Triengen, Büron, (punktiert).

Abb. 27. 8. Kïnstliche Berwässerung. T: Wässerwiesen vorhanden. U: Keine Wässerwiesen.

Abb. 28. rr. Ber.berwegung. V: Zunahme. W: Stagnation oder Abnahme.

Abb. 29. I2. Berufsstruktur. X: Aarg. Gemeinden mit Bahnverbindung: Industrie und Handwerk stark überwiegend, Landwirtschaft weist überall geringen Anteil auf. Y: Aarg. Gemeinden ohne Bahnverbindung: Anteil von Industrie und Handwerk zwischen 40 und $62 \%$. $Z$ : Luzern. Gemeinden: Anteil von Industrie und Handwerk unter $40 \%$. Anteil der Landwirtschaft über $33 \%$. Ausnahmen: Triengen, Büron, Sursee (punktiert). 


\section{Bevölkerungsentwicklung}

Aus Tab. 9 ist ersichtlich, daß die Bevölkerungsentwicklung in den Gemeinden 2 grundsätzlich verschiedene Tendenzen verfolgt: In den aargauischen Gemeinden mit Bahnstationen sowie in Sursee nahm die Bevölkerung in den vergangenen 100 Jahren stetig zu. Die übrigen Ortschaften hingegen verzeichnen in der Entwicklung einen Stillstand oder sogar eine Abnahme. In Abb. 28 sind die Gebiete mit gleichen Entwicklungstendenzen aufgezeichnet.

\section{Berufsstruktur}

Die in Abschnitt 1.126 vorgenommene Aufteilung der Gemeinden in 3 Gruppen kann hier unverändert beibehalten werden. Aus Abb. 29 gehen die von den strukturell homogenen Gruppen eingenommenen Areale hervor.

\section{Konfessionen}

Die konfessionellen Verhältnisse sind im Suhrental sehr eindeutig (Tab. 12). Auch hier scheidet die Kantonsgrenze wie bei der Bauart der Bauernhäuser (Abb. 25) die beiden Gebiete voneinander.

\section{Festlegung der Merkmale}

\subsection{TYPEN}

Nachdem nun das Suhrental nach den verschiedensten Gesichtspunkten beurteilt und so eine Vielfalt von Gegensätzen in der Landschaft festgestellt wurde, erscheint eine generelle 'Typisierung ziemlich kompliziert. Um dies zu vermeiden sollen die engen Beziehungen berücksichtigt werden, die zum Teil zwischen den Unterscheidungsmerkmalen bestehen. Dies erlaubt, oft mehrere Merkmale, denen die gleichen Einflußzonen $\mathrm{zu}$ Grunde liegen, in einem einzigen zusammenzufassen. Die daraus resultierenden Typen beruhen somit nicht bloß auf physiognomischen Merkmalen, sondern ebenso sehr auf ihren gegenseitigen Beziehungen. Sie haben also auch physiologisch betrachtet ihre Berechtigung.

1. Merkmal: Das Relief. Nach Abb. 23 dürfen noch folgende Merkmale dem Relief zugeordnet werden: Hydrographie, Siedlungslage, Forstwirtschaft, Ausnützung der natürlichen Wasserkräfte. Alle diese Merkmale ergeben deshalb auch die gleichen Landschaftstypen, oder genauer gesagt, ihre Areale sind kongruent. Weniger klar sind die Verhältnisse bei der künstlichen Bewässerung. Da diese nur auf der ebenen, wasserdurchläßigen Talsohle nötig ist, fehlt sie nicht nur im intramoränischen Gebiet sondern auch in einzelnen extramoränischen Gemeinden (Abb. 27).

2. Merkmal: Die Siedlungsform. Mit den Siedlungsformen, die die beiden großen Seitentäler vom übrigen Suhrental trennen, lassen sich keine weitern Merkmale vergleichen.

3. Merkmal: Bauart der Bauernhäuser, Konfession. Auch diese Merkmale sind sich gleichwertig, das heißt, die von ihnen ausgeschiedenen Landschaftsteile decken sich. Ebenso ergibt die Analyse nach den Betriebsgrößenverhältnissen und der Anzahl Tiere pro Betrieb mit wenigen Ausnahmen die gleichen Grenzen.

Nun verbleiben also noch die Bevölkerungsentwicklung und die Berufsstruktur. Wird jedoch erwartet, daß die Typisierung auf weite Sicht ihre Berechtigung beibehält, so muß auf die Berücksichtigung dieser beiden Merkmale verzichtet werden. Die Entwicklung der Bevölkerung und der Berufsstruktur könnte nämlich leicht durch eine plötzliche Veränderung der äußern Umstände in ganz neue Bahnen gelenkt werden. So ist zum Beispiel vorauszusehen, daß die geplante durchgehende Suhrentalbahn in einzelnen Gemeinden eine sprunghafte Zunahme der Bevölkerung bewirken oder die Ansiedlung neuer Industrien die Berufsstruktur stark beeinflussen wird. Damit sind die ursprünglich 13 Merkmale, nach denen das Suhrental in einzelne Landschaftstypen 
unterteilt werden soll, auf deren 3 reduziert worden. Dies erfüllt die Forderung, wonach sich das Festhalten von Landschaftstypen nach möglichst wenigen, aber markanten Unterschieden richten soll (44). Dadurch wird eine zu komplizierte, unübersichtliche Vielfalt von Typen vermieden.

Abb.30. Die Areale der vier Landschaftstypen.

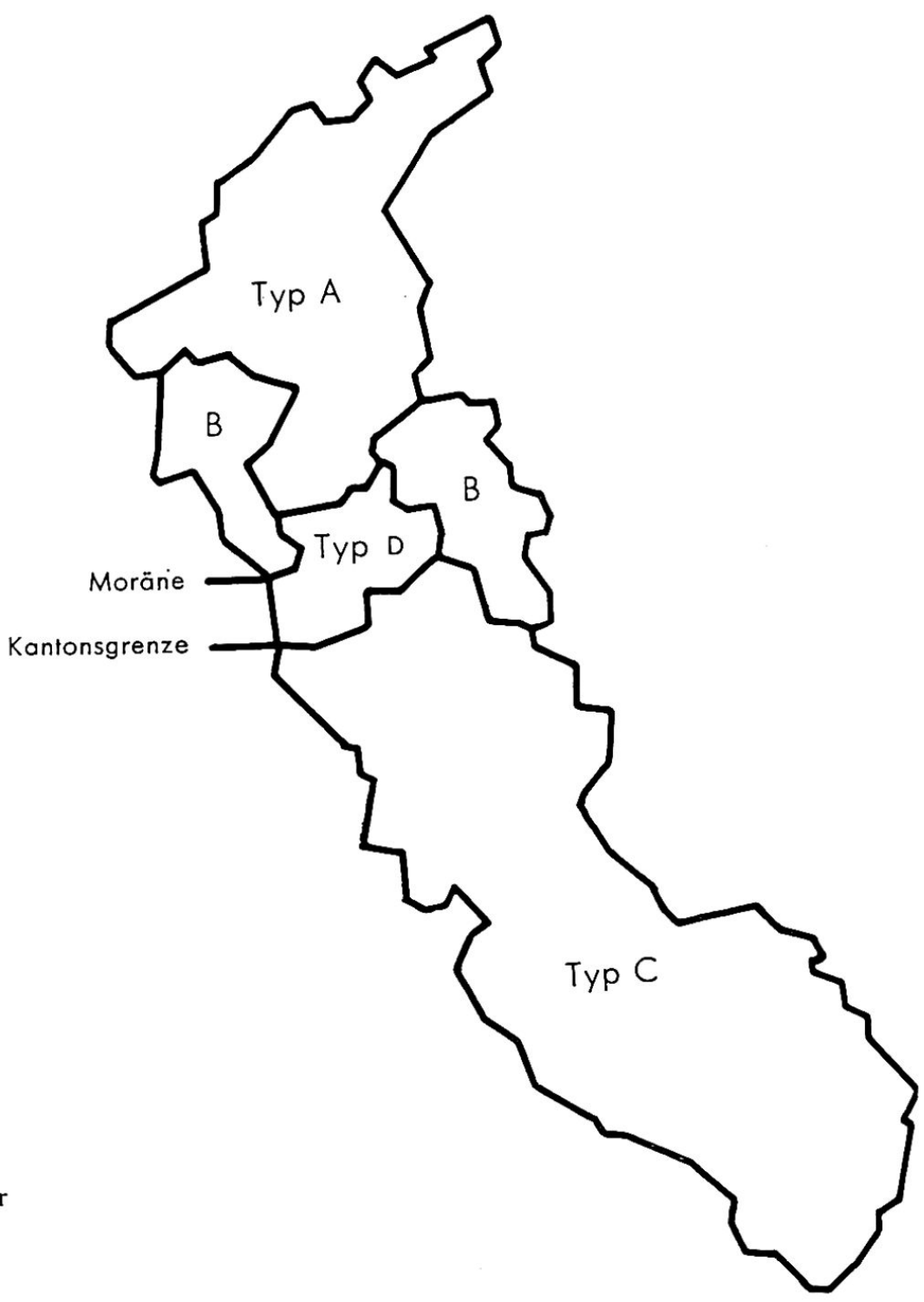

\section{Die Landschaftstypen im Suhrental}

Die nach den Merkmalen 1 bis 3 erhaltenen Landschaftstypen sind in Abb. 30 umgrenzt Sie sind durch Kombination der Abb. 23, 24 und 25 entstanden. Danach lassen sich im Untersuchungsgebiet 4 Typen unterscheiden.

Typ A: Die extramoränische Landschaft mit Haufensiedlung umfaßt die Gemeinden Suhr, Unterentfelden, Oberentfelden, Muhen, Kölliken, Safenwil, Holziken, Hirschthal, Schöftland, Staffelbach.

Typ B: Die extramoränische Landschaft mit Streusiedlung. Dazu gehören die Gemeinden in den großen Seitentälern: Uerkheim, Bottenwil, Wiliberg, Schloßrued, Schmiedrued.

Typ C: Die intramoränische, luzernische Landschaft. Wie die Benennung ausdrückt, lassen sich damit die Gebiete aller dem Kanton Luzern angehörender Gemeinden charakterisieren: Kulmerau, Winikon, Triengen, Wilihof, Schlierbach, Büron, Knutwil, Geuensee, Sursee, Schenkon, Oberkirch, Eich, Nottwil, Sempach, Neuenkirch. 
Typ D: Die intramoränische, aargauische Landschaft. Dieser Typ vereinigt alle südlich der Moräne gelegenen Dörfer des Kantons Aargau: Kirchleerau, Moosleerau, Attelwil, Reitnau.

Die Unterschiede im Landschaftsbild dieser 4 Typen sind nachfolgend zusammengestellt. Daraus geht auch hervor, daß sich die Gebiete der für die Typisierung unberücksichtigten Elemente ziemlich genau an die Typengrenzen halten. Die wenigen Ausnahmen beziehen sich nur auf einzelne Gemeinden.

\section{Die Landschaftstypen und ihre Merkmale}

Hydrographie
Siedlungslage
Betriebsgrößen-
verhältnisse
Ausnahmen
Anzahl Tiere
pro Betrieb
Ausnahmen
Künstliche
Bewässerung
Ausnahmen
Wasserwerke
Bevölkerungs-
entwicklung
Ausnahmen
Berufsstruktur

\section{Typ A}

Starkes Relief

Haufendorf

Mehrzweckgebäude Mehrzweckgebäude

Protestantisch

Steilstufe der Seitenbäche im Talhintergrund

Dorfzentrum auf der Talsohle

Durchschnittlich weniger als 600 a pro Betrieb

Durchschnittlich weniger als 11 Stück Großvieh pro Betrieb

Überall vorhanden Keine

Safenwil

15 Wasserwerke

Starke Zunahme der Bevölkerung

Industrie und Handwerk über $60 \%$ Staffelbach

Industrie
und Handwerk
$40-62 \%$

Typ C

Mildes Relief Mildes Relief

Haufendorf Haufendorf

Einzweckgebäude Mehrzweckgebäude Katholisch

Protestantisch

Steilstufe der Seitenbäche unmittelbar vor der Einmündung auf die Talsohle

Dorfzentrum etwas über der Talsohle am Hang

Durchschnittlich Durchschnittlich mehr als 600 a weniger als 600 a pro Betrieb pro Betrieb

Kulmerau, Triengen, Büron

Mehr als 11 Stück Weniger als Großvieh pro

Betrieb Kulmerau, Triengen, Büron

Keine Keine
11 Stück Großvieh pro Betrieb

10 Wasserwerke 2 Wasserwerke Keine

Bevölkerung nimmt ab oder bleibt ungefähr gleich

Sursee

Industrie

und Handwerk

unter $40 \%$

Triengen, Büron,

Industrie

und Handwerk

Sursee $40-62 \%$

\subsection{S C H LUSSWORT}

Die 4 Landschaftstypen sind auf Grund von nur 3 Merkmalen gebildet worden. Wenn dadurch eine eindeutige Zuteilung jeder Gemeinde zu einem Typ gelungen ist, so ist dies die Folge der doch ziemlich klaren Grenzen zwischen den einzelnen Gebieten des gleichen Typus. Die hier dargestellten Landschaftstypen existieren aber nicht nur theoretisch, sondern sie kommen in der Natur auch tatsächlich zum Ausdruck. Der Wanderer hat beispielsweise beim Überschreiten der Moräne bei Staffelbach das unmittelbare Gefühl, daß er eine ganz neue Landschaft betritt. Ähnlich ergeht es ihm wieder bei der Kantonsgrenze, obwohl sie sich an gar keine natürlichen Landschaftselemente hält. Eine kurze Umschreibung der angewandten Typisierungsmethode sieht wie folgt aus:

1. Untersuchung der betreffenden Landschaft nach dem üblichen monographischen Verfahren.

2. Herausgreifen der Merkmale, die eine Abgrenzung von Teilgebieten mit verschiedenartigem Charakter erlauben. 
3. Reduktion der Zahl der Merkmale. Dies kann gestützt auf ihre physiognomischen oder physiologischen Zusammenhänge oder anderer von Fall zu Fall wechselnder Gründe geschehen.

4. Beurteilung von Teilgebieten der zu untersuchenden Landschaft, die sich zum Beispiel an die Gemeindegrenzen halten können. Teilgebiete mit gleichen Merkmalen gehören dem gleichen Landschaftstyp an. Das hervortretendste Merkmal wird den Namen des Typen bestimmen.

\section{Zukunftslandschaft}

\subsection{EINLEITUNG}

Die bisherigen Untersuchungen dienten allein der objektiven Feststellung der bestehenden Tatsachen und ihrer Entwicklung. Wenn hie und da eine kritische Bemerkung fiel, so geschah dies nur aus der Überzeugung, daß man einige bestehende Mißstände leicht hätte vermeiden können, wenn man frühzeitig genug in die Entwicklung eingegriffen hätte. Einmal mehr zeigen sich hier die Nachteile, die aus der Unkenntnis der Landesplanung breiter Bevölkerungskreise resultieren. Erfreulicherweise dringt in neuerer Zeit die Erkenntnis der Notwendigkeit einer gewissenhaften Planung immer stärker durch. Wie nachfolgend zu sehen ist, sind auf dem Gebiet der Bodenreform (Güterregulierung und Melioration) bereits bedeutende Projekte verwirklicht worden und die Lösung der Verkehrsprobleme, gegenwärtig die dringendste Angelegenheit, soll ebenfalls nicht mehr lange auf sich warten lassen.

In diesem Abschnitt werden nun nicht große Phantasieprojekte zur Sprache kommen, die ohnehin nicht verwirklicht werden können. Es sollen vielmehr ein Bild über den heutigen Stand der Planung entworfen und einige Anregungen für die Zukunft angedeutet werden.

\subsection{DIE SIEDLUNGS- ODER ORTSPLANUNG}

hat sich zur Aufgabe gemacht, die Entwicklung der Gemeinden so zu lenken, daß sie zu jeder Zeit ein harmonisches Ganzes darstellen, was durch die Festlegung von Siedlungs-, Industrie-, Landwirtschafts- und anderer Zonen erreicht werden kann. Aus der Tab. 13 ist ersichtlich, daß diese Planung im Suhrental noch kaum über kleine Anfänge hinausgekommen ist. Eine einzige Gemeinde (Schöftland) verfügt über eine abgeschlossene Ortsplanung. Rechtskräftige Zonenpläne sind bis jetzt 2 ausgearbeitet worden. Hingegen besitzen 11 Gemeinden eine Bauordnung, die die Rechtsgrundlagen für den Erlaß von Teil- oder Gesamtzonenplänen geben. Die in einigen Gemeinden beschlossenen oder bereits in Bearbeitung stehenden diesbezüglichen Planungen lassen aber erkennen, daß die Bevölkerung nun doch von der Notwendigkeit einer geordneten Entwicklung überzeugt ist. Es ist deshalb nicht verwunderlich, daß in den Industrieorten mit einer besonders starken Bevölkerungsentwicklung die planerischen Arbeiten nun intensiv gefördert werden.

\subsection{DIE PLANUNG IM BEREICH DER LANDWIRTSCHAFT}

Tab. 13 bestätigt, daß die planerischen Möglichkeiten innerhalb der Landwirtschaft schon weitgehend verwirklicht worden sind und hier nur deshalb dargestellt werden, um als Beispiele bewußter, realisierter Planung zu dienen. Verständlicherweise widersetzte sich hier die Bevölkerung weniger, da den Beteiligten spürbare finanzielle 


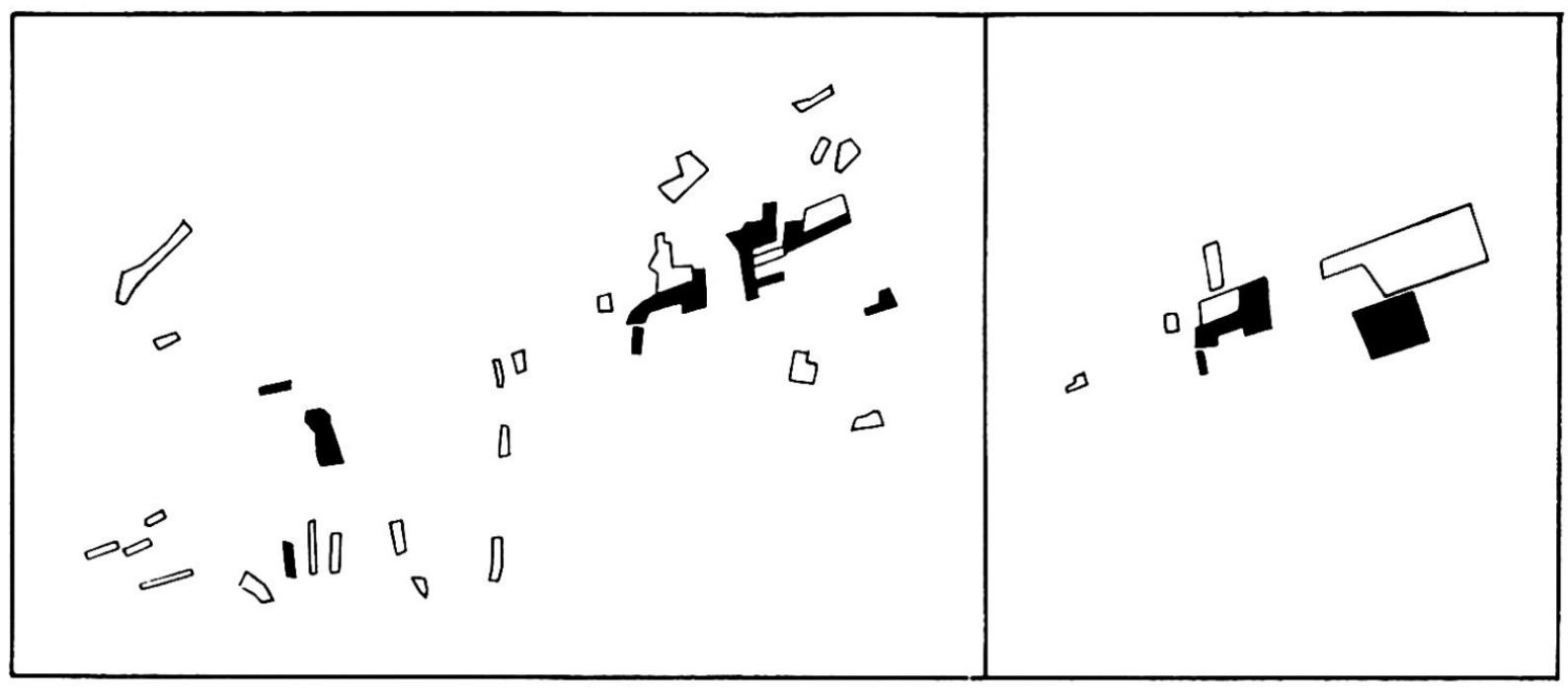

Abb. 31. Güterregulierung in Reitnau. Links alter Bestand, rechts neuer Bestand. Weiß: Landbesitz des Landwirtes Leuenberger, schwarz: Landbesitz des Landwirtes Hauri.

Vorteile winkten: Die Meliorationen brachten eine Verbesserung der Böden und oft auch eine Neulandgewinnung mit sich, da die vielen Flußwindungen einem geraden Kanal weichen mußten. Die Güterregulierungen wiederum erlauben eine rationellere Bewirtschaftung der bäuerlichen Nutzungsfläçhen. Anhand je eines Beispiels seien hier Wesen und Auswirkungen solcher Unternehmen dargestellt.

\subsection{GÜTERZUSAMMENLEGUNG IN DER GEMEINDE REITNAU}

Die im Jahre 1931 durchgeführten Regulierungsarbeiten bezweckten nebst der Arrondierung der Landwirtschaftsbetriebe eine Neugestaltung des Straßennetzes. So gibt es heute kein Grundstück mehr, das nicht zweiseitig von Wegen umgeben ist, was für die maschinelle Bearbeitung unbedingt erforderlich ist. Wie sich die Zusammenlegung des Grundbesitzes für die einzelnen Bauernbetriebe auswirkt, geht aus der Abb. 31 hervor, wo die Grundstücke von 2 Bauern in ihrer alten und neuen Lage aufgezeichnet sind. Der Bauer A hat vor 193125 Parzellen besessen. Die Regulierung hat ihm zweifellos große Vorteile gebracht; denn sein Betrieb setzt sich nun nur noch aus 5 Teilen zusammen. Ungefähr die gleichen Änderungen zeigt das Beispiel des Bauern $\mathrm{B}$, der ursprünglich 8 Parzellen besessen hat und jetzt noch deren 3.

\subsection{MELIORATION DES GEBIETES ZWISCHEN OBERENTFELDEN UND SUHR}

Früher war die Talsohle des Untersuchungsgebietes wie erwähnt wegen den ungenügenden natürlichen Entwässerungsverhältnissen stark versumpft. Als im Laufe der Zeit, besonders während des letzten Weltkrieges, das Bedürfnis nach neuem Kulturland immer stieg, entschloß sich die interessierte Bevölkerung, einzelne Gebiete einer Melioration zu unterziehen. Bis heute sind folgende 4 Gebiete auf diese Weise neu gestaltet worden:

a) Talsohle der Suhre zwischen Knutwil und Staffelbach.

b) Talsohle der Uerke zwischen Uerkheim und Holziken.

c) Suhrenmatten zwischen Oberentfelden und Suhr.

d) Brunnmatten im Westteil der Gemeinde Oberentfelden, die vom Unterlauf der Uerke durchflossen werden.

Diese Meliorationen verursachten eine grundlegende Neugestaltung des Landschaftsbildes. Da sich die Ausführung aller 4 Unternehmungen ungefähr nach den gleichen Prinzipien vollzog, wird nur das Gebiet der Suhrenmatten als Beispiel darge- 
stellt. Diese im Jahre 1941 von der Melioration erfaßte Region läßt sich wie folgt umgrenzen: Von der Suhrenbrücke am nördlichen Ausgang von Oberentfelden erstreckt es sich bis zu den ersten Häusern von Suhr, wobei es auf der Nordseite vom Gönhard und auf der Südseite von der Zürich-Bern-Straße abgeschlossen wird.

1. Charakterisierung des alten Zustandes. Das dominierende Element vor der Neugestaltung des Gebietes bildete das Wasser. Der Hauptfluß, die Suhre, schlängelte sich des geringen Gefälles wegen in unzähligen Windungen durch das $3 \mathrm{~km}$ lange Gebiet und erreichte auf diese Weise eine Länge von 5,2 km. Auch der Grundwasserstrom machte sich in dieser Region bemerkbar. Der Talverengerung bei Suhr zufolge staute sich das unterirdische Wasser und trat überall in Form von Quellen oder sogenannten Grundwasseraufstößen an die Oberfläche. Während einer längeren Regenperiode wurde das Gebiet sozusagen zweifach überschwemmt: Das untiefe, stark mäandierende Bachbett der Suhre vermochte die Wassermengen nicht mehr aufzunehmen. Zudem stieg der Grundwasserspiegel so stark an, daß die Grundwasseraufstöße wie Stromquellen hervorsprudelten. In solchen Zeiten boten die Suhrenmatten jeweils ein trostloses Bild. Die Wassermassen überschwemmten das ganze Gebiet, sodaß nur Bäume und Sträucher das überflutete Land verrieten. So war es natürlich vollkommen undenkbar, daß die Bauern ihre Grundstücke mit Getreide oder Hackfrüchten bepflanzen konnten. Die einzig mögliche Ausnützung des Areals bestand in der Gras- und Streuewirtschaft. Aber auch diese lieferte im allgemeinen qualitativ geringe Erträge, da in diesem durchnäßten Boden nur schlechte Gräser gedeihen konnten. Bei längeren Trockenperioden jedoch senkte sich das Grundwasser schnell ab, sodaß die Erdoberfläche einer raschen Austrocknung preisgegeben war. Um dennoch eine ausgiebige Ernte der wasserliebenden Gräser sicherzustellen, bauten die Landwirte noch künstliche Bewässerungsanlagen, die mit Wasser aus der Suhre gespiesen wurden. Die vielen Bewässerungs- und Entwässerungskanäle (Quellen) bildeten zusammen mit der Suhre ein kompliziertes Grabensystem. Die Grundstücke nahmen deshalb alle möglichen Formen an, sodaß eine rationelle Bearbeitung undurchführbar war. Charakteristisch für die damalige Landschaft waren ferner die Bäume und Sträucher, die die Gräben und Bäche beidseits umsäumten. Die wasserliebenden Arten wie Eschen, Erlen und Weiden waren natürlich am stärksten vertreten.

2. Die Meliorationsarbeiten. Das Ziel der Melioration war demnach klar vorgezeichnet: Nämlich die Verbesserung der hydrographischen Verhältnisse. Dies konnte durch eine künstliche Absenkung des Grundwasserspiegels und Korrektion der Suhre erreicht werden. Die Ausführung hingegen gestaltete sich nicht so einfach, weil man die Auswirkungen auf die Fruchtbarkeit des Bodens nicht beurteilen konnte. Vor allem bot aber auch die Trinkwasserversorgung der Stadt Aarau, welche am Südfuß des Gönhard im Jahre 1940 die neuen Grundwasserfassungsanlagen erstellt hatte, bedeutende Schwierigkeiten, weil der Grundwasserspiegel nicht ohne Bedenken verändert werden durfte.

Im Frühjahr 1941 begann man jedoch mit dem Ausheben des neuen Suhrelaufes. Seine Tiefe beträgt im Mittel 3,5 m. Wie Abb. 32 zeigt, hat man das Problem der Schonung der Aarauer Wasserversorgung dadurch gelöst, daß die neue Suhre in einem Bogen am Pumphaus vorbeigeführt wurde. Das Aushubmaterial diente zur Verebnung der Bewässerungskanäle. Natürlich mußten auch die alten Wege, die bei einer intensiven Bebauung des neuen Kulturlandes den Anforderungen nicht mehr genügen konnten, durch neue ersetzt werden. Der folgende Vergleich der Fluß- bzw. Wegdichten vor und nach der Melioration zeigt, wie die Landschaft einen ganz neuen Charakter erhalten hat.

$\begin{array}{lcc} & \text { Vor } & \text { Nach } \\ & \text { der } & \text { Melioration } \\ \text { Flußdichte } & 13,90 & 2,78 \\ \text { Wegdichte } & 9,14 & 10,02\end{array}$


Gleichzeitig mit der Melioration wurde auch die Güterregulierung durchgeführt, sodaß nun jeder Landwirt nur noch 1 oder höchstens 2 Grundstücke in den Suhrenmatten besitzt. So waren also die Voraussetzungen gegeben, daß ab Frühling 1942 das Gebiet nach modernen Gesichtspunkten bewirtschaftet werden konnte.

3. Die Auswirkungen der Melioration. Die Umfrage bei mehreren Landwirten von Suhr und Oberentfelden ergab, daß die Melioration befriedigt. Jetzt können ohne Bedenken alle Kulturpflanzen, wie Getreide, Kartoffeln, Rüben usw. angepflanzt werden. Ebenso tragen die vernünftige Parzellierung und die bequemen Zufahrtswege zu einer rationellen Bearbeitung des Bodens bei. Die Wasserversorgung der Stadt Aarau hat ebenfalls keine merkbaren Nachteile erlitten. Obwohl sich der Grundwasserspiegel nun im Mittel etwa 3 bis $4 \mathrm{~m}$ unter der Erdoberfläche befindet, steht auch während Trockenperioden noch genügend Wasser zur Verfügung. Um die Verunreinigung des Wassers durch künstlichen oder natürlichen Dünger zu verhindern, hat man um die Saugstollen eine Zone ausgeschieden, die der landwirtschaftlichen Bebauung entzogen wird. Dieses Areal, welches mit Ausnahme der Gräben ungefähr den ursprünglichen Charakter beibehalten hat, bietet noch heute gute Vergleichsmöglichkeiten zwischen den Zuständen von «Einst» und «Jetzt».

\section{Tab.13: Stand der Planungsarbeiten in den Gemeinden}

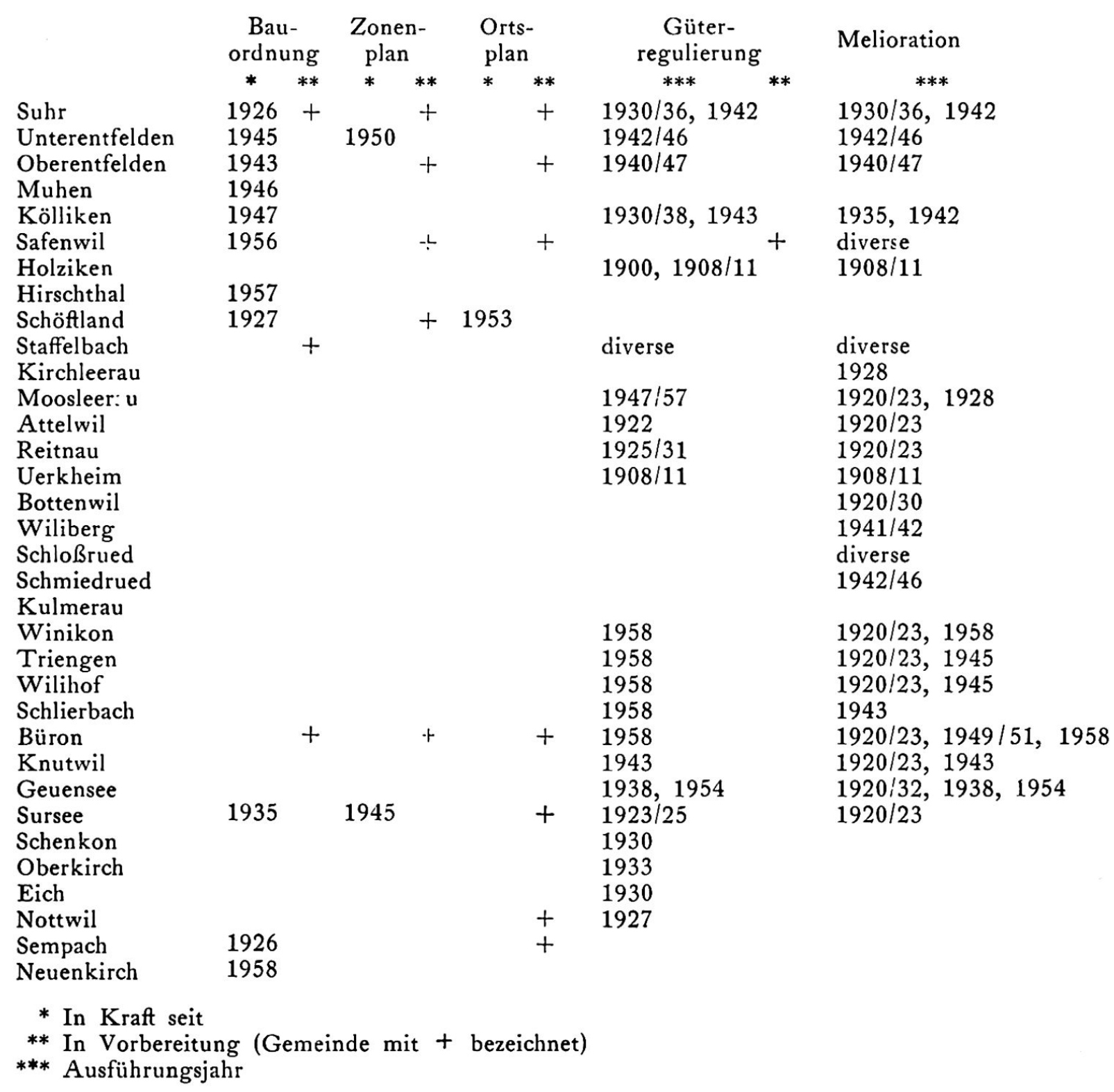



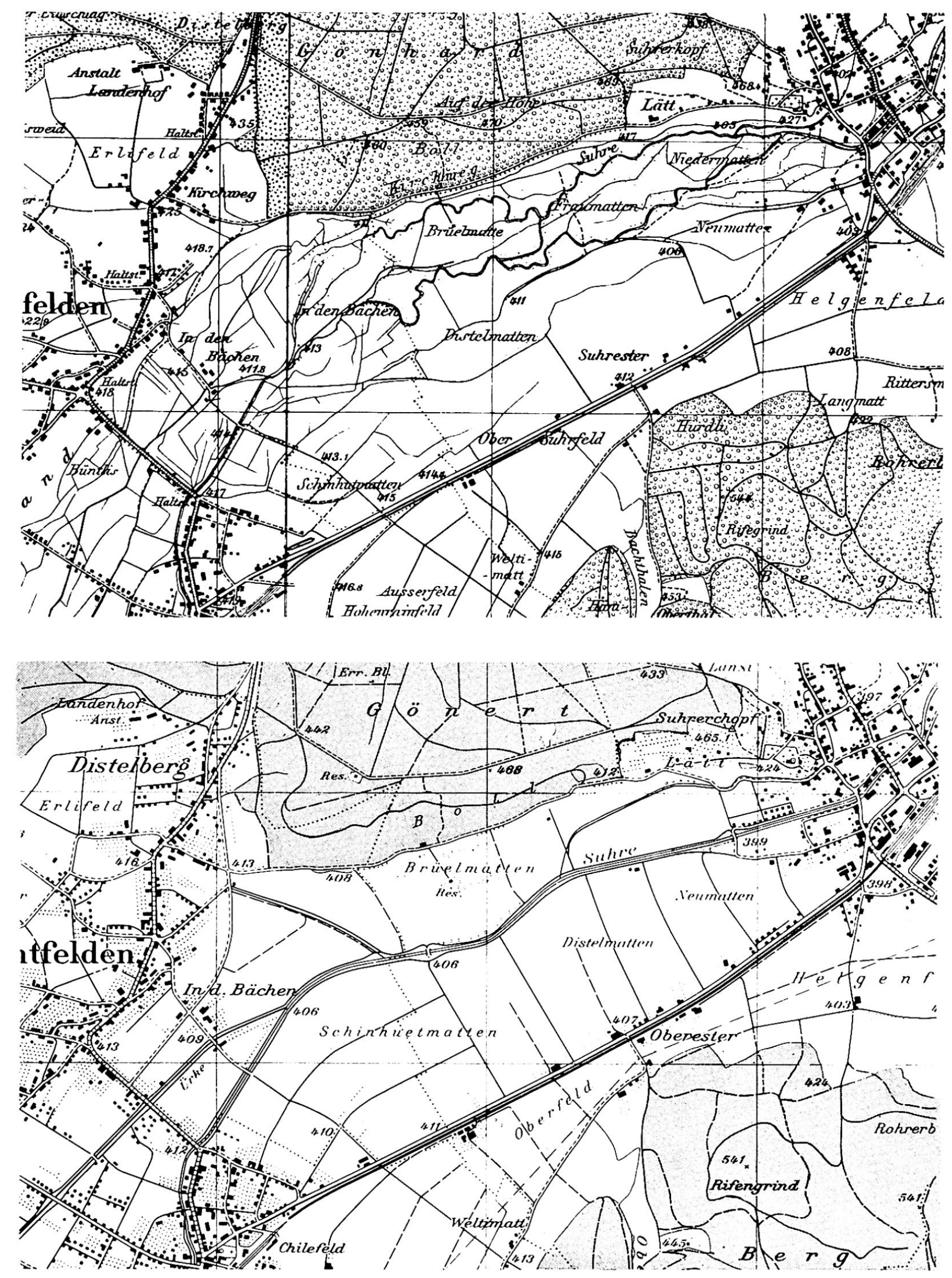

Abb. 32. Suhrenmatten « Einst" und "Jetzt». Oben: Siegfriedkarte, aufgenommen 1940. Unten: Neue Landeskarte, aufgenommen 1952. (Reproduziert mit Bewilligung der Eidg. Landestopographie vom 21. November 1960) 


\subsection{VERKEHRSPLANUNG}

\subsection{INTERNER VERKEHR}

In der vorliegenden Arbeit sind schon verschiedentlich die unbefriedigenden Verkehrsverhältnisse aufgefallen. Es bestätigt sich einmal mehr, daß die Lösung der Verkehrsprobleme weitgehend die Entwicklung der ganzen Talschaft bestimmen wird. Es sei hier nur kurz wiederholt, daß die Industrialisierung und als Folge davon die Bevölkerungsentwicklung im Suhrental aufs engste mit der Leistungsfähigkeit der Bahnen verbunden sind. Heute erscheint es unverständlich, daß sich in die $37 \mathrm{~km}$ lange Strecke zwischen Aarau und Neuenkirch 4 verschiedene Transportmittel teilen. Wenn aber das untere und das obere Suhrental unabhängig voneinander je eine sogenannte Stumpenbahn erstellen und schließlich die Postverwaltung die dazwischenliegende Lücke mit einem Autobusbetrieb notdürftig schließt, ist wohl einem allfälligen Sonntagsreisenden gedient, aber sicher nicht größeren Fabrikbetrieben und ihren Pendelwanderern, die eine rasche Beförderung ohne Umsteigen erwarten.

In neuerer Zeit ist nun unter allen interessierten Körperschaften der direkt betroffenen Gemeinden, den Behörden der Kantone Aargau und Luzern sowie des Bundes die Erkenntnis der Notwendigkeit einer Sanierung der Verkehrsverhältnisse durchgedrungen. Ein Expertenkomitee arbeitete folgende Gesamtlösung aus: Als Grundlage dient die Aarau-Schöftland-Bahn. Diese soll über Schöftland hinaus bis Triengen verlängert werden und dort an die bereits bestehende Sursee-Triengen-Bahn angeschlossen werden, deren Bahnkörper ebenfalls auf Schmalspurbetrieb abgeändert werden soll. Damit wäre die langersehnte durchgehende Verbindung durch das Suhrental geschaffen. Der Nachteil bestände aber darin, daß sich der Güterverkehr durch Umladen der Fracht oder der Benützung der bereits üblichen Rollschemel immer noch relativ kompli-

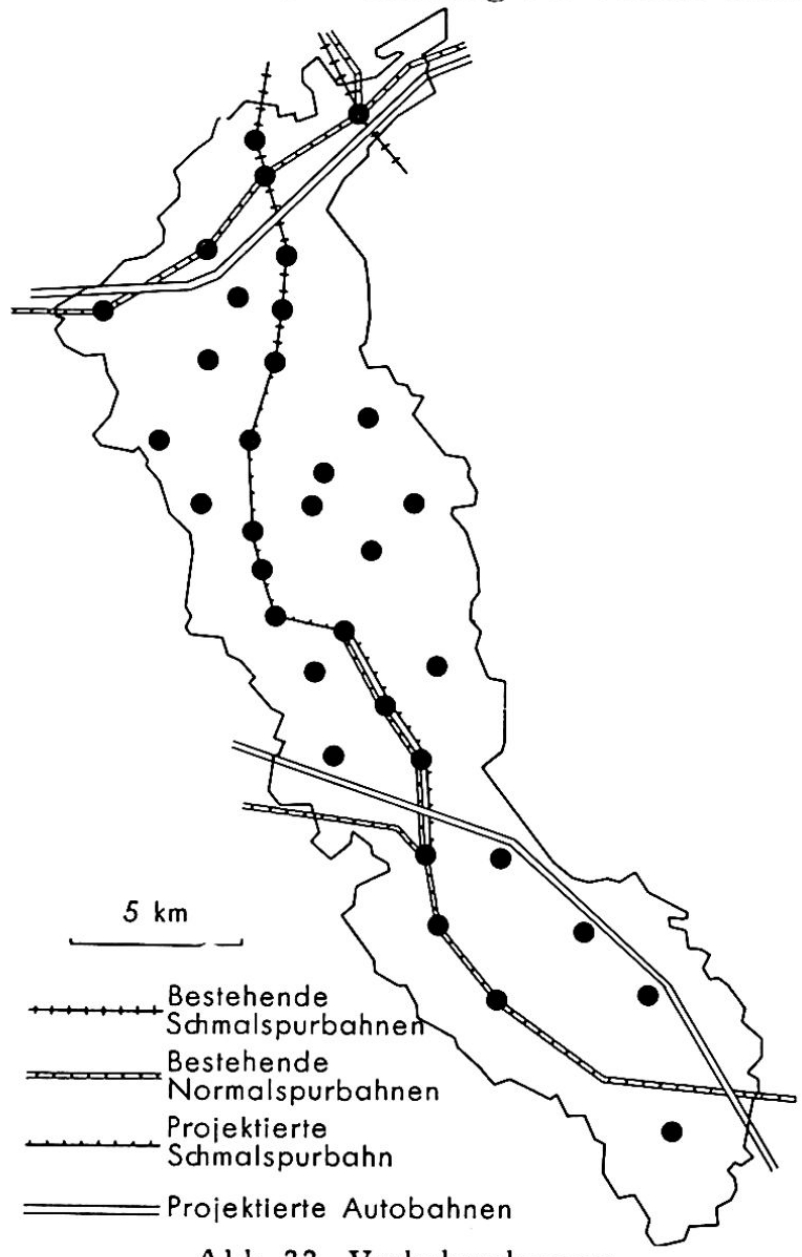

Abb. 33. Verkehrsplanung ziert abwickeln würde. Demgegenüber bevorzugte der Bund das Projekt des Eidgenössischen Amtes fürVerkehr, das zwischen Sursee und Aarau einen Autobetrieb vorschlägt. Empört über diesen Beschluß veranstaltete die Bevölkerung im Jahre 1957 in Triengen eine große Kundgebung zu Gunsten der durchgehenden Schmalspurbahn. Auch eine Versammlung der Gemeinderäte und Großräte des Suhrentales in Staffelbach schloß sich einmütig der Volksmeinung an. Einige Gemeinden haben denn auch bereits beträchtliche Geldsummen für deren Bau bewilligt. Es scheint somit nur noch eine Frage der Zeit zu sein, bis der geplante Ausbau verwirklicht wird. Es ist zu hoffen, daß als Folge dieser neuen Bahnverbindung endlich das zwischen Sursee und Schöftland klaffende Industrievakuum behoben werden kann. Triengen wäre wohl am ehesten für ein neues Zentrum prädestiniert. Inzwischen ist von den Behörden eine weitere Expertise veranlaßt worden, die kürzlich (Ende 1960) abgeschlossen worden ist. Sie spricht sich eher zugunsten eines Busbetriebes aus. 


\subsection{URCHGANGSVERKEHR}

Weniger umstritten sind die Projekte der beiden das Suhrental traversierenden Autobahnen, die Teilstücke des zukünftigen schweizerischen Hauptstraßennetzes darstellen. Da sie aber bloß dem Fernverkehr dienen werden, ist auch nicht anzunehmen, daß sie im Suhrental neue Entwicklungstendenzen nach sich ziehen werden.

\section{QUELLEN}

\section{Karten}

1 Amsler A.: Übersichtskarte der Böden des Kantons Aargau, 1:100 ooo. Männedorf 1925.

2 Eidgenössische Landestopographie: Landeskarte der Schweiz, 1:25 ooo. Blätter 1089, 1109, $1129,1130,1149,1150$.

3 Eidgenössiche Landestopographie: Topographische Karte der Schweiz, 1:100ooo. Blätter Aarau, Luzern.

4 Eidgenössische Landestopographie: Topographische Karte der Schweiz, 1:25 000. Blätter Schönenwerd, Gränichen.

5 Michaelis: Karte des Kantons Aargau, 1:25 000. 1844.

6 Mühlberg F.: Geologische Karte der Umgebung des Hallwilersees und des obern Wynenund Suhrentales, 1:25 000. Winterthur 1908.

7. Mühlberg F.: Geologische Spezialkarte: Aarau und Umgebung, 1:25 000. Aarau 1894.

8 Niggli P.: Geologische Karte von Zofingen, 1:25 ooo. Zürich 1912.

9 Schweizerische Naturforschende Gesellschaft: Geologische Karte der Schweiz, 1:100 ooo, Blatt VIII. 1913.

\section{Statistiken}

1o Amtliches Kursbuch. Winter 1954/55.

11 Anbaustatistik der Schweiz. Bern 1934, 1950.

12 Arealstatistik der Schweiz. Bern 1923/24, 1952.

13 Bodenbenützung 1939 und Ackerbau 1940-43 in der Schweiz. Bern 1943.

14 Das Klima in der Schweiz: Resultate der Meßstationen 1864-19oo.

15 Der Schweizerische Nutztierbestand in der Kriegs- und Nachkriegszeit. 1944-48. Bern 1949.

16 Der Schweizersiche Nutztierbestand 1951-54. Bern 1955.

17 Der Schweizerische Obstbaumbestand. Bern 1951.

18 Die Landwirtschaftsbetriebe in der Schweiz. Bern 1929.

19 Die Schweizerische Verkehrszählung 1928/29, 1936/37, 1948/49. Zürich.

2o Eidgenössische Viehzählung. Bern 1936.

21 Eidgenössische Volkszählung. Bern 1910.

22 Eidgenössische Volkszählung, Bände Aargau, Luzern 192o, 193o, 1941, 1950.

23 Graphisch Statistischer Verkehrsatlas der Schweiz. Bern 1915.

24 Landwirtschaftsbetriebe nach Größenklassen, nach Kantonen und Gemeinden. Bern 1939.

25 Niederschlagsmengen in der Schweiz, 19o1-1940.

26 Schweizerische Anbaustatistik, Bern 1917.

27 Schweizerische Arealstatistik. Bern 1912.

28 Schweizerische Fabrikstatistik. Bern 1929, 1937, 1949.

29 Statistisches Jahrbuch der Schweizerischen Bundesbahnen, Bern 1918, 1923, 1928, 1933, 1938, 1943, 1948, 1953, 1958.

3o Wohnbevölkerung der Gemeinden, 1850-1950.

\section{Fachliteratur}

31 Aargauische Naturforschende Gesellschaft: Aargau: Natur und Erforschung. Aarau 1953.

32 Ammann H.: Heimatgeschichte und Wirtschaft des Bezirks Aarau. Zürich 1947.

33 Ammann H.: Heimatgeschichte und Wirtschaft der Bezirke Kulm und Lenzburg. Zürich 1947.

34 Bernhard H.: Wirtschafts- und Siedlungsgeographie dse Tößtales. Zürich 1912.

35 Boesch G.: Sempach (Schweizer Heimatbücher). Bern 1956.

36 Brockmann H.: Schweizer Bauernhaus. Bern 1953.

37 Bronner F.X.: Der Kanton Aargau 1844. St. Gallen und Bern 1844.

38 BüHLER J.: Veränderungen in Landschaft, Wirtschaft und Siedlung im Entlebuch. Zürich und Schüpfheim 1938.

39 Diem/Dirlewanger/Metzger: Gutachten über die Sanierung der Verkehrsverhältnisse in Suhrental. Aarau 1953.

4o Fischer L.: Kalendermäßige Bindungen des Wetterablaufes in Luzern. Schüpfheim 1946.

41 FRÜH J.: Geographie der Schweiz. St. Gallen 1930. 
42 Gassmann und Gutersohn: Relieffaktor und Kotenstreuung. Zürich 1947.

43 Geographisches Lexikon der Schweiz. Neuenburg 19o2.

44 Gutersohn H.: Landschaften der Schweiz. Zürich 1950.

45 Haberstich H.: Chronik von Oberentfelden. Oberentfelden 1943.

46 HAuser W.: Aus der Vergangenheit unserer Landschaft. Brugg 1944.

47 Historisch-Biographisches Lexikon der Schweiz. Neuenburg 1934.

48 Howald O.: Die Dreifelderwirtschaft im Kt. Aargau. Bern 1927.

49 Hug J.: Die wichtigsten Typen der ausnutzbaren Grundwassergebiete der Schweiz. Zürich 1928.

5o Hunziker J.: Das Schweizer Haus, Band V und VI. Aarau 1910.

51 Jahresbericht der Aarau-Schöftland-Bahn. Aarau 1956.

52 KAESER W.: Das bernische Seeland. Biel 1949.

53 Mühlberg F.: Der Boden von Aarau. Aarau 1894.

54 MülleR J.: Die klimatischen Verhältnisse des Aargau. Aarau 1911.

55 Pfiffer C.: Der Kanton Luzern 1847. St. Gallen und Bern 1847.

56 Staehelin F.: Die Schweiz in Römischer Zeit. Basel 1931.

57 Staub J.: Die Pfahlbauten in den Schweizer Seen. Fluntern 1864.

58 Staub R.: Geologie der Schweiz. Zürich 1939.

59 Studer H.: Der Einfluß der Industrialisierung auf die Kulturlandschaft des Aarg. Mittellandes. Zürich 1939.

\section{LA VALLÉE DE LA SUHRE}

La vallée de la Suhre compte 34 communes, dont 19 sont situées dans le canton d'Argovie et 15 dans le canton de Lucerne. L'ensemble de ces communes couvre une surface de $233 \mathrm{~km}$ ?

En premier liei, l'aspect physique exige une distinction de différentes régions dont les contrastes sont très accentués. Ainsi, l'auteur s'est efforcé de trouver le plus grand nombre possible d'éléments géographiques qui manifestent les caractères divers des différentes zones de la région. Du point de vue physique, on reconnaît facilement deux sous-régions. Quoique la formation de l'une et de l'autre soit due à l'époque glaciaire, elles montrent tout de même une nette hétérogénéité: Le paysage extra-morainique (au $\mathrm{N}$ de la moraine de Staffelbach) présente un relief fortement marqué par des vallons latéraux. Le fond de la vallée principale y est large, son inclinaison est considerable. En outre, il est caractérisé par une nappe d'eau souterraine. Par contre, la partie intra-morainique (au S de la moraine de Staffelbach) se distingue par un relief moins accentué. Le fond de la vallée est étroit et peu incliné. Il est couvert d'une moraine de fond et ne produit pas d'eaux souterraines.

Ces faits physiques ont souvent fort influencé la formation culturelle du paysage. Dans la partie extra-morainique, on trouve les noyaux des villages dans le fond large et plat de la vallée, tandis que dans la région intra-morainique, ils sont limités à l'étroite lisière entre le fond de la vallée jadis marécageux et les pentes rapides. Les côtes moins fertiles (dues à une couche de molasse) au $\mathrm{N}$ de Staffelbach sont, pour la plupart, couvertes de forêts. Par contre, sur les féconds terroirs morainiques des pentes au $S$ de ce village, l'agriculture prédomine.

Le semis de l'habitat exige les distinctions suivantes: La vallée principale est caractérisée par des villages en tas (Haufendörfer) rarement accompagnés de fermes isolées, tandis que les vaux latéraux de l'Uerke et de la Ruederchen présentent un habitat dispersé typique. En outre, l'appartenance aux cantons joue un rôle important dans la formation de l'habitat et dans les aménagements économiques. Dans la partie argovienne (population protestante), les domaines ruraux sont en moyenne plus petits que dans la partie lucernoise (population catholique). C'est pourquoi les paysans lucernois préfèrent le type de bâtiment à but unique (Einzweckhaus) ou de la maison-cour (bâtiments d'habitation et d'exploitation séparés) tandis que dans la partie argovienne on trouve exclusivement le bâtiment à buts multiples (Mehrzweckhaus) ou la maison-bloc (un seul bâtiment pour l'habitation et pour l'exploitation). Enfin, l'industrialisation diffère: dans les villages de la partie septentrionale qui profitent de communication plusieurs grandes usines se sont établies; dans la partie lucernoise, c'est à Sursee seulement que l'on trouve des fabriques d'une certaine importance, malgré la ligne de chemin de fer Olten-Lucerne desservant encore d'autres villages de cette région.

Ces contrastes permettent de diviser le paysage en plusieurs secteurs et de représenter ceuxci comme types de différents caractères (fig. 3o).

Pour diriger et contrôler le développement de la région, les communes industrielles surtout sont en train d'établir des plans d'aménagements régionaux et locaux (avec subdivision en zones). Actuellement, l'amélioration des voies de communication est intensivement discutée; on examine avant tout si le trafic de transit entre Sursee et Aarau - jusqu'alors assuré par trois systèmes différents - doit être relié par une seule ligne de chemin de fer ou par un service d'autocars. La route nationale prévue entre Olten et Lucerne passera par la partie méridionale de la vallée.

Traduction de J.E. Morf 